https://theses.gla.ac.uk/

Theses Digitisation:

https://www.gla.ac.uk/myglasgow/research/enlighten/theses/digitisation/

This is a digitised version of the original print thesis.

Copyright and moral rights for this work are retained by the author

A copy can be downloaded for personal non-commercial research or study, without prior permission or charge

This work cannot be reproduced or quoted extensively from without first obtaining permission in writing from the author

The content must not be changed in any way or sold commercially in any format or medium without the formal permission of the author

When referring to this work, full bibliographic details including the author, title, awarding institution and date of the thesis must be given

Enlighten: Theses

https://theses.gla.ac.uk/

research-enlighten@glasgow.ac.uk 


\section{Factors affecting GUM clinic attenders decisions and intentions to seek HIV testing.}

\section{JEFF SALT}

Submitted in partial fulfilment of the degree of Doctor of Clinical Psychology within the faculty of medicine, University of Glasgow.

August 1997. 
ProQuest Number: 13815373

All rights reserved

INFORMATION TO ALL USERS

The quality of this reproduction is dependent upon the quality of the copy submitted.

In the unlikely event that the author did not send a complete manuscript and there are missing pages, these will be noted. Also, if material had to be removed, a note will indicate the deletion.

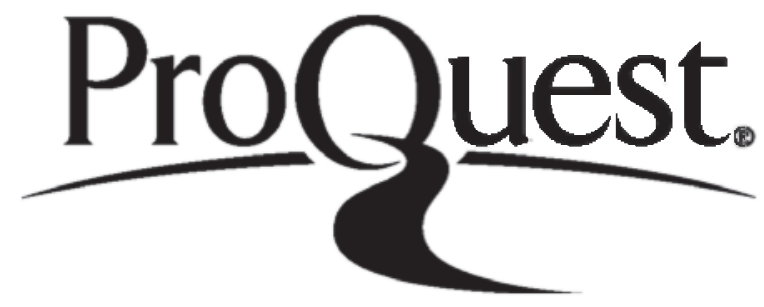

ProQuest 13815373

Published by ProQuest LLC (2018). Copyright of the Dissertation is held by the Author.

All rights reserved.

This work is protected against unauthorized copying under Title 17, United States Code Microform Edition (C) ProQuest LLC.

ProQuest LLC.

789 East Eisenhower Parkway

P.O. Box 1346

Ann Arbor, Ml $48106-1346$ 
Thesis 11021

GLASGOW

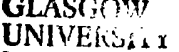

LIBRARY 


\section{TABLE OF CONTENTS}

Page

$\begin{array}{lll}\text { Chapter } 1 & \text { Small Scale Service Evaluation Project } & 1\end{array}$

Patterns of Referral To The Rehabilitation Unit,

Airbles Road, Motherwell

Chapter 2 Major Research Project Literature Review

The HIV Antibody Test : Exits and Entrances

Chapter 3 Major Research Project Proposal

41

Factors Affecting GUM Clinic Attenders Decisions

And Intentions To Seek HIV Testing

Chapter 4 Major Research Project Paper

Factors Affecting GUM Clinic Attenders Decisions

And Intentions To Seek HIV Testing

Chapter 5 Single Case Research Study (1)

80

Oppositional Defiant Disorder :

The Case For Measurement of Severity

Chapter 6 Single Case Research Study (2)

91

Symptoms Of A Syndrome : Differential Diagnosis of Aspergers Syndrome 
Chapter 7 Single Case Research Study (3)

Using The Transtheoretical Model Of Change As

Framework To Explain Treatment Success In A

Woman Presenting With Obsessive-Compulsive Disorder

Appendix 1 Major Research Project Literature Review

Appendix 2 Major Research Project Paper

Appendix 3 Single Case Research Study (1)

Appendix 4 Single Case Research Study (2)

Appendix 5 Single Case Research Study (3) 
CHAPTER 1

Small Scale Service Evaluation Project

Patterns Of Referral To The Rehabilitation Unit,

Airbles Road, Motherwell

Written for in-service presentation 


\section{Introduction}

The focus of rehabilitation services in the U.K. during the last 30 years has moved from long stay patients of mental hospitals, to people receiving psychiatric care in the community. The reasons for this shift in emphasis have been both professional and political.

The U.K. government has committed itself to community services through a series of white papers : 'Better Services for the Mentally Ill' (1975); 'Caring for People' (1989); and its policy document 'The Care Programme Approach' (1990). However, the governments underlying philosophy is driven by fiscal policy, rather than treatment gain. Fortunately these policies have complemented professional thinking, with the benefits of community based care being demonstrated in model services across the world (e.g. Stein and Test, 1980).

For many years psychiatric rehabilitation functioned solely by helping long stay psychiatric patients, with relatively stable illnesses, re-acquire the necessary skills to enable them to resettle in the community. However, now that the majority of these long term patients have left hospital, a new picture of rehabilitation clients is emerging. These people have complex mental health problems, often with unstable illnesses and challenging behaviour. These clients require the long term support of flexible services, and treatment interventions to suit their long term needs. A wider concept of rehabilitation is thus necessary.

Bridges et al. (1994b) summarises rehabilitation as ' a process which aims to minimise the negative effects of the dynamic relationships between biological, psychological, functional and environmental factors, and maximise the persons latent abilities and strengths' (p4). Shepherd $(1995,1991)$ has emphasised the dynamic interaction between functioning and environmental supports, and suggests that improving functioning may be a part of the rehabilitation process, but is not synonymous with it. 
These definitions are thus a far cry from the 'resettlement' models of the 60s and 70's, where providing a person with skills was the only goal. Today's rehabilitation services are geared toward supporting people function at their optimum level despite their disabilities.

Definitions of rehabilitation are important as they not only shape service provision, but provide templates for quality assurance and performance indicators (cf. Jenkins, 1990). The present free market for health services ensures that funding and commissioning of services is based upon the evaluation of local catchment populations, profiles of unmet need, and the accurate evaluation of existing services.

This paper is a result of an on-going attempt to effectively analyse the outcome of referrals to the rehabilitation unit, Airbles Road, Motherwell. This is in part a consequence of the need to monitor developments since the rationalisation of Hartwood Hospital, and in part a consequence of the accountable purchaser / provider environment in the health service.

The Airbles Road rehabilitation unit has been functioning in its present capacity since April 1990. Before this time the official rehabilitation unit was based in Ward 28 Hartwoodhill Hospital, in conjunction with Hartwood House, which has been used for rehabilitation since October 1989. The Airbles Road unit continues the role of Ward 28 (now a Psychiatric Intensive Care Unit) with greater access to community services, and hence provides a more realistic picture of how patients function in a community setting.

The Airbles Road unit is a 17 bed inpatient unit under the medical supervision of the Rehabilitation Consultant. There is also the capacity for 6 day patient places with a programme of care run by an Occupational Therapist (OT) and a staff nurse. There is multi-disciplinary input into the unit including Psychiatry, Clinical Psychology, Occupational Therapy, Social Work and Nursing. All referrals, 
assessments, admissions, treatments and reviews are conducted through this multi-disciplinary team (MDT).

At present the unit in Motherwell has a Lanarkshire wide remit taking referrals from the three districts (Hamilton / East Kilbride; Motherwell / Clydesdale ; Monklands / Cumbernauld). This includes both community and hospital referrals. However, with the recent opening of the Coathill House rehabilitation project, referrals from the Monklands district should be significantly reduced in the future.

Referral to the unit is a three stage process :

1) Referrals are received on brief standardised forms (RI). These forms contain basic information regarding personal details; diagnosis; history; reason for referral etc. These referral forms are then presented at MDT meetings.

2) An initial interview is completed by two members of the team to assess suitability for trial at the unit. This assessment is completed on RII standardised forms and covers the patients knowledge of the referral; presentation; motivation for rehabilitation etc., and includes the recommendation of the assessors.

3) The results of the assessment process are reported to the next MDT meeting, and a decision is made on acceptance or rejection of the referral. If the patient is accepted for trial they will be either admitted to the unit, or placed on the waiting list for the next available placement. 


\section{Objectives}

The main aims of the study were threefold :

1) To provide quantitative and qualitative data on the referrals received by the rehabilitation unit;

2) To provide statistics on admissions and discharges to the unit;

3) To establish the effectiveness of the current data collection procedures for the first two aims.

This data could then be used to inform the Lanarkshire Healthcare NHS Trust of the present performance of the unit together with possible future needs; provide a platform to argue for the financing for extended service delivery; provide information to refers' as to appropriate referrals; and shape a continuing and extended audit of service delivery by the rehabilitation unit. 


\section{Methods}

A data collection form was drawn up to collate all the necessary data. It had four main points of focus :

Personal Details : D.O.B.; sex; unit number; living circumstances etc.

Referral Information : when; by whom; diagnosis; reason for referral; medication etc.

Assessment / Admission Data: date of assessment; outcome; date of admission; diagnosis on admission etc.

Discharge Data : date of discharge; reason for discharge ; destination etc.

These forms were then completed for each patient referred for the period 1/1/94 - 31/12/94. This was achieved by analysis of the RI and RII forms previously collated by staff at the unit. However, it quickly became apparent that many of these forms were missing and even those that were available did not always contain the relevant information. In these cases, minutes of the MDT meetings were accessed in an attempt to complete missing data, and if necessary case notes were obtained. In a minimum of cases critical information (acceptance / rejection of referral) was completed by informal discussion with unit staff. Admission and discharge data was extrapolated from books kept by the consultants at Airbles Road. 


\section{Results}

The results of the data collection were analysed and are described below. Much of the information is presented in table form for ease of access. The results appear under the following headings :

1) Referral Characteristics

2) Diagnosis at Referral

3) Origin of Referrals

4) Outcome of Referrals

5) Admissions and Discharges

6) Additional Information

i) Reasons for referral

ii) Specific problems of patients referred.

iii) Alcohol abuse secondary to diagnosis

\section{Referral Characteristics}

During 1994 there were 38 referrals to the Airbles Road rehabilitation unit. There were 30 referrals for the inpatient services ( 21 males; 9 females); and 8 direct referrals to the day patient rehabilitation service ( 5 male; 3 female)

The age range of the referrals was $19-73$ years. The mean age of the referrals to the inpatient unit was 41 years ( 37 years for males; 47 years for females). The mean age of referrals to the day service was 45 years (40 years for males; 52 for females). 


\section{Diagnosis at Referral}

Table 1 contains the frequency of diagnosis of patients at referral. It must be emphasised that these diagnoses were made by the referrer not by the rehabilitation consultant.

As can be seen in Table 1, schizophrenia is by far the most common diagnosis with 16 patients (42\%) receiving this diagnosis. If both the schizophrenia and paranoid schizophrenia categories are combined, they account for $50 \%$ of the referrals. $18 \%$ of referrals were for alcohol abuse, and a further $8 \%$ were patients with Wernicke - Korsakoff Syndrome.

Table 1. Diagnosis At Referral.

\begin{tabular}{||l|c|c|c|c||}
\hline Diagnosis & Male & Female & Total & $\%$ \\
\hline Schizophrenia & 14 & 2 & 16 & 42.1 \\
\hline $\begin{array}{l}\text { Paranoid } \\
\text { Schizophrenia }\end{array}$ & 3 & 0 & 3 & 7.9 \\
\hline $\begin{array}{l}\text { Schizo-Affective } \\
\text { Disorder }\end{array}$ & 1 & 1 & 2 & 5.3 \\
\hline $\begin{array}{l}\text { Senile Paranoid } \\
\text { Psychosis }\end{array}$ & 1 & 1 & 2 & 5.3 \\
\hline $\begin{array}{l}\text { Bipolar Affective } \\
\text { Disorder }\end{array}$ & 1 & 0 & 1 & 2.6 \\
\hline $\begin{array}{l}\text { Manic Depressive } \\
\text { Psychosis }\end{array}$ & 0 & 1 & 1 & 2.6 \\
\hline $\begin{array}{l}\text { Alcohol } \\
\text { Abuse }\end{array}$ & 1 & 3 & 3 & 18.4 \\
\hline $\begin{array}{l}\text { Wernicke- } \\
\text { Korsakoff }\end{array}$ & 1 & 2 & 1 & 7.9 \\
\hline $\begin{array}{l}\text { Psychosis (drug } \\
\text { abuse) }\end{array}$ & 0 & 12 & 38 & 2.6 \\
\hline No Diagnosis & 26 & & & 5.3 \\
\hline & & & & 100 \\
\hline Total & 1 & & & \\
\hline
\end{tabular}




\section{Origin of Referral}

Table 2 contains the frequency of referral from acute units, long stay units and community referrals for 1994. The acute wards provided the highest number of referrals to Airbles Road, accounting for $55 \%$ of all referrals. The community sources provided only $18 \%$ of referrals, as did the Hartwood long stay wards and intensive care unit combined. A small percentage of referrals (8\%) came from the geriatric wards at Law hospital.

Table 2. Origin of Referrals

\begin{tabular}{|c|c|c|c|c|}
\hline & Male & Female & Total & $\%$ \\
\hline $\begin{array}{l}\text { Monklands Acute } \\
\text { Wards } \\
\text { Hairmyres Acute } \\
\text { Wards } \\
\text { Hartwood Acute } \\
\text { Wards }\end{array}$ & $\begin{array}{l}3 \\
5 \\
5\end{array}$ & $\begin{array}{l}3 \\
5 \\
0\end{array}$ & $\begin{array}{r}6 \\
10 \\
5\end{array}$ & 55.2 \\
\hline $\begin{array}{l}\text { Hartwood Long } \\
\text { Stay/Rehab } \\
\text { Psychiatric I.C.U. }\end{array}$ & $\begin{array}{l}5 \\
1 \\
\end{array}$ & $\begin{array}{l}1 \\
0 \\
\end{array}$ & $\begin{array}{l}6 \\
1 \\
\end{array}$ & 18.4 \\
\hline Law Hospital & 1 & 2 & 3 & 7.9 \\
\hline $\begin{array}{l}\text { Addiction Team } \\
\text { CPN } \\
\text { CMHT } \\
\text { Community } \\
\text { Consultant } \\
\text { Brain Injury Unit }\end{array}$ & $\begin{array}{l}1 \\
2 \\
1 \\
1 \\
1\end{array}$ & $\begin{array}{l}0 \\
1 \\
0 \\
0 \\
0\end{array}$ & $\begin{array}{l}1 \\
3 \\
1 \\
1 \\
1\end{array}$ & 18.4 \\
\hline
\end{tabular}




\section{Outcome of Referral}

Table 3. Referral Acceptance Rates

\begin{tabular}{||l|c|c|c|c||}
\hline & Male & Female & Total & $\%$ \\
\hline $\begin{array}{l}\text { Accepted Inpatient } \\
\text { Trial }\end{array}$ & 7 & 2 & 9 & 23.7 \\
\hline Accepted Day Trial & 5 & 1 & 6 & 15.8 \\
\hline $\begin{array}{l}\text { Not Accepted For } \\
\text { Trial }\end{array}$ & 7 & 7 & 14 & 36.8 \\
\hline $\begin{array}{l}\text { Accepted But } \\
\text { Declined }\end{array}$ & 2 & 1 & 3 & 7.9 \\
\hline $\begin{array}{l}\text { Assmt Declined / } \\
\text { Withdrawn }\end{array}$ & 5 & 1 & 6 & 15.8 \\
\hline
\end{tabular}

As can be seen in Table 3, 15 referrals (39.5\%) were accepted for trial at Airbles Road. A further 7.9\% were offered a place but declined. In 3 cases patients referred for the inpatient unit were declined places but were offered day care as an alternative. Initial interview assessments were not possible in 2 cases (as they had discharged themselves from acute wards); a further 4 referrals were withdrawn $(15.8 \%$ in total).

A total of 14 referrals (36.8\%) were not accepted for trial at Airbles Road. Table 4 contains the frequency of reasons for non-acceptance into the unit.

Table 4. Reasons for non-acceptance of referral.

\begin{tabular}{||l|c|c|c||}
\hline & Male & Female & Total \\
\hline Patients Clinically Unsuitable & 3 & 2 & 5 \\
\hline Patients Unwilling & 2 & 1 & 3 \\
\hline Patients Referred To Other Service & 2 & 0 & 2 \\
\hline Unknown & 0 & 4 & 4 \\
\hline
\end{tabular}

The clinically unsuitable patients were either not stable enough (i.e. their illness was not stable), were deemed to have unpredictable behaviour, or it was felt they would do better in a long term ward. One referral was turned down as it concerned a Secretary of State patient and there were already two such referrals in the unit already. It was felt unwise to accept the patient with present staffing levels. 


\section{Admissions and Discharges (from inpatient unit).}

During 1994 there were 17 admissions and 17 discharges from the Airbles Road inpatient unit. Two patients were admitted twice within the same year, temporarily returning to Hartwood acute wards for two weeks and five months respectively. In one case a patient had experienced a rapid deterioration of mental state whilst on a weekend pass, the other had written a suicide note and returned to an acute ward for close observations. They both returned to their rehabilitation trial.

Seven of the 15 patients admitted in 1994 were given diagnosis on admission. Diagnosis was completed by the consultant using ICD classifications. 3 patients received a diagnosis of schizophrenia, 2 personality disorder, 1 organic psychosyndrome and 1 paranoid psychosis.

Of the 17 discharges, 9 were to planned community settings (Table 5). The other discharges consisted of 5 permanent moves back to Hartwood acute wards, 2 patients returned to Hairmyres Hospital, and 1 patient died of myocardial infarction.

Table 5. Community Discharges

\begin{tabular}{||l|c|}
\hline Nature of Placement & No. of Discharges \\
\hline & \\
\hline Penumbra Housing, Wishaw & 3 \\
\hline Loretto Supported Housing, Coatbridge & 1 \\
\hline Comely Bank Hostel, Hamilton & 1 \\
\hline Home & 4 \\
\hline
\end{tabular}




\section{Additional Information}

The following information was recorded on the data collection forms in an attempt to gain a more indepth picture of the patterns of acceptance to the rehabilitation unit. However, as has been noted already, much of the necessary data was missing and hence a fully accurate analysis is unavailable.

\section{i) Reasons For Referral To Rehabilitation Unit}

Table 6 contains brief descriptions of the referrers reasons for accessing the rehabilitation unit. In some cases more than one reason was cited per referral.

The most common reason for referral was activities of daily living. These included 'domestic skills', 'personal hygiene', and 'functional skills'. 'Rehabilitation' was the second most frequent reason for referral, although no more detailed information was provided. Changes in environment and accommodation were also frequently sought.

Table 6. Reasons For Referral.

\begin{tabular}{||l|c||}
\hline Reason For Referral & Frequency \\
\hline & \\
\hline Activities of Daily Living & 13 \\
\hline 'Rehabilitation' & 9 \\
\hline Independent Accommodation & 3 \\
\hline Better Environment Required & 3 \\
\hline Social Skills & 2 \\
\hline Assess Mental State and Behaviour & 2 \\
\hline Not Coping At Home & 1 \\
\hline Lacks Volition & 1 \\
\hline Self Request & 1 \\
\hline & \\
\hline Missing Data & 8 \\
\hline
\end{tabular}


This information refers to specific problems the patients experience secondary to their primary illness (e.g. bipolar affective disorder and head injury). This data does not include alcohol abuse (see section 6 iii). Some referrals cited more than one significant problem.

Table 7 shows that there was considerable missing data on this section of data. However, the most notable difference between accepted and non-accepted referrals, is behavioural problems (self harm, violence etc.). For the 6 accepted referrals for which data was available, none were reported to exhibit behaviour problems (although one referral did include verbal aggression).

Table 7. Specific Problems Experienced At Time of Referral (secondary to diagnosis).

\begin{tabular}{||l|l|}
\hline Referral Accepted & Referral Not Accepted \\
\hline & \\
\hline Paranoid Delusions (2) & Self Harm (2) \\
\hline Verbal Aggression & Behaviour Problems (2) \\
\hline Low Motivation & Low Motivation (3) \\
\hline Head Injury & Head Injury \\
\hline Seizures & Rapid Mood Swings \\
\hline & Violent Behaviour \\
\hline & \\
\hline Missing Data 9/15 cases & Missing Data 5/14 cases \\
\hline
\end{tabular}


Table 8 contains the number of patients referred who have alcohol problems secondary to their main diagnosis. The table is split into two categories, schizophrenia and other diagnoses, for ease of clarity. Refer to table 1 for full diagnostic breakdown. Table 8 excludes referrals of alcohol abuse and Wernicke -Korsakoff Syndrome as a primary diagnosis.

$37 \%$ of patients referred with schizophrenia (7/19) also have alcohol problems. Only 2 of those referred with schizophrenia did not have alcohol related problems. By contrast none of the other primary diagnosed disorders experienced difficulties with alcohol. There was once again a large proportion of missing data.

Table 8. Number of Referrals With Alcohol Abuse Secondary To Primary Diagnosis (excludes alcohol as primary diagnosis).

\begin{tabular}{||l|c|c|c|}
\hline \hline Primary Diagnosis & Secondary Alcohol Abuse & No Alcohol Abuse & Missing Data \\
\hline Schizophrenia & 7 & 2 & 10 \\
\hline Other Diagnoses & 0 & 3 & 6 \\
\hline
\end{tabular}




\section{Discussion}

Traditionally in Lanarkshire, patients referred to rehabilitation services were from the long stay population, often institutionalised with low level skills. However, the majority of these long stay patients have now passed though the system and those old long stay patients remaining need either resettlement into highly supported accommodation in the community, or relocation for those who require continued hospital care. The pattern and type of referrals to the rehabilitation services is thus continuously evolving.

As can be seen by the 1994 referrals, long stay wards (including rehabilitation wards) referred only 7 patients from Hartwoodhill ( $18 \%$ of referrals), whereas referrals from the district's acute wards accounted for $55 \%$ of referrals. As has been discussed through the rehabilitation management group, and specifically Dr. Mitchell's 'Discussion paper on rehabilitation services, December 1993', it is increasingly likely that patients referred to the rehabilitation services will have only experienced acute hospital admissions, and will no longer fit the traditional 'institutionalised patient' mould.

The increase in referrals from the acute wards can be partially accounted for by pressure for longer term beds. With escalating energies being focused on long stay bed closures, accessing long term beds for patients on admission wards becomes increasingly difficult. In addition, community care assessments for those patients can be exceedingly time consuming, taking a number of months, and hence recommendations for progression to suitable residential facilities may not be available. These factors culminate in a low rate of bed turnover within the hospitals, resulting in patients becoming stuck in admission wards. This situation has been highlighted by occasions in the recent past whereby every psychiatric bed in Lanarkshire has been occupied. The rehabilitation services thus become part of the 'dumping grounds' for patients occupying expensive admission ward beds. 
As the main Hartwood and Hartwoodhill sites have decreased in their primary function of long stay psychiatric care, the rehabilitation unit has become more accessible to a wide range of community services. Community sources were responsible for $18 \%$ of referrals in 1994 . These included referrals from the Community Mental Health Team (CMHT) and the Community Addictions Team. The role of community referrals is likely to continue expanding in the near future.

One interesting referral pattern is the lack of women referred from the Hartwood hospitals. Only one woman was referred from a long stay ward, whereas 5 men were referred from long stay / rehabilitation wards, and 5 from acute wards. Does this reflect differing priorities of referral for men and women at Hartwood ? Or does it reflect more opportunities for accessing residential facilities for women, thus reducing the need for the rehabilitation beds? Some light may be shed on this issue by the types of patients being referred to rehabilitation.

As would be expected in this population (Groves, 1990 ; Shepherd, 1991), schizophrenia is the most frequent illness being referred to the service, accounting for $50 \%$ of all referrals. There were no diagnoses of neurosis, with the remaining referrals clustering on other forms of psychosis and alcohol related problems.

The most notable feature of the referral diagnoses was the predominance of males with schizophrenia. Only two out of 19 referrals of schizophrenia were women. This means that $44 \%$ of the total referrals to the rehabilitation unit were males with schizophrenia. A very similar picture has been reported at the national level, where younger new long stay patients are predominantly single men with schizophrenia (Lelliot et al., 1994). These trends may reflect the possible differences in the development of schizophrenia in men and women. As men tend to develop their illness at an early age, social development is disrupted which in turn may lead to increased social difficulties and associated behaviour problems. Women tend to develop schizophrenia at a later stage in life by which time their 
roles and skills have already been established. The distinct 'illness careers' of men and women with schizophrenia may thus present different challenges, with men more likely to require a rehabilitation service.

Alcohol abuse accounted for $18 \%$ of referrals (increasing to $26 \%$ if Korsakoff Syndrome referrals are included). Of the 7 referrals, 4 were for the inpatient unit, and 3 for the day service. 3 referrals were accepted, 1 referral was passed on to other services, 1 patient declined a trial, and 2 patients did not attend the initial assessment. Within the referrals there were also several patients who abuse alcohol secondary to their primary illness. These patients were predominantly people with schizophrenia (7 / 19 referrals), although with 16 referrals missing data regarding alcohol abuse , this may not be the entire picture. Smith and Hucker (1994) have reported high co-morbidity of schizophrenia and substance abuse, and also report that schizophrenics may be at an increased risk of behaving violently when intoxicated. This has been an issue within the rehabilitation unit in the past, where aggression to both staff and residents has been particularly disruptive. Caan and Crowe (1994) studied readmission rates of patients who had both problems with drinking and a psychotic illness. They found patients with schizophrenia were especially prone to readmission if alcohol or drug abuse was a co-morbid factor. It appears therefore that these individuals may have particularly high levels of needs which should be identified and met. Discussions on how these needs can be best assessed and catered for in Lanarkshire need to be established.

Although alcohol abuse was the most frequently cited problem secondary to the patients primary difficulties, other specific problems were included on the referral forms. These included challenging behaviours (e.g. violence and self harm); head injury; delusions; motivational problems; and social skill deficits. Because of the variety of special needs in this population, patients very often fall into more than one service category (e.g. rehabilitation and community mental health). This situation can be problematic when planning treatments and accessing services for these patients. These examples of multiple 
difficulties, emphasise the fact that the patients in the rehabilitation services are a heterogeneous population, who require individual programmes of care. The individual problems of the patients referred undoubtedly influence the acceptance / non-acceptance of the referral.

Overall $40 \%$ of referrals were accepted for trial at Airbles Road. A further $8 \%$ were offered a trial but declined. Of the accepted referrals $80 \%$ were male ( $12 / 15$ accepted referrals). As many of the RII forms had not been completed in detail, only a preliminary analysis of acceptance / non- acceptance patterns could be completed. The reason for rejection of the referral was unknown in about one third of cases. However, the main reason for non -acceptance of the referral was 'clinical unsuitability'. This appears to have two subcategories : unstable illness and unpredictable behaviour. Examples of unstable illness include rapid cycles of mood, and examples of unpredictable behaviour include the desire to choke people.

In studying the specific problems of accepted / rejected patients (table 7), the most notable difference between the two is problems of challenging behaviour. Whilst severely challenging behaviour is obstructive in any setting, it is perhaps most difficult to manage in a small residential unit. The effects of a patient's behaviour must be analysed not only in terms of its frequency and severity, but also in terms of its effects on the other patients and the rehabilitation environment itself. It is therefore perhaps no surprise that issues of challenging behaviour distinguish accepted and rejected referrals. Challenging behaviour is a considerable drain on service resources in many locations (Cushion and Edwards, 1994), and has been used to argue for the continuation of limited hospital based rehabilitation services (Bridges et al., 1994a). If this preliminary analysis of acceptance patterns is valid for Lanarkshire rehabilitation services, a needs assessment should be completed for individuals displaying challenging behaviour so their long term needs, and the appropriate accompanying resources, can be planned for. 
A further point of concern with resources is the Secretary of State restricted patients referred to the service. While only one referral was made from the Psychiatric Intensive Care Unit, two people were on CPA 376/379 sections (Criminal Prosecution Act) and five were Section 18 Mental Health Act status. With regard to government policy to increase the rehabilitation of offenders in community settings, Gournay (1995) reports that it is imperative not to under estimate the necessary resources to cope with such patients. While Secretary of State patients require extensive long term rehabilitation, and are being referred to the rehabilitation unit, it is important to provide adequate resources to provide for them. This may particularly apply to staffing levels.

Access to a wide range of community based resources is critical for an effective locally based service The importance of a wide variety of good housing provision has been advocated by many over the years (Bachrach 1994; Shepherd 1991); and it has been a challenge confronting the Lanarkshire mental health services for some time. Most patients who come through the rehabilitation system require some level of supported accommodation (although some manage their own tenancies), yet there is little available. In 1994, 5 patients were discharged to supported accommodation, and 4 were discharged to their own home. With too few accommodation resources being commissioned, there is a stagnation of beds in the rehabilitation services, resulting in waiting lists being utilised.

Other issues compound the blocked flow of discharges from the unit. As funding is attached to long stay discharge patients whose bed closes behind them, Airbles Road residents are disadvantaged as no resource transfer is secured for them. A further sticking point for finding supported accommodation is the 'means testing' of patients who are not receiving housing benefit. Patients who may have to pay for their accommodation are less likely to want to move on if it means losing part of their own revenue. The present stagnation of planned discharges is likely to be exacerbated by the increase in referrals from acute wards as very often these patients are homeless, or their previous home situation has collapsed. 
As the rehabilitation unit is effectively blocked, the number of referrals the unit receives may not accurately reflect the real need for the service. Referrers may be less frequently attempting access to the service in the knowledge that only small numbers go through the system at any one point in time. If a more efficient referral - discharge programme could be maintained, an increase in service referrals seems likely.

While the process of acceptance / rejection of referrals by the unit is one evaluative exercise, the reasons why patients are referred to the unit is an entirely separate issue. The most frequently cited reason for referral was in connection to daily living skills. These included personal hygiene and domestic skills that patients required assistance with. However, the second most frequent reason for referral was 'rehabilitation'. While it is entirely reasonable to expect the rehabilitation unit to assess every patient for their own individual needs, and tailor packages of treatment to meet them, referring patients for 'rehabilitation' is perhaps a little too vague to be of any use at all. This statement by at least 9 referrers raises the questions Do referrers know what services they are referring the patient to? and Do they know what to expect out of such a referral? The reasons why patients should be referred to the Airbles Road unit thus seems to be a point for future education of referrers.

At present the role of the unit and the definition of the rehabilitation it provides is not clear. Referrers have little information as to what constitutes an appropriate referral and receive sparse feedback as to why a patient has been not been accepted to the unit. The function of the unit needs to be clarified and its boundaries with other services established (for example the relationship between referral to the CMHT and the rehabilitation services). With increasing emphasis on the power of purchasers, and the role of service evaluation, optimum process and outcome data will be reliant on succinct service remits in establishing effective service provision for the population needs. 
In summary, the pattern of referrals to the Airbles Road rehabilitation unit is becoming more community focused, receiving referrals from multiple agencies; and becoming less focused on old long stay populations. The service is hence no longer purely skills based in its approach, but is becoming increasingly holistic in its view of rehabilitation clients. Approximately half of the referrals involve people with schizophrenia, and approximately one quarter of referrals are related to alcohol abuse. Patients often have a multitude of related problems including challenging behaviour, head injury, seizures and motivational problems. The most notable subgroup of referrals involve people with schizophrenia who also abuse alcohol. $80 \%$ of accepted referrals are men. A preliminary study of accepted or rejected referrals suggests severe behavioural difficulties as a dissection point. The main challenge facing the unit appears to be moving patients on to appropriate accommodation, and finding suitable services to support them. Issues regarding the exact definition of the unit and its remit in relation to other mental health services, as well informing the referrers of appropriate referrals, need to be addressed.

\section{Analysis of Data Collection Procedures}

$13 \%$ of RI and RII forms were missing. The forms were rarely complete, specifically the RII initial assessment sheets. Frequently the 'recommendations of the team' section was blank, as was the 'present needs / intervention required' section. The basic information of if a trial was to be offered and the reason for rejection / acceptance of referral was the most important missing information. This data would have enabled a more specific analysis of patterns of acceptance into the rehabilitation unit. Although this information could have probably been obtained by interviewing staff, one aim of this study was to establish the effectiveness of current data collection procedures. These were found to be patchy at best. 
For the minimum statistics to be effectively collated, the only changes to the system need to be full completion of the RI and RII forms, and the addition of an outcome of the MDT meeting. This would enable accurate data collection on numbers of referrals, origin of referrals, and acceptance patterns.

However, if a more complete audit is required, a data collection form should be formulated. This form could then include : background data such as family circumstances, drug / alcohol abuse, convictions, living skills etc.; assessment data ; waiting list time; admission date; details of treatment; discharge date; nature of discharge; drugs on admission / discharge etc. This form of data collection would require a more committed approach from the unit however, as updates would be required after initial assessment. The time taken to complete such data collection may also have knock on effects on other competing 'therapeutic' staff duties.

\section{Recommendations}

1. Establish an effective data collection mechanism.

This should be designed to catch data related to number of referrals; outcome of referrals; admission; treatment; discharge.

\section{Define the role and position of the unit.}

This should include a concise definition of the unit, its remit, and its relationship to other services. This can be achieved through the continuing work of the Rehabilitation Planning Group, and communication with appropriate purchaser and provider units.

\section{Provide written information to referrers.}

This should include the definition and remit of the unit as established above; and indicate the nature of appropriate referrals. 
4. Assess the impact of the 'dual diagnosis' of schizophrenia and alcohol / substance abuse.

The service needs to establish the magnitude of the problem and the needs of this particular group of patients.

5. Address the needs of rehabilitation patients who display challenging behaviour.

A service wide audit is required to establish the current treatment options, and plan future approaches, for dealing with people who display challenging behaviour. 


\section{References}

Bachrach, L.L. (1994). Residential Planning : Concepts and Themes. Hospital and Community Psychiatry, Vol. 45, No. 3, 202-203.

Bridges, K., Davenport, S., \& Goldberg, D. (1994a). The need for hospital-based rehabilitation services. Journal of Mental Health,3,205-212.

Bridges, K., Huxley, P., \& Oliver, J. (1994b). Psychiatric rehabilitation redefined for the 1990's. International Journal of Social Psychiatry, Vol.40,No.1,1-16.

Caan, W., and Crowe, M. (1994). Using readmission rates as indicators of outcome in comparing psychiatric services. Journal of Mental Health,3,521-524.

Cushion, B., \& Edwards, C. (1994). Summary of a survey: 'challenging behaviour' within the South Devon Psychiatric Rehabilitation Service. Clinical Psychology Forum,67,33-35.

Department of Health and Social Security (1975). Better services for the mentally ill.Cmnd. 6233, HMSO.

Department of Health and Social Security (1989). Caring for people: Community care in the next decade and beyond. London Cm849.

Department of Health, Department of Social Security, Health and Social Development (1990). Caring for people care programme. Approach for people with a mental illness referred to the special psychiatric services. London (Jt. circular HC(90)23, LASSL(90)11).

Gournay, K. (1995). What clinical psychology trainees should know about psychiatric rehabilitation. Clinical Psychology Forum,82,21-26.

Groves, T. (1990). Who needs long term psychiatric care? British Medical Journal, Vol.300,999-1001. Jenkins, R. (1990). Towards a system of outcome indicators for mental health care. British Journal of Psychiatry,157,500-514.

Lelliot, T., Wing, J., \& Clifford, P. (1994). A national audit of new long stay psychiatric patients. I method and descriptions of the cohort. British Journal of Psychiatry,165,160-9. 
Shepherd, G. (1991). Foreword : psychiatric rehabilitation for the 1990s. In F. Watts and D. Bennett (Eds). Theory and Practise of Psychiatric Rehabilitation. Chichester : Wiley.

Shepherd, G. (1995). A personal history of rehabilitation (or knowing me, knowing you-aha?). Clinical Psychology Forum,82,4-8.

Smith, J., \& Hucker, S. (1994). Schizophrenia and substance abuse. British Journal of Psychiatry,165,13-21.

Stein, L., \& Test, M. (1980). Alternatives to mental hospital treatment. I: Conceptual model treatment programme and clinical evaluation. Archives of General Psychiatry,37,392-7.

This small scale research project was formatted for in-service presentation, following the BPS Guidelines for the Small Scale Research Project, as presented in the West of Scotland Handbook 


\section{CHAPTER 2}

Major Research Project Literature Review

The HIV Antibody Test : Exits and Entrances.

Written for submission to AIDS CARE : Appendix 1 contains notes for contributors. 
HIV testing has become one of the main strategies for prevention of HIV infection across the world. The behavioural and psychological outcomes of HIV testing have varied across studies. There are many methodological problems which hinder firm conclusions being drawn. It does appear however that counselling and testing can decrease risk behaviours, at least in the short term. Regardless of the outcome literature, HIV testing should be recommended on the grounds of early access to medical treatment. However many individuals with high risk factors for HIV infection have not been tested for HIV. Potential barriers to testing include fear of a positive test result, fear of stigma, and fear of losing friends or partners. Furthermore concerns over the anonymity of the testing process and increased anxiety at having to wait for test results prevent many of those at high risk from entering the testing process. The main limitations to these conclusions are the focus on the gay male population and the predominantly American orientation to these studies. Factors that encourage or inhibit HIV test seeking are needed in other risk populations and in the UK health care setting. 


\section{Introduction}

The test for the HIV antibody, which causes AIDS, has now been available for over ten years. In this time, the HIV test, in conjunction with counselling, has become one of the main strategies for prevention and early detection of HIV infection throughout the developed world. Counselling and testing enables individuals to determine their antibody status, make informed decisions based upon this knowledge, change the behaviours that put themselves and others at risk, and seek medical care if HIV positive (Philips \& Coates 1995).

Since it's inception in 1985, HIV testing has been a contentious issue and continues to be a source of great debate. Originally, testing received a rather negative press. Widespread utilisation of HIV testing was prevented by fears concerning the accuracy of the test (Meyer \& Pauker, 1987); lack of medical treatments and risk of psychological problems (Pollack, 1992); and the real fear of discrimination for those who tested positive (Bayer, 1991; Shilts, 1987). More recently however, testing for the HIV antibody has been wholly encouraged due to the development of greater understanding of HIV transmission routes and the advantages of risk reduction practises, together with the development of treatments to delay disease progression (Friedland, 1990).

The U.K. government has now developed a proactive policy towards testing as the demand for testing has increased (Beardsell, 1994). Department of Health guidelines (Pl/Co 1992) encouraged wider testing and the development of alternative testing sites. Some services (eg GUM clinics), now offer testing to all clients, instead of only those who request testing. 
The aim of this article is to look at two distinct aspects of the HIV testing literature:

1. What are the behavioural and psychological outcomes of HIV counselling and testing ?

2. What factors influence a persons decision to enter the testing process?

The paper will attempt to review the available research, and highlight issues which need to be addressed.

\section{What are the behavioural and psychological outcomes of HIV counselling and testing ?}

One of the main aims of HIV testing is to reduce risk behaviours of both HIV positive and HIV negative individuals. Pre- and Post-test counselling sessions provide education to reduce behaviours that put the individual at risk of future infection if HIV negative; and to change behaviours to protect the future partners of those who are HIV positive. However, evidence that risk reduction occurs following counselling and testing, is mixed at best.

A review by Higgins et al (1991) established the effectiveness of counselling and testing for certain risk groups, as measured by a set of variables including condom use, sexual partners, needle sharing etc. Studies of gay men reported substantial reductions in risky behaviours among both tested and untested men; and some reported greater decreases among the seropositive men than among the seronegative men and those untested or unaware of their serostatus. For intravenous drug users (IVDUs) reductions in intravenous drug use was reported, along with some sexual risk behaviour reduction. However, all subjects were simultaneously in methadone maintenance programmes, so the unique effect of counselling and testing cannot be distinguished. Higgins et al (1991), reported little impact of counselling and testing on incidence of pregnancy and/or termination for either seropositive or seronegative women. Heterosexual couples with one infected partner showed substantial risk reduction. 
There are a number of methodological problems with these studies (see Beardsell, 1994), the main one being the lack of any control or comparison group (Higgins et al 1991). With regards to the long term effects of HIV testing on risk reduction practises, it is almost impossible to distinguish the specific effects of counselling and testing from the multitude of other factors that will influence individual's behaviour, for example, media campaigns, changes in cultural norms and changes in individuals' relationships. In addition, studies that look at behaviour change are always faced with the possibility that individuals may have made significant changes in risk behaviours in the period prior to entering the testing process (Jacobsen et al 1990). It is also possible that individuals who initially adopt safer sex behaviours "relapse" over time and engage in unsafe sex once more (Stall et al 1990; see Hart et al 1992 for a critique of the concept of relapse). Some investigators have even found counselling and testing to increase risk behaviour (eg Otten et al 1993), although these effects appear to be limited and again confounded by methodological weaknesses (Chamot et al 1995).

One of the uncontrolled factors between each study of behaviour change following counselling and testing is the counselling itself. A wide variety of professionals undertake pre- and post-test counselling and there is limited research on what actually occurs within sessions. Large variation in content and approach to counselling have been found by Silverman (1990) and there is evidence of different testing uptake rates for different counsellors (Meadows et al 1990). Clearly, pre- and post-test counselling content needs to be more accurately assessed and its role in initiating behaviour change established.

Providing patients with positive test results is never going to be an easy task for counsellors and this may reflect the dissatisfaction patients express with receiving their test results. Pergami et al (1994), studied the views of thirty HIV positive patients regarding the communication of their test results. Only $30 \%$ were satisfied with the way they were told their diagnosis. This supports similar results by McCann \& Wandsworth (1991). The way in which a positive test result is conferred to individuals will 
clearly effect their emotional reaction to such news. Various studies have assessed the effects that HIV testing can have on mental health.

Studies have consistently found that receiving negative results is associated with reductions in psychological distress (Ostow et al 1989; Perry et al 1990). However, notification of positive results has produced inconsistent findings. Earlier studies, such as Jacobsen et al (1988) and Cleary et al (1988) found significant levels of psychological distress following a positive test result; however, Perry et al (1990) found that levels of distress upon notification did not increase, and decreased significantly at ten week follow up. The most notable difference in the Perry et al (1990) study is the use of extensive post-test counselling utilising cognitive behaviour therapy.

From the evidence reviewed it is apparent that variation in content and quality of HIV counselling may explain the inconsistent findings for both behavioural and psychological outcomes of testing. This is an issue that needs further exploration.

Further information on how to make counselling and testing a useful primary prevention strategy is needed so that the testing experience can facilitate optimal numbers of people to protect themselves and others from the virus (Philips and Coates, 1995). This does not mean however that counselling and testing should not be encouraged on other grounds such as early access to treatment (Beardsell, 1994). 


\section{What factors influence a persons decision to enter the testing process?}

Assuming that early access to antiretroviral and prophylactic medications, and reduction of risky practices are both possible, and desirable, then those most at risk should be encouraged to enter the counselling an testing process. It appears however that a large proportion of these people are not seeking testing. Studies have demonstrated that between 30 and $70 \%$ of people with high risk factors have not been tested for the HIV antibody (Berrios et al, 1993; Anderson et al, 1992; Kalichman and Hunter, 1993). Furthermore, research in both the US and the UK has established that many people are tested late in their course of HIV infection, and hence delayed initiating medical care (Wortley et al, 1995; Wenger et al, 1994; McCann \& Wadsworth, 1991). Despite these findings few studies have examined factors which influence HIV test decision making, and the barriers to entering the HIV testing process.

\section{Reasons For Testing.}

Studies that have examined reasons for taking the HIV test have mainly focused on gay men (eg Myers et al, 1993; Lyter et al 1987). A few studies have researched the views of women (Beevor \& Catalan, 1993) and IVDUs (Sonnex et al, 1989). Reasons for having the HIV test include reduction of stress associated with not knowing serostatus; a belief of exposure to infection due to prior risk behaviour; and need for confirmation of serostatus to inform future decision making. In an interesting study by Lupton et al (1995), the authors used qualitative interviews to discuss sociocultural meanings surrounding the HIV test in low risk individuals. they reported less obvious reasons for testing such as pressure from parents and lovers, a symbolic closure or commencement of a sexual relationship, and notions of responsibility and purity on the part of test uses. 


\section{Barriers To Testing}

Potential barriers to entering the testing process include: fear of stigma and discrimination (Myers et al, 1993; Jacobson et al, 1990); fear of coping with positive test results (Coates et al 1988); potential for adverse consequences in social relationships (Lyter et al 1987); and perceived lack of need for testing (Perry et al, 1990; Bauman \& Siegal, 1987).

As stated in a recent study of gay men by Stall et al (1996)

"in interpreting these reasons for not getting tested, it should not be forgotten what HIV testing means to an individual with a history of behavioural risk: it is a test to determine whether one is infected with a virus for which there is no known cure, which is likely to result in painful debilitation and eventual death, and may result in overt discrimination even among men who are open about their sexual orientation' (p157).

The results of the Stall et al study found that over $50 \%$ of their sample endorsed each of the following as justification that they did not need testing: they've maintained their health; they were already doing all they could to stay healthy; fear of stress of getting test results; denial of risk of infection; and AIDS related discrimination. In one of the few studies involving STD clinic patients, Kalichman et al (1996) found that untested subjects feared testing and had a sense of not knowing if they needed to be tested. In contrast, those seeking testing believed testing would help them feel better about their health. They also found that subjects lacked accurate information about testing procedures employed by the clinic, specifically the difference between confidential and anonymous testing. 
Concerns over anonymity of testing appear to be a major barrier to testing . Kegeles et al (1990) found that on self administered questionnaires, all sexual orientation and gender groups expressed reluctance to obtain testing if anonymity were not assured. Bisexual men were especially concerned about seeking testing if there was mandatory reporting. Kegeles et al make the point that these men may be 'closeted' to their partners about their sexual orientation and were particularly concerned that their partners may find out. Philips et al (1995) analysed 3175 people in high risk US cities who had HIV risk factors. They reported that $7 \%$ planned to be tested and $30 \%$ would get tested if no one could find out the results. They concluded that options to increase testing rates should be explored, including easily accessible test sites together with policies and procedures to increase perceptions of testing privacy.

Counselling and testing is provided at a number of differing sites including GUM clinics, drug services, specialist HIV services, family planning clinics and by GP's. Knowledge of, and easy access to these services is thus essential for effective counselling and testing provision. Valdiserri et al (1993) studied American adults knowledge of HIV testing and availability. They found the 3 most frequent responses were private doctor (42\%), hospital or emergency room (23\%), and 'don't know / not sure' (12\%). Hong and Berger (1994) evaluated 3 distinct counselling and testing settings (scheduled confidential, scheduled anonymous, confidential walk in), and found each attracted clients with differing levels of risk behaviours. The importance of developing and maintaining multiple access sites for at risk individuals in thus advocated.

The findings of Valdiserri et al (1993) in the US raise particular issues of concern regarding use of GP's in counselling and testing. Studies in the UK have shown GP's to have negative attitudes towards HIV related issues (Boyton et al, 1988), and ambivalence to whether they should be offering any HIV service at all (Hoolaghan et al, 1993). Furthermore, Hoolaghan et al reported that only $27 \%$ of their survey of GP's never or only sometimes discussed safer sex guidelines when patients asked about HIV testing, and $11 \%$ never or only sometimes offered counselling to patients who requested HIV tests. 
These findings obviously have dire consequences in terms of behavioural risk reduction following testing at GP clinics. A review of GP's provision of HIV services and training in HIV related counselling seems necessary.

The length of time patients have to wait for test results may also play a role in accessing services. McCann and Wadsworth (1991) found that $34 \%$ those tested had to wait a week for their results, $29 \%$ waited for 2-3 weeks, and $14 \%$ waited over 3 weeks. Patients views of the testing experience have highlighted these delays for results as cause for concern. Davies et al (1993) found that a tenth of gay men interviewed reported anxiety over waiting for test results as a reason for not being tested. Although same day testing has been advocated by the Department of Health (PL/CO(92)5), there have been no reported evaluations of this testing service in comparison to other methods of providing test results.

From the studies reviewed it appears that both physical availability and psychological access ( Myers et al 1993) appear to affect utilisation of testing services. However all of the studies quoted have researched individual elements of either service provision or social / psychological barriers to testing. There is a need to evaluate these elements in combination across a range of risk groups, so effective testing services can be established, and policies developed to maximise utilisation of services.

Particular areas that need research are the different formats of providing testing results eg same day testing versus one week testing; and confidential vs. anonymous testing. It is imperative that users of services are consulted on these issues, as it is their confidence and ease of access to services that needs to be established.

There are still very few studies that examine the exact nature and course of an individuals decisions to enter the testing process. Although there are many reasons why an individual seeks testing, the factors that inhibit and encourage the person to seek a test site, go for pre-test counselling, decide to take the test and return for results are not well established. 


\section{Summary and conclusions}

Decreases in high risk behaviours have been found following HIV antibody testing accompanied by counselling. The usefulness of counselling and testing as an integral part of primary prevention strategy has been advocated. However, effective HIV prevention requires multi-faceted approach at the national, community, interpersonal and individual levels (Choi \& Coates, 1994).

In addition other benefits of testing occur to those who are seropositive in the form of early medical treatment. Thus the barriers to entering the HIV testing process need to be identified, to accordingly change service provision. Analysis of service users experiences and requirements for model HIV testing services thus need to be researched.

There are several limitations to all of the evidence reviewed in this paper. Firstly much of the work is conducted in the united states and there are questions as to how well this translates to the UK. The main drawbacks are the differences between the private health care system involving health insurance, and the more socialised health service system in the UK. This may apply particularly to the work on testing sites. Secondly, the majority of the work conducted in the HIV testing field utilises gay men. Although in the western world they are still the most at risk group of individuals, research needs to generalise its work to further incorporate heterosexuals, women, couples and minorities. Thirdly, the role of differing testing facilities is not clear eg between specialist HIV testing centres and GUM clinics. Each may have different significance to the clients they serve (cf. Hong \& Berger, 1994). 


\section{References}

Anderson, J., Hardy, A., Cathill, K. \& Aral, S. (1994). HIV antibody testing and post-test counselling in the US. American Journal of Public Health, 82, 1533-1535.

Bayer, R. (1991). Private acts, social consequences: AIDS and the politics of Public Health. New Brunswick, NJ, Rutger University Press.

Bauman, L. \& Siegal, K. (1987). Misperception of gay men at risk of AIDS associated with their sexual behaviour. Journal of Applied Social Psychology, 17, 329-350.

Beardsell, S. (1994). Should wider HIV testing be encouraged on the grounds of wider HIV practise? Aids Care, 6(1), 5-19.

Beevor, A.S. \& Catalan, (1993). Women's experience of HIV testing : the views of HIV positive and HIV negative women. Aids Care, 5, 177-179.

Berrios, D., Hearst, N., Coates, T.J., Stall, R., Hudes, E.S., Turner, H., Eversley, R., \& Catanian, J. (1993). HIV antibody testing among those most at risk for HIV infection : the National Behaviour Survey. Journal of the American Medical Association, 270,1576-1580.

Boyton R \& Scrambler G (1988). Survey of G.P. attitudes to AIDS in N.W. Thames and East Anglia Regions. British Medical Journal, 296, 538-541.

Chamot, E., Laborde, D.J., \& Rice, J.C. (1995). Do HIV testing and counselling increase risk behaviour. American Journal of Public Health, 85, 9, 1297-8.

Choi, K., \& Coates ,T.J. (1994). Prevention of HIV infection. AIDS, 8, 1371-1389.

Clearly, P.D., Singer, E., Rogers, T.F.,Avoron, J., Van Devanter, N., Soumeri, S., Perry, S., \& Pindyck, J. (1988), Sociodemographic and behavioural characteristics of HIV antibody positive blood donors. American Journal of PublicHealth, 78, 953-957.

Coates, T.J., Stall, R., \& Kegeles, S.,Lo, B., Morin, S.F., \& McCKusick, L. (1988). Aids antibody testing : will it stop the epidemic? Will it help people with HIV infection. American Psychologist, 43, 859- 864 . 
Davies, P.M., Hickson, F.C., Weatherburn, P., \& Hunt, A.J.(1993). Sex, gaymen and AIDS. Falmer. London.

Department of Health (1992). Additional sites for HIV antibody testing/ offering voluntary named HIV antibody testing to women receiving antenatal care/ partner notification for HIV infection. PL/CO (92)5.

Friedland, L.H. (1990). Early treatment of HIV: the time has come. New England Journal of Medicine, 332, 1000-1002.

Hart, G., Boulton, M.,\& Fitzpatrick, D. (1992). Relapse to unsafe sexual behaviour among gay men: a critique of recent behavioural HIV/AIDS research. Sociology of Health and Illness, 14(2), $216-232$.

Higgins, D.L., Galavetti,C., O'Reilly, K.R., Scnell, D.J., Moore, Rugg, D.L. \& Johnson, R.(1991). Evidence for the effects of HIV antibody counselling and testing on risk behaviours. Journal of the American Mental Association, 216, 2419-2429.

Hoolaghan, T., Blache, G., \& Pidock, J. (1993). The role of HIV prevention. Camden and Islington Health Promotion Service. London.

Hong, B. A., \& Berger S.G. (1994). Characteristics of individuals using different HIV/AIDS counselling and testing programs. AIDS, 8, 259-262.

Jacobsen, P.B., Perry, S.W., \& Hirsh, D. (1990). Behavioural and psychological responses to HIV antibody testing. Journal of Clinical and Consulting Psychology, 58, 31-37.

Jacobsen, P.B., Perry, S.W., Hirsh, D. (1988). Psychological reactions of individuals at risk for AIDS during an experimental drug trial. Psychosomatics, 29, 182-187.

Kalichman S.C. \& Hunter T.L.(1993). HIV related risk and antibody testing : a community survey. AIDS Education \& Prevention, 5, 234-243.

Kalichman, S.C., Somalai ,A., \& Adair, V. (1996). Psychological factors in HIV testing among STD clinic patients: an exploratory study. Psychology and Health, 11, 593-604. 
Kegeles, S.M., Catania, J.A., \& Coates, T.J.(1990). Many people who seek anonymous testing would avoid it under other circumstances. AIDS, 4, 585-588.

Lupton, D., McCarthy, S., \& Chapman, S.(1995). 'Doing the right thing'. The symbolic meaning and experience of having an HIV antibody test. Social Science and Medicine, 41(22), 173-180.

Lyter, D.W., Valdiserri, R.O., Kingsley, L.A.,Amoroso, W.P \& Ranaldo, C.R.(1987). The HIV antibody test : why gay men and bisexual men want or do not want to know their results. Public Health Reports, 102, 468-474.

McCann, K., \& Wadsworth, E. (1991). The experience of having a positive HIV antibody test. AIDS Care, 3, 343-347.

Meadows, J., Jenkinson, S., Catalan, J., \& Gazzard, B. (1990). HIV testing in the antenatal clinic: differing uptake rates for individual counselling mid-wives. AIDS Care, 2, 229-231.

Meyer, K., \& Pauker, S. (1987). Screening for HIV: can we afford the false positive rate. New England Journal of Medicine, 317, 238-246.

Myers, T., Orr, K.W., Locker, D., \& Jackson, E.A.(1993). Factors affecting gay and bisexual mens decisions and intentions to seek HIV testing. American Journal of Public Health, 83(5), 701-704.

Ostow, D.G., Joseph, J.G., \& Kessler, R. (1989). Disclosure of HIV antibody status: behavioural and mental health characteristics. AIDS, Education and prevention, 1, 1-11.

Otten, M.W., Zaidi, A.A., \& Worten, J.E. (1993). Changes in STD rates after HIV testing and post test counselling, Miami, 1988 to 1989. American Journal of Public Health, 83, 529-533.

Pergami, A., Catalan, J., Hulme, N., Burgess, A., \& Gazzard, B. (1994). How should a positive HIV result be given? The patient's view. AIDS Care, 6(1), 21-27.

Perry, S.W., Jacobsberg, L.B., \& Fishman, B. (1990). Psychological responses to serological testing for HIV. AIDS, 4(2), 145-152.

Philips, K.A. \& Coates, T.J. (1995). HIV counselling and testing: research and policy issues. AIDS Care, 7(2), 115-124. 
Philips, K.A., Eversley, R.B., Coates, T.J., \& Cantania, J.A. (1990). Who plans to be tested for HIV or would get tested if no one could find out the results. American Journal of Preventive Medicine, 11(3), 156-162.

Pollack, M. (1992). Organising the fight against AIDS. In M. Pollack, G. Parchler, J. Pierret (Eds). AIDS : a problem for psychological research. Sage, London.

Shilts, R. (1987). And the band goes on. Penguin, Harmondsworth.

Silverman, D. (1990). The social organisation of HIV counselling. In Aggleton, Davies \& Hart (Eds). AIDS: Individual, cultural and policy dimensions. Falmer, London.

Sonnex, C., Petherick, A., Hart, G., Adler, M.W. (1989). An appraisal of HIV test counselling of injecting drug users. Aids Care, 1, 307-312.

Stall, R., Ekstrand, M., \& Pollack, L.(1990). Relapse from safer sex: the next challenge for AIDS prevention efforts. Journal of AIDS, 3, 1181-1187.

Stall, R., Hoft C., \& Coates T.J.(1996). Decisions to get tested and to accept antiretroviral therapies among gay / bisexual men: implications for secondary prevention efforts. Journal of AIDS, $11,151-160$

Valdiserri, R.O., Holtgrave, D.R., Brackbill, R.M. (1993). American adults knowledge of HIV testing availability. American Journal of Public Health, 83(4), 525-528.

Wenger, N.S., Kusseling, F.S., Beck, K. \& Shapiro, M.F. (1994). When patients first suspect and find out they are infected with HIV: implications for prevention. Aids Care, 1, 307-312.

Wortley, P.M., Chu, S.Y., Diaz, T., Ward, J.W., Doyle, B., Davidson, A.J., Checko, P.J., Herr, M., Conti, L., Fann, S.A., Sorvillo, F., Mokotoff, E., Levy, A., Hermann, P., \& Norris-Walczak, E. (1995). HIV testing patterns: where, why, and when were persons with AIDS tested for HIV? AIDS, 9, 487-492. 
CHAPTER 3

Major Reasearch Project Proposal

Factors affecting GUM clinic attenders decisions and intentions to seek HIV testing. 


\section{APPLICANTS}

Jeff Salt

2nd Year Trainee

Dept. of Psychological Medicine

University of Glasgow

\section{SUPERVISORS}

Dr. Kate Davidson

Research Supervisor

Dept. of Psychological Medicine

University of Glasgow

Dr. J. Harvey

Consultant in Genito-urinary Medicine

Falkirk Royal Infirmary

Falkirk 


\section{SUMMARY}

The identification of factors that encourage or inhibit an individual to enter the HIV testing process has become a matter of importance in HIV testing research. Recent evidence suggests that approximately $40 \%$ of individuals with high risk factors have not been tested for the HIV antibody. The incorporation of health behaviour change models into HIV testing research has been advocated as a means to greater understanding of individuals decisions to seek testing. Another identified factor is the association between perceived risk, actual risk behaviours and their predictability of intention to be tested. Research has shown that people with risk factors do not necessarily perceive themselves to be at risk.

The present study intends to compare 3 groups of subjects categorised by their HIV testing status (already tested, getting tested and not testing) in order to :

(i) evaluate factors that predict HIV testing using the model of health care utilisation as its conceptual framework (Andersen and Newman, 1972)

(ii) analyse some of the factors that encourage or inhibit seeking an HIV test in this population

The research is to be conducted in 2 GUM (Genito-urinary medicine) clinics in the Forth Valley Health Board area, by means of a self administered questionnaire developed from previous research and results of semi-structured interviews conducted in a pilot study.

Ethical approval is to be obtained from Forth Valley Health Board. 


\section{INTRODUCTION}

It is a major decision for any individual to take an HIV test, with multiple costs and benefits to be weighed. A positive result informs the individual that they have contracted a terminal illness, with potential associated burdens including stigmatisation, rejection and isolation. Alternatively a negative result may bring relief and increased optimism regarding an individuals future.

Although the actual numbers of HIV tests has increased over time, recent research has identified that approximately $40 \%$ of individuals with risk factors have not been tested for the HIV antibody (Berrios et al., 1993). Furthermore research in both the U.S. and in the U.K. has found that HIV + individuals were tested late in their course of HIV infection (Elliot, 1996; Wortley et al., 1995). The identification (and removal) of factors which prevent or delay persons with risk factors from seeking testing, and if positive from seeking early medical care, is an issue which must be addressed in all high risk populations (Phillips and Coates, 1995; Wortley et al., 1995).

Potential barriers to testing identified in previous research with gay men include : fear of a positive test result (Siegal et al., 1989); fear of stigma / discrimination (Myers et al., 1993); and negative consequences in relationships (Lyter et al., 1987). The confidence placed in the anonymity of the test process is another potential barrier to testing. There is evidence that individuals of all risk groups will only consider testing under strict confidential or anonymous conditions (Phillips et al., 1995; Kegeles et al., 1990). Other barriers to testing include perceived lack of need for testing; lack of awareness of availability of testing, or of access to it; and lack of knowledge of early medical treatment.

There are two main limitations to these findings. One is the specificity to a particular subset of the testing barriers in each study e.g. reasons for not being tested, lack of knowledge, or confidence in anonymity. Few studies, if any, have investigated a range of these barriers within differing high risk populations. And secondly, gay men have been the target group in the majority of these studies, and the findings may not replicate to other risk groups.

The interaction between risk behaviours, risk perceptions, and intentions to be tested, has been identified as a specific area for future research (Philips and Coates, 1995). Some studies have found that people with risk factors do not necessarily perceive themselves to be at risk for HIV infection (Kelly et al., 1990; Bauman and Siegal, 1987). Other studies have reported that individuals with high risk factors have adequate perceptions of their own risk (Van der Velde et al., 1994). The association between perceived risk and seeking testing is also in dispute. Several studies (Meadows et al., 1993; Myers et 
al., 1993) found perceived risk to be a leading reason for seeking testing, whereas a more recent paper did not report this finding (Wortley et al., 1995).

Although perception of risk has been identified as a critical component in many models of health behaviour change (Gillies and Carballo, 1990), it may not in itself be sufficient for behaviour change. Other factors such as health beliefs and perceived control over ones health may also have a crucial role to play. Although theories such as The Health Belief Model (Janz and Becker, 1984) and Health Locus of Control (Wallston et al., 1978) have been utilised in programmes to reduce high risk HIV behaviours (e.g. Kelly et al., 1990), they have not been used extensively in predicting HIV testing intentions in risk populations. A major criticism of much previous research on the HIV testing process has been its lack of theory.

The model of health care utilisation has been used in prior studies to conceptualise the factors that predict both intentions to be tested and actual HIV testing. The model hypothesises that predisposing characteristics (e.g. demographics, health beliefs), enabling characteristics (e.g. family resources), and need characteristics (e.g. perceived and actual risk of disease) influence utilisation. This model can thus be used to determine the interaction between risk behaviours, perception of risk and testing intentions, as well as the role of health beliefs in predicting intentions to be tested.

\section{Present study}

The present study intends to compare 3 groups of subjects categorised by their HIV testing status (already tested, getting tested and not testing) in order to :

(i) evaluate factors that predict HIV testing using the model of health care utilisation as its conceptual framework (Andersen and Newman, 1972)

(ii) analyse some of the factors that encourage or inhibit seeking an HIV test in this population

It is intended to complete semi-structured interviews with volunteer GUM clinic attenders, to generate some of the factors that may influence HIV testing with this population. A questionnaire will then be developed using this information and questions for the first part of the study ( risk behaviours, perceived risk etc.) for self administration by clinic attenders. 
(1) To determine if perceived risk of HIV infection is accurate in this population.

(2) To determine if perception of risk is associated with intention to be tested.

(3) To determine if health locus of control is associated with intention to be tested.

(4) To determine the usefulness of the model of health care utilisation to predict HIV testing.

(5) To determine which factors encourage an individual to enter the testing process, and which factors inhibit an individual from entering the testing process.

\section{HYPOTHESES}

1. It was predicted by the model of health care utilisation that age, gender, internal and powerful other health locus of control (predisposing factors), education, income (enabling factors), and perceived risk of HIV (need factors), would be the primary correlates of testing behaviour.

2. It was hypothesised that perceived risk and actual risk would be moderately correlated.

3. It was predicted that internal and powerful others scales of the health locus of control would be significantly higher in the testing group; and that chance scores would be significantly higher in the not testing group.

4. Factors influencing individuals intentions to be tested will be accounted for by

(i) perceived personal costs / benefits.

(ii) confidence in the confidentiality of the testing process.

(iii) ease of access to testing. 


\section{PLAN OF INVESTIGATION}

\section{SUBJECTS}

Three groups of GUM clinic attenders will be required : those who have already been tested for HIV; those who are planning to be tested within the next month; and those who have no intention to test. Approximately 200 subjects will be required. Consecutive GUM clinic attenders will be approached, as random selection is not feasible. Those below the age of 16 will be excluded from the study.

\section{MEASURES}

(i) Semi-structured interviews

These will be used to elucidate factors that encourage / inhibit individuals to enter the testing process. The interview will be based upon the hypotheses that perceived personal costs / benefits; confidentiality; and ease of access to testing will account for a large proportion of individual factors. This measure is intended to confirm ideas based on previous findings and to identify factors specific to this population. The information from these interview will be used to guide development of the main study questionnaire.

(ii) Questionnaire

The questionnaire will have five main components (i) demographic details (ii) measure of sexual risk behaviours (iii) measure of perceived risk (iv) Health Locus of Control (v) items related to barriers to testing.

- Demographic details : include age, sex, level of education etc.

- Sexual Risk Behaviours : include type of sex (oral, anal, vaginal); use of condoms; number of partners; previous history of STD.

- Perceived risk: measured on a visual analogue scale

- Multi-dimensional Health Locus of Control (Wallston et al., 1978).

This scale measures generalised expectancy beliefs with respect to health along 3 dimensions: 
internal health locus of control; powerful others and chance. Internal health locus of control measures the extent to which a person believes their health is a result of their own actions;

Powerful others locus of control measures the extent to which a person believes their health is under the control of powerful others in their lives-e.g. doctors; Chance locus of control measures the extent to which a person believes their health is owing to chance factors.

- Barriers to testing : this section will be designed from the results of the semi-structured interviews.

\section{DESIGN AND PROCEDURE}

1. Pilot study.

(i) Semi-structured interviews

15-20 people will be asked for interview to discuss in depth their HIV testing intentions, and the factors that they believe inhibited or encouraged their decision to be tested or not be tested for the HIV antibodies. Informed consent will be obtained and confidentiality assured. Interviews will be taped for transcription at a later time.

The information from these interviews will be used to guide development of the main study questionnaire.

(ii) Development and testing of questionnaire

The developed questionnaire will be tested on a small number of subjects at the GUM clinic in Falkirk. Ease of completion and comprehensibility can then be assessed and adapted if necessary.

\section{Main Study.}

Subjects will be asked to participate in a study looking at factors associated with HIV testing. On agreeing to participate, subjects will be given the questionnaire and a brief explanation of how to complete it. Subjects will be asked to return the questionnaire before they leave the clinic that day. A box will be available to deposit completed questionnaires. All responses will be unmarked and confidential. Arrangements will be made for individual subjects to confidentially discuss any aspects of the study if desired. 


\section{SETTINGS AND EQUIPMENT}

The study will be conducted in two GUM clinics at Falkirk Royal Infirmary and Orchard House, Stirling. The only equipment needed will be the questionnaires themselves, envelopes for return of the questionnaire and a filing cabinet to store completed forms.

\section{DATA ANALYSIS}

Interviews will be taped, transcribed and analysed for common themes. Questionnaires will be coded into a computer package (SPSS) for analysis.

A risk index based on sexual behaviour for the past month will calculated (Crisp and Barber, 1995; Kelly et al., 1990) by multiplying the number of sexual partners by the frequency of unprotected intercourse. A risk index of zero is obtained if condoms are used on every occasion of intercourse, or if no intercourse is reported. This will provide a measure of actual risk behaviour for the past month. The risk index can then be used in latter stages of the analysis.

Logistic regression will be used to determine the best predictors of HIV testing using our model. Logistic regression can be used to predict group membership from a set of variables that can be interval or categorical, and is therefore more flexible than other regression models.

Spearmans Rho will be calculated for correlation analysis, and ANOVA's for between group differences

\section{PRACTICAL APPLICATIONS}

(1) Identification (and future reduction) of the barriers to entering the HIV testing process.

(2) Education of individuals and groups who are incorrect in their perception of HIV risk.

(3) Identification of high risk sexual practices in GUM clinic attenders.

The information collected on factors associated with testing intentions can be used to inform future provision of HIV counselling and testing and the way in which testing is offered to people. If particular factors deter people from seeking an HIV test, these can be approached at two levels: the GUM clinic itself and through wider education / public health policies. Once barriers to testing are identified, work 
can begin to decrease these inhibitions and encourage people with high risk factors to enter the testing process.

If this sample has inaccurate perception of risk based on the risk behaviours reported, education drives can focus on increasing knowledge within this group. This may be through the clinic itself i.e. health advisors, or through public information services. The information gathered through this sample can also be used to measure perception of risk over time and any changes that may take place.

\section{TIMESCALES}

It is hoped that the main study will begin in August 1996 and data will be collected by the end of December 1996. The four months between proposal and main study will allow for development of the questionnaire, pilot study and testing of the final draft questionnaire. The first 3 months of 1997 will be used to code and analyse data, and the project will be written up by 1st August 1997.

\section{ETHICAL APPROVAL}

Approval from the ethical committee of the Forth Valley Health Board will be sought. Approval from the staff at GUM clinics has already been obtained. 


\section{REFERENCES}

Andersen, R. \& and Newman, J (1972). Societal and individual determinants of medical health care utilisation in the United States, Millbank Quarterly, 51, pp 95-124.

Bauman, L., and Siegal, K. (1987). Misperception among gay men of the risk of AIDS associated with their sexual behaviour. Journal of Applied Social Psychology, 17, pp 329- 330 .

Berrios, D., Hearst, N., Coates, T.J., Stall, R., Hudes, E.S., Turner, H., Eversley, R., \& Catanian, J. (1993). HIV antibody testing among those most at risk for HIV infection : the National Behaviour Survey. Journal of the American Medical Association, 270, 1576-1580.

Crisp, B.R. and Barber, J.G. (1995). The effect of locus of control on the association between risk perception and sexual risk taking. Personality and Individual Differences, 19, 6, pp841-845.

Elliot, L., (1996). Personal Communication.

Jans, N., and Becker, M.H. (1984). The Health Belief Model: A Decade Later, Health Education Quarterly, 11, 1-47.

Kegeles, S.M., Catania, J.A., Coates, T.J., Pollack, L.M., and Lo, B. (1990). Many people who seek anonymous HIV antibody testing would avoid it under other circumstances. AIDS., 4, 585-588.

Kelly, J.A., St.Lawerence, J.S., Brasfield, T.L., Lemke, A., Amidei, T.,\& Roffman, R.E. (1990). Psychological factors that predict AIDS high risk versus AIDS precautionary behaviour. Journal of Consulting and Clinical Psychology, 58(1), 117-120.

Lyter, D.W., Valdiserri, R.O., Kingsely, L.A., (1987). The HIV antibody test: Why gay men and bisexual men want or do not want to know their results. Public Health Report, 102, 468-474.

Meadows, J., Catalan, J. Gazzard, B. (1993). "I plan to have the HIV test" - Predictors of testing intention in women attending a London antenatal clinic. AIDS Care, 5, 141-148.

Myers, T., Orr, K.W., Locker, D., and Jackson E.A. (1993). Factors affecting gay and bisexual mens decisions and intentions to seek HIV testing. American Journal of Public Health, Vol. 83, No. 5, 701-704. 
Phillips, K.A., and Coates, T.J. (1995). HIV counselling and testing: Research and policy issues. A.I.D.S. Care, Vol 7, No. 2, 115-124.

Phillips, K.A., Coates, T.J., Eversley, R.B. and Catania, J.A. (1995). Who plans to be tested for HIV or who would get tested if no one could find out the results? American Journal of Preventive Medicine, May-June, Vol. 11 (3), 156-162.

Siegal, K., Levine, M., Brooks, C., and Kern, R. (1989). The motivation of gay men for taking or not taking the HIV antibody test. Social problems, 36, 368-371.

Van der Velde, F.W., Van der Pligt, J., and Hooykaas, C. (1994). Perceiving AIDS related risk: ' accuracy as a function of difference in actual risk. Health Psychology, Jan 13 (1), 25- 33.

Wortley, P.M., Chu, S.Y., Diaz, T., Ward, J.W., Doyle, B., Davidson, A.J., Checko, P.J., Herr, M., Conti, L., Fann, S.A., Sorvillo, F., Mokotoff, E., Levy, A., Hermann, P., \& Norris-Walczak, E. (1995). HIV testing patterns: where, why, and when were persons with AIDS tested for HIV? AIDS, 9, 487-492 


\section{CHAPTER 4}

Major Research Project Paper

Factors affecting GUM clinic attenders decisions and intentions to seek HIV testing.

(Written for submission to the British Journal of Health Psychology. See Appendix 2.1 for notes for contributors) 
Objective : The present study compared 2 groups of GUM clinic attenders categorised by their HIV testing status to : (1) evaluate factors that predict HIV testing using the model of health care utilisation as its conceptual framework (Andersen and Newman, 1972); (2) analyse some of the factors that encourage or inhibit seeking an HIV test in this population

Design : Cross sectional questionare study.

Methods : A questionnaire was developed from pilot study information. It was administered at two GUM clinics in Central Scotland. Data was analsysed by logistic regression, t-test and Mann-Whitney statistics.

Results : $67 \%$ of those not tested for HIV reported at least one HIV risk factor. Percieved risk was the strongest predictor of HIV testing. Those not seeking testing endorsed less benefits of testing and more denial of the need to be tested. $23 \%$ of the sample did not know where to obtain a HIV test. Same day testing, testing without an appointment and anonymous testing were endorsed as factors to encourage testing.

Conclusions : Studies to determine the main predictors of percieved risk are now needed if we are to increase testing in relevant populations. Furthermore programmes to increase testing for people who have high risk factors should highlight the benefits of testing which would be lost if they do not test (e.g. early medical treatment). Increasing the range of services for HIV testing seems advocated (e.g. same day testing). 


\section{Introduction}

Although the actual number of HIV tests has increased since its inception in 1985, recent research has identified that approximately $40 \%$ of individuals with risk factors for HIV infection have not been tested for the HIV antibody (Berrios, Hearst, Coates, Stall, Hudes, Turner, Eversley, \& Catania, 1993).

Furthermore, research in both the U.S. and in the U.K. has found that HIV positive individuals were tested late in their course of HIV infection (Elliot, 1996; Wortley, Chu, Diaz, Ward, Doyle, Davidson, Checko, Herr, Conti, Fann, Sorvillo, Mokotoff, Levy, Hermann, \& Norris-Walczak, 1995). The identification (and removal) of factors which prevent or delay persons with risk factors from seeking testing, and if positive from seeking early medical care, is an issue which must be addressed in all high risk populations (Phillips and Coates, 1995; Wortley et al., 1995).

From the studies reviewed (Chapter 2; literature review), it appears that both physical availability and psychological access (Myers, Orr, Locker, \& Jackson, 1993) appear to affect utilisation of testing services. However the studies reviewed have utilised gay male populations to research individual elements of either service provision or social / psychological barriers to testing. There is a need to evaluate these elements in combination across a range of risk groups. With the incidence of heterosexually transmitted HIV increasing over recent years both in Scotland (Goldberg, Allardice, McMenamin, Codere, Raeside, Burns, \& Davis, 1997) and world-wide (Centre for Disease Control and Prevention, 1995, 1994), this is one risk group that requires further research.

Furthermore, the association between perceived risk and seeking testing is also unclear. Several studies (Meadows, Catalan, \& Gazzard, 1993; Myers et al., 1993) found perceived risk to be a leading reason for seeking testing, whereas a more recent paper did not report this finding (Wortley et al., 1995). The interaction between risk behaviours, risk perceptions, and intentions to be tested, has been identified as a specific area for future research (Philips and Coates, 1995).

Previous research of the HIV testing process has been mainly atheoretical. One model that has been applied is the model of health care utilisation (Andersen and Newman, 1972). This model hypothesises 
that predisposing characteristics (e.g. demographics, health beliefs), enabling characteristics (e.g. family resources), and need characteristics (e.g. perceived and actual risk of disease) influence utilisation. This model has been used in prior studies to conceptualise the factors that predict both intentions to be tested and actual HIV testing (Phillips, Coates, Eversley, \& Catania, 1995; Philips, 1993). The incorporation of health behaviour models and decision making theories into HIV testing research has been advocated as a means to a greater understanding of predictors of HIV testing, as well as individuals decisions to seek testing (Beardsell and Coyle, 1996). The Multi-dimensional Health Locus of Control (MHLC; Wallston et al., 1978) has been previously utilised in studies of HIV risk behaviour change (e.g. St. Lawrence, 1993) but not in studies predicting HIV testing. This scale measures attributions concerning internal vs external factors that influence health. High scores on the internal subscale reflect a belief that individual choices influence health, whereas high scores on the external subscales reflect a belief that health is determined by either random events / luck (chance subscale) or due to the influence of powerful others (e.g. medics; powerful others subscale).

Present study

The present study intends to compare 3 groups of subjects categorised by their HIV testing status (already tested, planning to be tested and not testing) in order to :

(i) evaluate factors that predict HIV testing using the model of health care utilisation as its conceptual framework (Andersen and Newman, 1972). The model will determine the role of risk behaviours, perception of risk and health locus of control beliefs in predicting intentions to be tested.

(ii) analyse some of the factors that encourage or inhibit seeking an HIV test in this population. 
This study will use Genito Urinary Medicine (GUM) clinic attenders to address the above issues. GUM clinic patients are a population at potentially high risk for all sexually transmitted diseases including HIV infection, due to practising risky sexual behaviours. The GUM clinics offer confidential HIV testing to the general public as well as to all patients.

Pilot Study

Semi-structured interviews were administered to 17 volunteer patients at the Falkirk GUM clinic, to generate factors that encourage or inhibit seeking an HIV test in this population. The themes that emerged were grouped as costs and benefits of testing; knowledge of test sites; knowledge of drug treatments / support services; and factors relating to the service provision of HIV tests (confidentiality, same day results etc). These factors were developed to form the final questionnaire. Cost and benefit items were replicated from a recent study by Kalichman et al., (1996). Appendix 2.2 contains details of the pilot study interview schedule; results of the interviews; and rationale for replicating Kalichman et al., (1996). 
Main hypotheses:

1. It was predicted by the model of health care utilisation that age, gender, internal and powerful other health locus of control (predisposing factors), education, income (enabling factors), and perceived risk of HIV (need factors), would be associated with having an HIV test.

2. It was hypothesised that perceived risk and actual risk would be moderately correlated.

3. It was predicted that internal and powerful others scales of the health locus of control would be significantly higher in the testing group; and that chance scores would be significantly higher in the not testing group.

4. It was hypothesised that the testing group would endorse more benefits and less costs of testing than the not testing group; and that the not testing group would endorse more denial and negativistic thinking than the testing group.

5. It was hypothesised that people in the testing group would identify more testing sites than the not testing group.

6. It was hypothesised that all items relating to service provision of HIV tests would be endorsed significantly higher in the not testing group than the testing group.

7. It was hypothesised that the not testing group would have less accurate information regarding support services and confidentiality issues than the testing group. 


\section{Method}

Measures

HIV Testing Questionnaire: (appendix 2.3).

Demographic information : gender; age; marital status; income; employment; level of education.

History of HIV testing : 'Have you ever been tested for the aids virus?'; Do you intend to be tested for the aids virus within the next month?' (yes/no).

Measurement of perceived risk : 'What is your personal risk of getting the aids virus?'; $10 \mathrm{~cm}$ visual analogue scale, no risk at all (0)- extremely high risk (10)

Risk behaviours for the past month : number of sexual partners; frequency of unprotected and protected anal and vaginal sex.

$\underline{\text { Risk behaviours for the past year: number of sexual partners; engagement in vaginal and anal sex (yes }}$ /no); frequency of condom use (never/sometimes /always).

Lifetime risk behaviours : ever shot up drugs; partner who has shot up drugs; partner with HIV/AIDS; sexually transmitted disease (yes/no)

Multi-dimensional health locus of control scale (MHLC; Wallston et al., 1978); 3 scales (internal, chance, powerful others) measured on a 6 point Likert type scale ranging from 'strongly agree' to 'strongly disagree'. Previous studies have confirmed the factor structure of this scale (Marshall et al., 1990) and have produced acceptable levels of reliability (Cronbachs alpha 0.87 internal, .068 powerful others, 0.76 chance; Cooper and Fabroni, 1990).

Knowledge of HIV test sites : 'where can you get an AIDS test ?(name as many places as possible)'. Knowledge of HIV drugs, support services, and confidentiality of test results : 6 questions, 4 point Likert scale 'very true' to 'very false'.

Barriers to testing : 5 questions, 4 point Likert scale 'not at all true for me' to 'very true for me'.

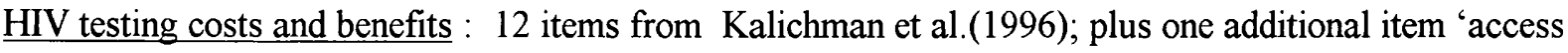
to medical treatments'; 4 point Likert scale 'not at all true for me' to very true for me'. 
The final questionnaire was reviewed by the health advisors and the consultant at the clinics, but no changes were madc. The Flesch Reading Ease index was calculated as 77.6 (range 0-100). An average index is around 60 . The higher the score the greater the number of people who can readily understand the text. The questionnaire was then piloted on five people for readability and ease of completion.

Setting and procedure

The study was carried out in two GUM clinics in Stirling and Falkirk. Subjects were given a brief description of the questionnaire content and asked to complete the form while waiting for their appointment. Completed questionnaires were placed in a box at the reception desk of the clinic. Informed consent was provided by agreeing to complete the anonymous questionnaire.

\section{Sample}

In total 214 patients were asked to complete the final questionnaire. 14 patients declined to participate and 5 patients returned unusable questionnaires. The final sample therefore consisted of 195 questionnaires, representing a $91 \%$ return rate.

Sixty percent of respondents were female $(n=118)$. The mean age of the sample was $27.83(\mathrm{sd}=8.28)$. Seventeen percent of the sample $(n=33)$ were married, $41 \%(n=79)$ had never been married, $22 \%(n=43)$ were part of an unmarried couple and $20 \%(n=38)$ were divorced / separated. Sixty one percent of respondents were employed $(n=118), 22 \%$ were unemployed $(n=42), 17 \%$ were students $(n=33)$, and $1 \%(n=2)$ were retired. Seventy five percent of the patients received an income of less than $£ 15,000$ $(n=147)$. The mean age of leaving education was 17.29 years $(s d=2.57)$. 


\section{Results}

The results are presented as follows : testing groups; between group differences (demographic information; risk behaviour, actual and perceived risk, health locus of control); model of health care utilisation; costs and benefits of testing; access to test sites; barriers to testing.

Support services and confidentiality information can be found in Appendix 2.42

Testing groups

The respondents were grouped according to their HIV testing status : already tested ( $n=53$; including those planning to be re-tested); planning to be tested within the next month $(n=13)$; no intention to seek testing $(\mathrm{n}=129)$.

As the getting tested group contained only 13 subjects comparisons were made with the already tested group on risk behaviours for the month prior to questionnaire completion. These variables did not approximate the normal distribution, so nonparametric Mann-Whitney tests were calculated. No significant differences were found : unprotected vaginal intercourse $(u=336, n s)$; unprotected anal intercourse $(u=332, n s)$; number of partners $(u=335, n s)$; risk index $(u=78, n s)$; perceived risk $(u=255$, ns). The already tested group and getting tested group were therefore combined (Appendix 2.41 contains risk behaviour means and standard deviations for the original 3 testing groups).

The remaining analysis for the study thus focused on 'testing' vs 'not testing' group comparisons. 
Between group differences

\section{Demographic Data}

There were no significant differences between the testing and not testing groups on Mann-Whitney tests at the .05 significance level for : gender $(u=3775.5, n s)$; employment status $(u=3915.5, n s)$; income $(u=3640, n s)$; or marital status $(u=3775.5, n s)$. Age and education variables did not approximate the normal distribution, so nonparametric Mann-Whitney tests were also calculated. There were no significant differences between the two groups : age $(u=3610.5, n s)$; education $(u=3628, n s)$.

Risk behaviours

Table 1(below) contains the means and standard deviations of sexual risk behaviour for each of the testing groups for the past month.

A risk index based on sexual behaviour for the past month was calculated (Crisp and Barber, 1995; Kelly et al., 1990) by multiplying the number of sexual partners by the frequency of unprotected intercourse. A risk index of zero is obtained if condoms are used on every occasion of intercourse, or if no intercourse is reported.

Table 1: Sexual risk behaviour means and SD's for the past month by testing group.

\begin{tabular}{|l|c|c|c|c|c|c|}
\hline & \multicolumn{5}{c|}{ HIV TESTING GROUPS } \\
\hline & \multicolumn{2}{|c|}{ Testing } & \multicolumn{2}{c|}{ Not Testing } & & \\
\hline & \multicolumn{2}{|c|}{$\mathrm{n}=66$} & \multicolumn{2}{c|}{$\mathrm{n}=129$} & & $\mathbf{p}$ \\
\hline MONTH RISK & Mean & (SD) & Mean & (SD) & u & $\mathbf{p}$ \\
\hline Unprotected & 1.95 & $(3.74)$ & 4.51 & $(7.2)$ & 3064 & $\mathrm{p}<.01$ \\
\hline Vaginal Intercourse & & & & & & \\
\hline Unprotected Anal & 0.17 & $(0.94)$ & 0.21 & $(1.68)$ & 4070 & $\mathrm{~ns}$ \\
\hline Intercourse & & & & & & \\
\hline \% intercourse with & 49.82 & $(47.45)$ & 40.02 & $(45.30)$ & 1499 & $\mathrm{~ns}$ \\
\hline condoms & & & & & & \\
\hline Sexual Partners & 1.32 & $(3.75)$ & 1.10 & $(1.08)$ & 3329 & $\mathrm{p}<.01$ \\
\hline (last month) & & & & & & \\
\hline Risk Index & 0.64 & $(0.71)$ & 0.75 & $(0.86)$ & 1535.5 & $\mathrm{~ns}$ \\
\hline Perceived Risk & 2.94 & $(2.67)$ & 1.49 & $(1.68)$ & 2593 & $\mathrm{p}<.0001$ \\
\hline
\end{tabular}

$\mathrm{SD}=$ standard deviation ; $\mathrm{u}=$ Mann Whitney score; $\mathrm{p}=$ significance value; $\mathrm{ns}=$ not significant 
As can be seen in table 1, the means for unprotected anal intercourse, vaginal intercourse, and risk index were higher in the not testing group, although only the frequency of vaginal intercourse was significantly different. Number of sexual partners was significantly higher in the testing group.

Of the overall sample, $54(28 \%)$ reported no sexual behaviour for the past month. However, 27 (14\%) reported multiple sexual partners (more than one) in the past month This figure rose to $89(47 \%)$ for the past year. Of those reporting sexual behaviour over the past month, $69 \%$ (97) reported less than $100 \%$ condom use.

Of the not testing group $86(67 \%)$ had at least one risk factor (index score greater than 0 , multiple partners over the past year, IVDU or IVDU partner, had a partner with HIV / AIDS). Of the testing group $42(64 \%)$ had at least one risk factor.

Of the overall sample, $171(87 \%)$ reported that they were heterosexual; $5(3 \%)$ bisexual and $5(3 \%)$ homosexual. It was therefore not viable to make comparisons between sexual orientation groups due to these low numbers. 
Actual and perceived risk

It was hypothesised that perceived risk and actual risk would be moderately correlated.

The results of Pearson correlation statistics between risk index scores and perceived risk scores were not significant for the testing group $(r=.23, n s)$ or the not testing group $(r=.14, n s)$.

Health Locus of Control

It was predicted that internal and powerful others scales of the health locus of control would be significantly higher in the testing group; and that chance scores would be significantly higher in the not testing group.

Table 2 below contains the means and standard deviations of health locus of control scores for the testing and not testing groups. These variables were positively skewed so log transformations were calculated to normalise these distributions. No significant differences were found at the .05 significance level.

Table 2 : Health Locus of Control mean and standard deviations by testing group.

\begin{tabular}{|l|c|c|c|c|c|c|c|}
\hline & \multicolumn{2}{|c|}{$\begin{array}{c}\text { Testing } \\
\mathbf{n}=66\end{array}$} & \multicolumn{2}{c|}{$\begin{array}{c}\text { Not Testing } \\
\mathbf{n}=129\end{array}$} & \multicolumn{2}{l|}{} & \\
\hline H.L.O.C. & Mean & SD & Mean & SD & $\mathbf{t}$ & df & p \\
\hline Internal & 24.06 & 5.03 & 24.47 & 4.42 & -.57 & 181 & ns \\
\hline Powerful Others & 18.87 & 6.13 & 17.89 & 5.63 & 1.09 & 181 & ns \\
\hline Chance & 18.08 & 5.96 & 17.47 & 4.82 & .75 & 181 & ns \\
\hline
\end{tabular}

$\mathrm{SD}=$ standard deviation; $\mathrm{t}=\mathrm{t}$-test score; $\mathrm{d} f=$ degrees of freedom; $\mathrm{p}=$ significance level; ns=not significant 
The model of health care utilisation

It was predicted by the model of health care utilisation, that age, gender, education, income,

perceived risk of HIV, internal and powerful other health locus of control would be associated with having an HIV test.

Table 3 : Logistic regression results for the model of health care utilisation.

\begin{tabular}{|c|c|c|c|}
\hline & $\begin{array}{c}\text { Test / No Test } \\
\beta\end{array}$ & $\mathbf{S E}$ & $\mathbf{P}$ \\
\hline Age & -0.0158 & .0185 & ns \\
\hline Sex - female & 0.4688 & .3076 & ns \\
\hline \multicolumn{4}{|l|}{$(\text { male })^{*}$} \\
\hline Marital Status & & & ns \\
\hline unmarried couple & -0.8862 & .5881 & ns \\
\hline never married & -1.3380 & .5368 & $\mathrm{p}<.05$ \\
\hline divorced / separated & -1.4040 & .5862 & $\mathrm{p}<.05$ \\
\hline \multicolumn{4}{|l|}{ (married)* } \\
\hline Employment & & & ns \\
\hline unemployed & -0.904 & .3828 & ns \\
\hline student & -0.6012 & .4020 & ns \\
\hline retired & 5.4162 & 15.72 & ns \\
\hline \multicolumn{4}{|l|}{ (employed)* $^{*}$} \\
\hline Income & & & $\mathrm{p}<.05$ \\
\hline$£ 5-10,000$ & 0.9478 & .4479 & $\mathrm{p}<.05$ \\
\hline$£ 10-15,000$ & 0.6795 & .4579 & ns \\
\hline$>£ 15,000$ & -0.3207 & .4259 & ns \\
\hline \multicolumn{4}{|l|}{$(£ 0-5,000)^{*}$} \\
\hline Education & -.0395 & .0597 & ns \\
\hline \multicolumn{4}{|l|}{ H.L.O.C } \\
\hline Internal & 0.191 & .0337 & ns \\
\hline Chance & -0.0224 & .0297 & ns \\
\hline Powerful Others & -0.0293 & .0270 & ns \\
\hline Perceived Risk & -0.3166 & .0787 & $\mathrm{p}<.0001$ \\
\hline Actual Risk (index) & 0.2001 & .2885 & ns \\
\hline
\end{tabular}

$\beta=$ regression coefficient; $S E=$ standard error; $p=$ significance level; $n s=$ not significant *denotes comparison group. 
Table 3 above contains the results of logistic regression analysis carried out for the testing and not testing data sets. The strongest predictor of HIV testing was perceived risk $(p<.0001)$. Being divorced / separated, having never been married and having an income between $£ 5-10,000$ were also associated with being tested $(\mathrm{p}<.05)$.

Costs and benefits of testing

It was hypothesised that the testing group would endorse more benefits and less costs of testing than the not testing group; and that the not testing group would endorse more denial and negativistic thinking than the testing group.

Table 4 below contains the means and standard deviations of the costs /benefits statements endorsed by the two testing groups. Totals for each subgroup were calculated by adding the individual subgroup items together.

Mann-Whitney tests indicated a number of differences between the two testing groups. Compared to people not testing, the testing group believed testing would make them feel better about their health $(u=3267.5, p<.05)$ and that people should get tested to protect their partners $(u=2783, p<.001)$. Total perceived benefits were also significantly higher in the testing group $(u=2702.5 \mathrm{p}<.01)$.

In total the not testing group endorsed more denial items than the testing group $(u=2824, p<.01)$. They would rather not know if they had the AIDS virus $(\mathrm{u}=3385, \mathrm{p}<.05)$; and would rather forget about testing for the virus $(\mathrm{u}=3094 \mathrm{p}<.01)$. The not testing group also felt sure they did not have the AIDS virus so they did not need to be tested $(u=2794 p<.001)$. No other testing perceptions were significantly different between the two groups. 
Table 4 : Means and standard deviations for testing perception statements by testing group.

\begin{tabular}{|c|c|c|c|c|}
\hline & $\begin{array}{c}\text { Testing } \\
n=66\end{array}$ & $\begin{array}{c}\text { Not } \\
\text { Testing } \\
\mathrm{n}=129\end{array}$ & & \\
\hline & $\begin{array}{c}\text { mean } \\
\text { (sd) }\end{array}$ & $\begin{array}{c}\text { mean } \\
\text { (sd) }\end{array}$ & $\mathbf{u}$ & $\mathbf{p}$ \\
\hline Perceived benefits (total) & $\begin{array}{c}9.19 \\
(2.31)\end{array}$ & $\begin{array}{c}8.59 \\
(3.56)\end{array}$ & 2702.5 & $\mathrm{p}<.01$ \\
\hline $\begin{array}{l}\text { Getting tested for the aids virus would help me feel } \\
\text { better about my health }\end{array}$ & $\begin{array}{c}2.85 \\
(1.21)\end{array}$ & $\begin{array}{c}2.69 \\
(2.36)\end{array}$ & 3267.5 & $\mathrm{p}<.05$ \\
\hline $\begin{array}{l}\text { People should get tested for the AIDS virus to } \\
\text { protect their partners. }\end{array}$ & $\begin{array}{c}3.45 \\
(1.03) \\
\end{array}$ & $\begin{array}{l}3.05 \\
(2.04) \\
\end{array}$ & 2783 & $\mathrm{p}<.001$ \\
\hline $\begin{array}{l}\text { Knowing the results of my AIDS test would allow } \\
\text { me access to medical treatments. }\end{array}$ & $\begin{array}{c}2.86 \\
(1.08)\end{array}$ & $\begin{array}{c}2.79 \\
(1.08)\end{array}$ & 3616 & ns \\
\hline Perceived costs (total) & $\begin{array}{c}5.86 \\
(1.87)\end{array}$ & $\begin{array}{c}5.60 \\
(1.89)\end{array}$ & 3475.5 & ns \\
\hline $\begin{array}{l}\text { If I got tested for the AIDS virus today I would be } \\
\text { scared about the results. }\end{array}$ & $\begin{array}{c}2.59 \\
(1.21)\end{array}$ & $\begin{array}{c}2.43 \\
(1.22) \\
\end{array}$ & 3775 & ns \\
\hline $\begin{array}{l}\text { People in my life would leave me if I had the AIDS } \\
\text { virus. }\end{array}$ & $\begin{array}{c}1.92 \\
(1.07)\end{array}$ & $\begin{array}{c}1.91 \\
(0.98)\end{array}$ & 3978 & ns \\
\hline $\begin{array}{l}\text { People outside the clinic can find out the results of } \\
\text { an AIDS test. }\end{array}$ & $\begin{array}{c}1.38 \\
(0.87)\end{array}$ & $\begin{array}{c}1.26 \\
(0.69)\end{array}$ & 3689.5 & ns \\
\hline Denial and awareness (total) & $\begin{array}{c}9.31 \\
(3.24)\end{array}$ & $\begin{array}{l}10.98 \\
(3.93)\end{array}$ & 2824 & $\mathrm{p}<.01$ \\
\hline $\begin{array}{l}\text { I do not know enough about AIDS to know if I need } \\
\text { to be tested. }\end{array}$ & $\begin{array}{c}1.68 \\
(0.93)\end{array}$ & $\begin{array}{c}1.84 \\
(0.95)\end{array}$ & 3748.5 & ns \\
\hline I would rather not know if I have the AIDS virus. & $\begin{array}{c}1.71 \\
(1.47)\end{array}$ & $\begin{array}{c}1.94 \\
(1.07) \\
\end{array}$ & 3385 & $\mathrm{p}<.05$ \\
\hline $\begin{array}{l}\text { I would rather forget about getting tested for the } \\
\text { AIDS virus. }\end{array}$ & $\begin{array}{c}1.75 \\
(1.09) \\
\end{array}$ & $\begin{array}{c}2.2 \\
(1.16) \\
\end{array}$ & 3094.5 & $\mathrm{p}<.01$ \\
\hline $\begin{array}{l}\text { It is better for me not to know if I have the AIDS } \\
\text { virus. }\end{array}$ & $\begin{array}{c}2.11 \\
(1.27)\end{array}$ & $\begin{array}{c}1.98 \\
(1.13)\end{array}$ & 3942.5 & ns \\
\hline $\begin{array}{l}\text { I am so sure I do not have the AIDS virus that I do } \\
\text { not have to get tested. }\end{array}$ & $\begin{array}{c}2.09 \\
(1.20)\end{array}$ & $\begin{array}{c}2.99 \\
(2.98)\end{array}$ & 2794 & $\mathrm{p}<.001$ \\
\hline Negativistic Thinking (total) & $\begin{array}{c}2.56 \\
(1.04) \\
\end{array}$ & $\begin{array}{c}2.65 \\
(1.16) \\
\end{array}$ & 3910.5 & ns \\
\hline $\begin{array}{l}\text { I am so sure that I have the AIDS virus I do not } \\
\text { need to get tested. }\end{array}$ & $\begin{array}{c}1.30 \\
(0.74)\end{array}$ & $\begin{array}{c}1.42 \\
(0.92)\end{array}$ & 3987 & ns \\
\hline $\begin{array}{l}\text { I probably have the AIDS virus so why bother } \\
\text { getting tested. }\end{array}$ & $\begin{array}{c}1.25 \\
(0.71)\end{array}$ & $\begin{array}{c}1.23 \\
(0.70)\end{array}$ & 3950.5 & ns \\
\hline
\end{tabular}

$\mathrm{sd}=$ =standard deviation; $\mathrm{u}=$ Mann-Whitney score; $\mathrm{p}=$ significnace level; $\mathrm{ns}=$ not significant

4 point Likert scale 'not at all true for me' to very true for me' 
Access to testing sites

It was hypothesised that people in the testing group would identify more testing sites than the not testing group.

Table 5 below contains the frequencies, means and standard deviations of the number of HIV testing sites named by the participants. Out of the total sample $23 \%$ did not know where they could obtain a HIV test. This finding was not accountable by differences between new and return patients $(\chi, \mathrm{df}=1$, ns). A t-test between responses for the testing and not testing groups revealed that people in the testing group could name significantly more HIV test sites than in the not testing group $(\mathrm{t}=2.64, \mathrm{df}=193$ $\mathrm{p}<.01$ ). Six people who reported they had previously taken an HIV test could not name a test site.

Table 5: Frequencies of HIV test sites named by testing group.

\begin{tabular}{|l|c|c|c|c|c|}
\hline No. of test sites & Testing & Not Testing & & & Total Sample \\
\hline & $\mathrm{n}=66$ & $\mathrm{n}=129$ & & & $\mathrm{n}=195$ \\
\hline & $\%$ & $\%$ & & & $\%$ \\
\hline Don't Know & 8 & 37 & & & 23 \\
\hline Named one or more & 92 & 63 & & & 77 \\
\hline & & & & & \\
\hline
\end{tabular}


HIV test service provision

It was hypothesised that all items relating to service provision of HIV tests would be endorsed significantly higher in the not testing group than the testing group

Table 6 below contains the means and standard deviations of items making access to HIV testing easier for GUM clinic attenders. Receiving test results on the same day as the HIV test were most commonly endorsed by both the testing and not testing groups. Having the HIV test at home was least often endorsed. The not testing group endorsed being able to walk in for an HIV test without an appointment significantly more than the testing group (Mann-Whitney : $u=3085, \mathrm{p}<.05$ )

Table 6 : Means and standard deviations of barriers to testing by testing group and total sample.

\begin{tabular}{|l|c|c|c|c|c|c|c|c|}
\hline & \multicolumn{2}{|c|}{ Testing } & \multicolumn{2}{c|}{ Not Testing } & & & \multicolumn{2}{c|}{ Total Sample } \\
\hline & \multicolumn{2}{|c|}{$\mathrm{n}=66$} & \multicolumn{2}{c|}{$\mathrm{n}=129$} & & & \multicolumn{2}{c|}{$\mathrm{n}=195$} \\
\hline & mean & sd & mean & sd & u & p & mean & sd \\
\hline Same day results & 3.06 & 1.18 & 3.15 & 1.11 & 3765 & $\mathrm{~ns}$ & 3.12 & 1.13 \\
\hline No appointment necessary & 2.36 & 1.25 & 2.75 & 1.11 & 3085 & $\mathrm{p}<.05$ & 2.61 & 1.18 \\
\hline No name taken & 2.45 & 1.32 & 2.47 & 1.21 & 3798 & $\mathrm{~ns}$ & 2.46 & 1.25 \\
\hline While attending another clinic & 2.29 & 1.24 & 2.28 & 1.20 & 3648 & $\mathrm{~ns}$ & 2.28 & 1.21 \\
\hline Test at home & 1.98 & 1.21 & 1.90 & 1.10 & 3698 & $\mathrm{~ns}$ & 1.93 & 1.14 \\
\hline
\end{tabular}

$\mathrm{sd}=$ =standard deviation; $\mathrm{u}=$ Mann-Whitney score; $\mathrm{p}=$ significance level; $\mathrm{ns}=$ not significant 4 point Likert scale 'not at all true for me' to very true for me' 


\section{Discussion}

Risk behaviours

As expected the predominantly heterosexual GUM sample reported a number of risk behaviours, namely high levels of unprotected sex and multiple partners. The testing group reported significantly higher numbers of sexual partners for both the past year and the past month.

Consistent with previous studies (e.g. Berrios et al., 1993), 67\% of the not testing group reported at least one HIV risk factor (i.e. multiple sexual partners, partner who was an IVDU, partner with HIV / AIDS). With the incidence of heterosexually transmitted HIV increasing, these findings require ongoing research and debate to change this trend.

Risk perception

The role of risk behaviours, risk perception and intentions to test may be one avenue to explore. This study found that the testing group made significantly higher estimates of their own risk than the not testing group. Furthermore, perceived risk was the strongest predictor of testing using logistic regression to test the model of health care utilisation. Previous studies of women (Meadows et al., 1993), STD clients (Jones et al., 1993), and gay men (Myers et al., 1993) have also found perception of risk to be a leading reason for having an HIV test. However, actual risk and perceived risk were not significantly correlated in either testing group. This suggests that perception of risk is not accurate in this sample. Previous studies of heterosexual populations have reported similar findings ( Simon et al., 1996; Wortley et al., 1995).

Perception of risk is a complex phenomenon with a research literature much of which is outside the scope of this paper (see Van der Pligt et al., 1993). However, biases in risk perception are relevant to infectious diseases and AIDS / HIV in particular (Glanz and Yang, 1996). Perception of risk for HIV / 
AIDS may operate on two independent levels : personal risk and societal risk (Snyder and Rouse,1992). Personal risk reflects an individuals concept of their own vulnerability to HIV infection; and societal risk would reflect a perception that HIV infection exists at a community or national level. It has been consistently reported across a number of health related behaviours, that people believe they are at less risk than the people around them; known as 'optimism bias' (Weinstein, 1989, 1982,1980). However, personal experience with HIV may increase risk perception (Van der Velde et al., 1992).

For effective education and communication about HIV and AIDS, health professionals and researchers need to be aware of the complex distortions associated with perceived risk and devise ways to overcome them. This may be particularly relevant to pre and post test counselling strategies associated with HIV testing, as well as HIV testing promotion campaigns.

\section{Conceptual framework}

The conceptual model used in this study predicted that predisposing, enabling and need characteristics would be associated with testing. As previously stated, the strongest predictor of HIV testing was perceived risk. Being divorced / separated, having never been married and having an income between £5-10,000 were also associated with being tested. These results therefore only partially confirm our hypotheses. Interestingly, actual risk behaviour was not associated with testing. This may be because the risk index calculated was based on the last months' reported sexual behaviours, not on lifetime risk behaviours. It is also possible that the sexual behaviours were not reportedly accurately and therefore did not reflect the actual level of risk behaviour. The incorporation of health locus of control into the study added little to our understanding of seeking testing. There were no significant differences between the testing and not testing groups on any of the MHLC subscales, and they were not significant in the prediction of testing using our model. 


\section{Costs and benefits}

The testing and not testing groups differed in their perceptions of the benefits of HIV testing. The testing group believed, more than the not testing group, that being tested for the AIDS virus would help them feel better about their health, could help protect their partners, and help gain early access to medical treatments. However both groups perceived the costs of testing in a similar manner. The main concern for both groups was being worried about receiving test results. As predicted the not testing group endorsed more denial items than the testing group, reporting that they would rather forget about testing, would rather not know if they had AIDS, and felt no need to test for AIDS.

The results found here are comparable to Kalichman et al., (1996) for perceived benefits of testing. However in the earlier study, denial items were not significantly different between those testing and not testing. It appears that promoting the benefits of testing may be an effective method for encouraging HIV testing (at least in GUM clinic populations).

Previous authors (Fischoff, 1989; Kalichman and Coley, 1995; Philips and Coates, 1995) have suggested that an appropriate approach may be Kahnemen and Tverskys Prospect Theory (1979). This is essentially an economic theory regarding risky decisions, that takes into consideration cognitive biases and heuristics. The theory states that risk taking decisions are influenced by the perceived costs of not taking the risk. Re-framing HIV testing messages in terms of lost benefits of not testing (e.g. protection of partners, access to medical benefits) may therefore increase the likelihood that people at risk will take an HIV test. This may be particularly pertinent considering the recent advances in HIV drug treatments (see Newell, 1996). However any programmes highlighting the benefits of testing would also have to ensure perceived risk was accurate in the target population.

Two other models that could be introduced into this area of research would be the stages of change model (Prochaska and DiClemente, 1984) and Motivational Interviewing (Miller and Rollnick,1991). These models describe movements through different stages of motivation to change. They argue that treatment plans should be matched to an individuals current stage of change. By influencing a persons 
decisional balance, they can then be projected to further stages of change. These principles would be useful in pre test counselling to help a high risk client reach a point where they may consider testing for HIV.

Knowledge of test sites

However, people must know where to obtain a HIV test if and when they do decide to test.

Surprisingly, $23 \%$ of the sample did not know where to obtain an HIV test. This is nearly double the figure in one large scale American study (Valdiserri et al., 1993). This finding is particularly troublesome as it could not be accounted for by differences between new and return patients to the clinics. Clinic policy dictates that all new patients should be notified that HIV testing is an option, therefore return patients should be able to identify at least one test site! There are several possible reasons for this finding. First, new patients may be anxious about their first GUM visit, and may focus on information relevant to their primary reason for attendance at the clinic (e.g. a STD). Second, it is well reported that patients only recall approximately $60 \%$ of information they receive in a consultation (Ley, 1988). This finding suggests that raising public awareness of test sites should be continued, and GUM clinics need to focus on presenting the option of testing to all patients repeatedly, through different sources (e.g. the consultant, health advisor etc).

A curious finding was that 6 people who did not know where to access an HIV test, reported that they had already been tested! However, inconsistencies in self reports of HIV testing, due to poor recall and high self presentation bias (i.e. providing socially acceptable answers) have been noted by Philips and Catania, 1995. 
Increasing Access to testing

The results of this study indicate at least 3 options that may decrease peoples inhibitions to seek HIV testing. These are same day testing, anonymous testing, and walk-in testing.

Several studies have highlighted concerns about waiting for HIV test results (Davies et al., 1993; Mansson, 1990) and same day testing services have been advocated by the Department of Health (1992). However, the health region where this study was carried out does not have such an option, and patients would have to travel to Edinburgh to receive this service. Same day test results were endorsed by both testing and not testing groups.

Anonymous testing (i.e. not having to give your name) has been proven in the US to increase plans to be tested by those with high risk factors (Phillips et al., 1995; Kegeles et al., 1990), and to attract individuals with high risk factors compared to confidential testing (Hong and Berger,1994).

Furthermore, acceptance rates of HIV testing in STD clinics that offered anonymous only testing, or confidential and anonymous testing, were higher than those STD clinics that offered only confidential testing (Simon et al., 1996).

Furthermore, this study found that it would be easier for those not seeking testing to have an HIV test if no appointment was necessary. The only study to compare walk in, anonymous and confidential HIV testing services (Hong and Berger, 1994) reported that walk-in clinics attracted the largest number of individuals seeking testing for the first time, bur that they had less reported risk factors. In theory, the GUM clinics in this study already operate a walk-in policy, however in practice telephone appointments on the day of the clinic will be deferred if the clinic is full. Of course the clinics are not just seeing people seeking HIV testing per se, and need ways to manage their schedules.

These results suggest that a variety of testing services could be explored in an attempt to increase testing rates among those at highest risk. The introduction of same day testing and the option of anonymous testing would seem advocated. 


\section{Limitations}

Several limitations are evident. Firstly the sample was relatively small, so the degree to which these results will generalise is unknown. Secondly, both the GUM clinics sampled were in towns, not large cities, so the levels and types of risk behaviours may not be representative of all GUM clinics. Thirdly this was a cross sectional study so changes in self reports of testing, risk behaviours, and decision making over time could not be validated.

\section{Conclusions}

The process of accessing HIV testing is multifaceted, involving perception of risk, belief in the benefits of testing, knowledge of the availability of testing, confidence in the testing procedures, and the ability to cope with test results. All of these factors need to be addressed by those promoting HIV testing services.

Almost two thirds of this sample had not undergone HIV testing, even though $67 \%$ of these people had at least one HIV risk factor. This study found that perception of risk was the main predictor of HIV testing within this sample, but risk perception was not necessarily accurate. Studies are now needed on the main contributors to perceived risk if we are to increase HIV testing in relevant populations.

Patients who do not know they are HIV positive cannot protect their partners and cannot access medical treatments. Both of these benefits of testing were endorsed significantly less by those not testing. Future HIV testing promotions and pre test counselling need to find ways to emphasise the lost benefits associated with not testing for HIV.

This study also provides evidence for increasing the types of HIV testing services available. Same day testing, anonymous testing and walk-in services were all endorsed by this sample. The introduction and evaluation of these services is recommended. In addition both HIV testing service providers and promotional bodies need to maintain awareness of availability of testing, as $23 \%$ of this sample could not name a HIV test site. 


\section{References}

Andersen, R. \& Newman, J. (1972). Societal and individual determinants of medical health care utilisation in the United States. Millbank Quarterly, 51, 95-124.

Beardsell, S. \& Coyle, A. (1996). A review of research on the nature and quality of HIV testing services: a proposal for process based studies, Social Science and Medicine, 42(5), 733-743.

Berrios, D., Hearst, N., Coates, T.J., Stall, R., Hudes, E.S., Turner, H., Eversley, R., \& Catanian, J. (1993). HIV antibody testing among those most at risk for HIV infection : the National Behaviour Survey. Journal of the American Medical Association, 270, 1576-1580.

Center for Disease Control and Prevention (1994). Heterosexually acquired AIDS: United States 1993, $M M W R, 43,155-160$.

Center for Disease Control and Prevention (1995). First 500,000 cases - 1995. $M M W R, 44,46$.

Crisp, B.R. \& Barber, J.G. (1995). The effect of locus of control on the association between risk perception and sexual risk taking. Personality and Individual Differences, 19(6), pp841-845.

Davies, P.M., Hickson F.C., Weatherburn, P., \& Hunt, A.J.(1993). Sex, gaymen and AIDS. Falmer. London.

Department of Health (1992). Additional sites for HIV antibody testing/ offering voluntary named HIV antibody testing to women receiving antenatal care/ partner notification for HIV infection. PL/CO, 92(5).

Fischhoff, B. (1989). Making Decisions About AIDS. In V. Mays \& G.W. Albee (Eds), Primary Preventions of AIDS: Psychological Approaches, pp.168-205. Sage Publications.

Glanz, K.\& Yang, H. (1996). Communicating About Risk of Infectious Diseases. Journal of the American Medical Association, 275(3), 253-263.

Goldberg, D., Allardice, G., McMenamin, J.,Codere, G., Raeside, F., Burns, G., \& Davis, B. (1997). Monitoring the Spread of HIV and AIDS in Scotland. AIDS News Supplement to the Weekly Report, 32, $1-12$. 
Hong, B.A. \& Berger, S.G. (1994). Characteristics of individuals using different HIV/AIDS counselling and testing programs. AIDS, 8, 259-262.

Jones, J.L., Hutto, P., Meyer,P., Dowda, H., Gamble, W.B., \& Gunn, R.A. (1993). HIV seroprevalence and reasons for refusing and accepting HIV testing. Sexually Transmitted Diseases, 20, 334-337.

Kahneman, D. \& Tversky, A. (1979). Prospect theory: an analysis of decision under risk. Econometrica, 47(2), 263-291.

Kalichman, S.C. \& Coley, B. (1995). Context framing to enhance HIV-antibody-testing messages targeted to African American women. American Psychological Association, 14(3), 247-254.

Kalichman, S.C., Somalai A., \& Adair V. (1996). Psychological factors in HIV testing among STD clinic patients: an exploratory study. Psychology and Health, 11, 593-604.

Kegeles, S.M., Catania, J.A., \& Coates, T.J. (1990). Many people who seek anonymous testing would avoid it under other circumstances. AIDS, $4,585-588$.

Kelly, J.A., St.Lawerence, J.S., Brasfield, T.L., Lemke, A., Amidei, T.,\& Roffman, R.E. (1990). Psychological factors that predict AIDS high risk versus AIDS precautionary behaviour. Journal of Consulting and Clinical Psychology, 58(1), 117-120.

Ley, p.(1988). Communicating with patients: improving communication, satisfaction and compliance. London. Croom Helme.

Mansson, S.A. (1990). Psycho-social aspects of HIV testing-the Swedish case. AIDS Care, 2, 5-10. Marteau, T.M. (1995). Health beliefs and attributions. In A. Broome \& S. Llewelyn (Eds), Health Psychology: Process and applications, pp. 3-20. Chapman \& Hall.

Meadows, J., Catalan, J. \& Gazzard, B. (1993). "I plan to have the HIV test" - Predictors of testing intention in women attending a London antenatal clinic. AIDS Care, 5, 141-148.

Miller, W.R. \& Rollnick, S. (1991). Motivational Interviewing : preparing people to change addictive behaviour. Guilgford Press : New York. 
Myers, T., Orr, K.W., Locker, D., \& Jackson, E.A. (1993). Factors affecting gay and bisexual mens decisions and intentions to seek HIV testing. American Journal of Public Health, 83(5), 701-704.

Newel, T. (1996). Medical interventions : highlights from the Vancouver conference July 1996.

In Testing Times : should we promote an HIV testing strategy. Terrence Higgins Trust.

Phillips, K.A.(1993). Factors associated with voluntary HIV testing for African-Americans and Hispanics. Aids Education and Prevention, 5(2), 95-103.

Phillips, K.A. \& Catania, J.A. (1995). Consistency in self-reports of HIV testing: longitudinal findings from the National AIDS Behavioural Surveys. Public Health Reports, 110, 749-753.

Philips, K.A. \& Coates, T.J. (1995). HIV counselling and testing: research and policy issues. AIDS Care, 7(2), 115-124.

Phillips, K.A., Coates, T.J., Eversley, R.B. \& Catania, J.A. (1995). Who plans to be tested for HIV or who would get tested if no one could find out the results? American Journal of Preventive Medicine, 11(3), 156-162.

Prochaska, J.O. \& DiClemente, C.C.(1984). The transtheoretical approach : crossing traditional boundaries of change. Homewood, IL: Dorsey Press.

Simon, P.A., Weber,M., Ford, W.L., Cheng, F., \& Kerndt, P.R. (1996). Reasons for HIV antibody test refusal in a heterosexual sexually transmitted disease clinic population. AIDS, 10, 1549-1553.

Snyder, L.B. \& Rouse, R.A.(1992). Targeting the audience for AIDS messages by actual and perceived risk. AIDS Education \& Prevention, 4(2), 143-159.

St.Lawrence, J.S. (1993). African-American adolescents' knowledge, health-related attitudes, sexual behaviour, and contrasceptive decisions: implications for the prevention of adolescent HIV infection. American Psychological Association, 61(1), 104-112.

Valdiserri, R.O., Holtgrave D.R., \& Brackbill, R.M. (1993). American adults knowledge of HIV testing availability. American Journal of Public Health, 83(4), 525-528.

Van der Pligt, J., Otten, W., \& Richard, R. (1993). Perceived risk of AIDS: unrealistic optimism and self-protective action. In R. Pryor \& D. Reeder (Eds), Social Psychology of HIV infection, pp.39-58. 
Lawrence, Erlbaum Associates.

Van der velde, F.W. \& Van der Hooykaas, C. (1992). Risk perception and behaviour: pessimism, realism, and optimism about AIDS-related health behaviour. Psychological Health, 6, 23-38.

Wallston, K.A., Wallston, B.S., \& DeVellis, R. (1978). Development of the Multidimensional Health Locus of Control (MHLC) scales. Health Education Monographs, 6(2), 160-170.

Weinstein, N.D. (1980). Unrealistic optimism about future life events. Journal of Personality and Social Psychology, 39, 806-820.

Weinstein, N.D. (1982). Unrealistic optimism about susceptibility to health problems. Journal of Behavioural Medicine, 5, 441-460.

Weinstein, N.D. (1989). Perceptions of personal susceptibility to harm. In V. Mays \& G.W. Albee (Eds), Primary Prevention of AIDS, pp. 142-167. Sage Publications.

Wortley, P.M., Chu, S.Y., Diaz, T., Ward, J.W., Doyle, B., Davidson, A.J., Checko, P.J., Herr, M., Conti, L., Fann, S.A., Sorvillo, F., Mokotoff, E., Levy, A., Hermann, P., \& Norris-Walczak, E. (1995). HIV testing patterns: where, why, and when were persons with AIDS tested for HIV? AIDS, 9, 487-492. 


\section{CHAPTER 5}

\section{Single Case Research Study}

Oppositional Defiant Disorder : the case for measurement of severity.

(written for submission to Clinical Child Psychology and Psychiatry. See Appendix 3.1 for notes for contributors) 


\begin{abstract}
This paper describes the treatment of a six year old boy with a diagnosis of Oppositional Defiant Disorder (ODD). The case was treated with parent management training techniques. The parents successfully changed their pattern of parenting which had beneficial effects on their relationship with their son and his behaviours. It is argued that this case represents a mild presentation of ODD. However DSM IV criteria do not allow for severity specifiers in the diagnosis of ODD. It is argued that adding severity measures to the classification of ODD may aid the debate surrounding the prediction of conduct disorder by early onset of ODD.
\end{abstract}

Keywords : Oppositional Defiant Disorder; Parent Management Training; Severity of symptoms. 


\section{Introduction}

Oppositional defiant disorder (ODD) has been a controversial concept since its inception in DSM III. Some researchers and clinicians have argued that ODD can be a developmental precursor of conduct disorder (CD; Lahey et al., 1992). Others claim that ODD is a milder form of CD, and argue that the two categories should be collapsed and considered as one syndrome (e.g. Rey et al., 1988). Yet others feel ODD is not sufficiently distinct from normal developmental oppositional behaviour to be a diagnostic category (Rutter and Shaffer, 1980). Regardless of the arguments over ODD's exact position in diagnostic nosology, ODD remains a common clinical diagnosis (Rey, 1993).

As the introductory comments highlight, there are still many issues to be resolved surrounding ODD. Perhaps most pertinent is the exact criteria for diagnosis of ODD. What constitutes a label of ODD has changed over the years, altering its prevalence accordingly. DSM III required 2 of 5 symptoms, and DSM III R required 5 out of 9 symptoms. DSM IV requires a pattern of negativistic, hostile, and defiant behaviour lasting six months, during which four of the following are present : often loses temper; often argues with adults; often actively defies or refuses to comply with adults rules; often deliberately does things that annoy other people; often blames others for his or her mistakes; is often touchy or easily annoyed; is often angry and resentful, and is often vindictive. These behaviours have to cause significant impairment in functioning.

The way ODD is diagnosed is critical for several reasons. If ODD does have value in predicting later incidence of $\mathrm{CD}$ or adult anti-social behaviour, then different symptoms may have different predictive utility. For example early or late onset CD may have different relationships with symptoms of ODD diagnosed at an earlier age (Loeber, Green, Keenan, Lahey, 1995). Furthermore, symptoms of ODD may have different relationships with severity of CD (Lahey and Loeber, 1994). DSM IV allows for a severity specifier in the diagnosis of $\mathrm{CD}$ (mild, moderate, severe) but not in the diagnosis of ODD. Secondly, there may be treatment implications for ODD and CD. If ODD is a milder form of CD, then effective treatments for ODD may transfer to CD (see Kazdin, 1997 for a review). Finally, the way ODD is diagnosed will effect its incidence (Lahey, Applegate, Barkley, et al., 1994). This will 
This will obviously have an effect on all of the issues raised so far, particularly the nature of the relationship between ODD and forms of behavioural disorder associated with it in later life.

This article raises the issue of including severity of ODD as part of diagnostic criteria. The case described is a 'mild' case of ODD, only manifesting within one environment ( the home setting) and responding rapidly to parent management training intervention. However, the case clearly reached criteria for the diagnosis of ODD.

\section{Case description}

Reason for referral : SC, a six and a half year old boy, was referred by his G.P. for treatment of behavioural problems at home.

Presenting problem : For at least 3 years SC had exhibited behavioural difficulties at home. These behaviours ranged from non-compliance with the families routines (e.g. mealtimes, shopping, betimes) to 'temper tantrums' consisting of spitting, shouting, hitting and destroying material objects. SC also hit / kicked his sister and her friends, and on two occasions shortly before referral had disappeared from the local vicinity for several hours.

$\mathrm{Mr}$ and $\mathrm{Mrs} \mathrm{C}$ reported that $\mathrm{SC}$ was controlling their lives with his unreasonable behaviour. Mrs $\mathrm{C}$ felt particularly under stress as she spent longer periods of time with SC. She reported that every request was met with a battle of wills, which SC nearly always won. Arguing, loss of temper and purposefully annoying other family members had made it very difficult to take SC out with the family. Attempts to persuade $\mathrm{SC}$ resulted in severe temper tantrums.

Bedtime routines were a particular source of stress for the family. The extent to which SC disrupted the family became apparent on obtaining a detailed description of a typical night-time routine. SC would battle to take a bath; would not get out of the bath; would not let a towel touch his skin, sat in front of a heater until he was dry; insisted on staying up until his sister went to bed; and insisted mum make a tent from sheets in the front room for him to lie down in until he fell asleep (around 2 a.m.). Similar descriptions were elicited for other behaviours. 
make a tent from sheets in the front room for him to lie down in until he fell asleep (around 2 a.m.). Similar descriptions were elicited for other behaviours.

Family Background: Both $\mathrm{Mr}$ and Mrs $\mathrm{C}$ work in the hotel industry. Mrs $\mathrm{C}$ is a day shift worker, but $\mathrm{Mr} \mathrm{C}$ works variable shift patterns including night shift. $\mathrm{Mr} \mathrm{C}$ gets the children up in the morning and takes them to school while Mrs $\mathrm{C}$ is at work. The children return to their grandfathers flat after school until Mrs C returns. During the school holidays, SC's grandfather watches the children all day. SC has one older sister NC who is 11 . The family live in a one bedroom flat, where SC and his sister share a room. There is no history of psychiatric or behavioural problems within the family.

Developmental and Medical History: $\quad$ Mrs C reported a normal pregnancy and birth, and SC reached his developmental milestones appropriately. The only medical factor is the onset of asthma at around 2 years of age when SC required a ventilation system for approximately 3 weeks. He still experiences asthma attacks but it is not a significant problem.

School performance : With permission SC's teacher was contacted. No behavioural difficulties were reported by the school. They stated that SC was very quiet, almost withdrawn, and was frequently exhausted in school. Academically SC had not progressed well, and received learning support for reading and maths. Mrs $\mathrm{C}$ had attended a group run by learning support staff to assist $\mathrm{SC}$ with his reading. The teacher also reported that $\mathrm{SC}$ had difficulty following more than one instruction at a time. If a list of instructions was announced in class, SC would only pick up on one of them. The teacher questioned whether many of SC's schooling difficulties were in connection with his 'mentally tired' state when coming to school.

Assessment Measures: Functional analysis of target behaviours using $\mathrm{ABC}$ charts; frequency charts of targeted behaviours; WISC III (UK) - Wechsler Intelligence Scale for Children; WORD - Wechsler Objective Reading Dimensions. (See appendices 3.2-3.6 for full results).

Formulation: SC meets the DSM IV criteria for oppositional defiant disorder, code 313.81 .

The precise onset of oppositional behaviours was not clear, although they had become progressively worse over a 3 year period. Non-compliance, arguing, hitting and loss of temper were displayed 
frequently by SC and had become a considerable source of stress for the family. These behaviours were being reinforced by the attention they received from $\mathrm{Mr}$ and $\mathrm{Mrs} \mathrm{C}$, which were mainly verbal reprimands. Boundaries and limits of acceptable behaviour had not been established for SC and inconsistent management resulted in threats of punishment not being followed through, and tantrums being given into. This situation was compounded by both parents working separate shift patterns and a third person (grandfather) being involved in the day to day care of SC. Intermittent reinforcement was therefore increasing the likelihood SC would behave in such a way again.

$\mathrm{Mr}$ and Mrs $\mathrm{C}$ appeared to have a good relationship and displayed love and concern for the two children. There were times during the week when the family did engage in activities together which were enjoyed. However, both parents felt SC was in control most of the time and wanted a more relaxed life for the whole family. Mrs $\mathrm{C}$ had recently taken time off for stress related illnesses and was the primary reason for referral at this point in time.

Psychometric testing revealed SC to be within the 'borderline' range of intellectual functioning. There was no evidence of a specific receptive language difficulty. His academic problems were undoubtedly exacerbated by excessive tiredness in school. As clear limits were set for SC within the school environment there was no displays of oppositional behaviour.

Treatment rationale: A behaviour modification / social learning approach to child management skills was adopted. Direct training of parents in child management skills has been established as the treatment of choice for reducing oppositional behaviour in children (Anastopoulos and Barkley, 1989; Kazdin, 1997). Parenting skills such as establishing rules for the child to follow, providing positive reinforcement for appropriate behaviour, delivering extinction or time out for undesirable behaviour and negotiating compromises are taught. Parents can then put these techniques into practice at home, with supervision from the therapist. Parent training can also involve relationship enhancement to generalise and maintain the positive effects of behaviour modification (Kazdin, 1997).

Treatment sessions: 12 sessions were conducted in total. The first sessions focused on assessment, presentation of formulation, and treatment rationale. As requested by $\mathrm{Mr}$ and $\mathrm{Mrs} \mathrm{C}$, the initial focus 
for intervention was the bedtime routine. A star chart system was implemented for successful completion of a new night-time routine. Stars were faded to variable reinforcement and then eliminated as treatment progressed. The focus of our sessions then moved onto mealtime routine / environmental manipulation; prevention and management of temper tantrums; parental requests and commands; and anticipation of behavioural difficulties. The sessions included positive feedback to parents on their efforts, reinforcement of the techniques they were utilising, and additional teaching of strategies if necessary.

Outcome of treatment: Full results are to be found in Appendices 3.2-3.6.

Both parents were motivated to learn and use behavioural techniques, and experienced substantial successes in a relatively short period of time. By establishing routines that $\mathrm{SC}$ understood, and training $\mathrm{Mr}$ and $\mathrm{Mrs} \mathrm{C}$ in reinforcement techniques, substantial changes in SC's behaviour occurred. For $\mathrm{Mr}$ and Mrs C the 'new style' of management was almost a complete reversal of their previous strategy, which was practically non-existent. Undoubtedly finding a very successful tangible reinforcer (stars) initially aided the success of these strategies.

Compliance with the bedtime routine increased to 6 out of 7 nights within the first week of intervention. This was probably due to Mrs C's high motivation and SC's delight at receiving both stars and praise for good behaviour. High compliance with bedtime routines has been maintained, even with the withdrawal of the star chart. Both parents reported general improvements in behaviour within the first week. These immediate improvements had two effects. Firstly it provided $\mathrm{Mr}$ and $\mathrm{Mrs} \mathrm{C}$ with the self efficacy that they could alter SC's behaviour; and secondly, it meant that they had time to themselves in the evenings. The effects of an improved sleep pattern were evident when SC returned to school.

Mealtime routines and behaviour also improved significantly. By maintaining that all food should be eaten at the table, not offering multiple alternatives to the food provided, and socially reinforcing eating with the family, the pattern of meals changed. Again, this positive change appears to have been maintained over sessions. 
As was mentioned previously, within the first weeks of intervention, $\mathrm{Mr}$ and $\mathrm{Mrs} \mathrm{C}$. reported improvements in SC's overall behaviour. By the end of our sessions SC's temper tantrums had decreased to only 3-4 per week. These outbursts however were less ferocious and less destructive. $\mathrm{Mr}$ C admitted still losing his temper over trivial matters which may have been maintaining SC's outbursts.

When SC returned to school after the summer break, both his parents and his teacher reported that SC had been happier, with no major behavioural difficulties. A 2 month follow up appointment was declined by the family as they were still coping well.

\section{Discussion}

Successful treatment was completed in a limited number of sessions using a relatively straightforward treatment strategy. The fact that $\mathrm{SC}$ responded so quickly to the intervention is suggestive of a mild form of oppositional behaviour. Furthermore, SC only displayed oppositional behaviours in one distinct environment (i.e. when with his parents). However the DSM IV diagnosis for oppositional defiant disorder was appropriate in this case. Diagnostic criteria does not allow for specification of the degree of severity of ODD i.e. mild, moderate, severe.. Research into the usefulness of severity measures in ODD seems advocated.

One of the few studies to compare categorical and dimensional measures of ODD (Fergusson and Horwood, 1995) concluded that : ' (1) disruptive behaviour symptoms showed clear evidence of dimensional properties in which the severity of disturbance varied from none to severe, and (2) the use of diagnostic classifications based on DSM III R criteria produced measures that were less than optimal predictors of future outcomes'( $\mathrm{p} 482)$. This study supports the notion that measurement of severity may be important in ODD. There are two limitations to this study however. Firstly, these conclusions are only valid for DSM III R criteria and secondly, the children were assessed at 15 years and followed up at 16 , and may not be predictive for younger age ranges. It would be interesting to replicate this study 
on a younger age range of children. They could then be followed up over time to determine if severity of disturbance at a younger age enhances prediction of severity at a later age.

It has been hypothesised (Patterson, DeBaryshe \& Ramsey, 1989) that there may be two developmental pathways related to conduct disorders. An early onset pathway begins with oppositional disorders in early pre-school years, and progresses to aggressive and non-aggressive symptoms of conduct disorder in middle childhood, and then on to the most serious symptoms by adolescence. In contrast a late starter pathway begins with symptoms of $\mathrm{CD}$ during adolescence. Adolescents who are most likely to be chronically antisocial are those who display oppositional behaviours in the pre-school years (White, Moffit, Earl and Robbins, 1990). However these findings are based upon the concept of ODD as a unitary concept without dimensional properties. If severity of ODD was considered as a factor perhaps these findings would not be as predictive. At this stage severity of ODD cannot be distinguished due to diagnostic criteria. Therefore its value of predicting later onset of CD cannot be evaluated.

Considering the evidence that ODD leads to CD in at least a percentage of cases, it is critical we are researching the same levels of symptom presentation. This would seem to be especially significant as diagnosis of conduct disorder is labelled with a severity measure. The predictive validity of ODD as a precursor of CD may be enhanced if severity of disorder is taken into account.

\section{Conclusion}

In clinical language the use of severity descriptors(e.g. mildly anxious) is often used intuitively to discriminate the variety of disorders seen in practice. However, when researching the development of clinical disorders, a common language must be used to ensure clarity of communication. It is crucial that we as clinicians and researchers are identifying, diagnosing, and treating childhood problems with the same range of symptoms which result in same level of impairment. Without the use of severity measures within ODD diagnostic criteria, researchers may be describing different presentations of the same disorder. 


\section{References}

Anastopoulos, A.D., \& Barkley, R.T. (1989). Parent training for oppositional preschoolers. In

Schaeffer C.E. and Briesmeister J.M. (Eds.), Handbook of parent training. John Wiley and sons.

American Psychiatric Association. (1987). Diagnostic and statistical manual of mental disorders ( $3^{\text {rd }}$ ed., rev.). Washington, D.C: Authors.

American Psychiatric Association. (1994). Diagnostic and statistical manual of mental disorders $\left(4^{\text {th }}\right.$ ed.). Washington, D.C. Authors.

Fergusson, D.M., \& Horwood, L.J. (1995). Predictive validity of categorically and dimensionally scored measures of disruptive childhood behaviours. Journal of the American Academy of Child and Adolescent Psychiatry, 34(4), 477-487.

Kazdin, A.E. (1997). Practitioner review: psychosocial treatments for conduct disorder in children. Journal of Child Psychiatry, 38(2), 161-178.

Lahey, B.B., Loeber, R., Herbert, C.Q., Frick, P.J., \& Grimm, J. (1992). Oppositional defiant and conduct disorders: issues to be resolved for DSM-IV. Journal of the American Academy of Child and Adolescent Psychiatry, 31(3), 539-546.

Lahey, B.B., \& Loeber, R. (1994). Framework for a developmental model of ODD and conduct disorder. In D. Routh (Ed). Disruptive Behaviour Disorders in Childhood. Plenum Press. New York. Lahey, B.B., Applegate, B., Barkley, R.A., Garfinkel, B., McBurnett, K., Kerdyk, L., Greenhill, L., Hynd, G.W., Frick, P.J., Newcorn, J., Biederman, J., Ollendick, T., Hart, E.L., Perez, D., Waldman, I., \& Shaffer, D. (1994). DSM IV field trials for ODD and conduct disorder in children and adolescents. American Journal of Psychiatry, 151(8), 1163-1171.

Loeber, R., Green, S.M., Keenan, K. \& Lahey, B.B. (1995). Which boys will fare worse? Early predictors of the onset of conduct disorder in a six year longitudinal study. Journal of the American Academy of Child and Adolescent Psychiatry, 34(4), 449-509. 
Patterson, G.R., DeBaryshe, B.D. \& Ramsey, E. (1989). A developmental perspective on anti-social behaviour. American Psychologist, 44, 329-335.

Rey, J.M., Bashir, M.R., Schwarz, M., Richards,I.N., Plapp, J.M., \& Stewart, G.W. (1988).

Oppositional disorder: fact or fiction? Journal of the American Academy of Child and Adolescent Psychiatry, 27, 157-162

Rey, J.M. (1993). Oppositional Defiant Disorder. American Journal of Psychiatry, 150(12), 17691778.

Rutter, M. \& Shaffer, D. (1980). DSM-III: a step forward or back in terms of the classification of child psychiatric disorders. Journal of the American Academy of Child Psychiatry, 19, 371-394.

Wechsler Intelligence Scalc for Children-Third Edition UK (1993). The Psychological Corporation. Wechsler Objective Reading Dimensions (1993). The Psychological Corporation.

White,J., Moffit, T.,Earl, F., \& Robbins, L. (1990). Pre-school predictors of persistent conduct disorder and delinquency. Criminology, 28, 443-454. 


\section{CHAPTER 6}

Single case research study

Symptoms of a syndrome : Differential diagnosis of Asperger's Syndrome.

(written for submission to Autism : An International Journal of Research and Practice. See Appendix 4.1 for notes for contributors) 


\begin{abstract}
Asperger's syndrome (AS) has been a controversial disorder since it came to prominence in 1981 . Originally described in an Austrian journal in 1944, it did not receive a full classification until DSM IV (1994). Asperger's syndrome has been validated as a distinct disorder separate from autism and high functioning autism in its characteristic presentation. However, there are still debates surrounding the exact criteria for classification. The disorder is diagnosed by impairments in social interaction and a restricted range of interests, but no significant delay in the development of language or cognitive abilities. This case describes a differential diagnosis of a 13 year old boy thought to have Asperger's syndrome at referral. The case highlights the need for a comprehensive assessment, incorporating multiple informants and different sources of information. The case is discussed in terms of the usefulness of a diagnosis to child and family. A diagnosis needs to be supplemented by details of the strengths and weaknesses of an individual child so that services can be tailored to meet these individual needs.
\end{abstract}




\section{Introduction}

Since Kanner's first descriptions of Autism, it was recognised that there were subgroups of children with similar but not identical features. These features were given recognition by Wings' (1981) account of 34 children with Asperger's syndrome (AS). The commonly described clinical features of the syndrome include (a) paucity of empathy; (b) naive inappropriate one sided social interaction, little ability to form friendships, and consequent social isolation; (c) pedantic and poorly intonated speech; (d) poor non-verbal communication; (e) intense absorption in circumscribed topics; (f) clumsy and ill coordinated movements and odd posture (Wing 1981).

Although several different sets of criteria for Asperger's syndrome diagnosis were proposed over the next 15 years (see Ghaziuddin et al., 1992), it was not until ICD 10 (1992) and DSM IV (1994) that operational criteria were formalised. However, even since these criteria were published, differences of opinion still exist regarding the degree of impairment, position on the Autistic spectrum, and the early developmental history of Asperger cases (Gilmore and Hayes, 1996). Asperger's syndrome is now defined on the basis of social deficits and restricted patterns of interests and behaviour of the type seen in autism, although there must be no clinically significant delay in language acquisition or in cognitive skills. Motor deficits are not an essential diagnostic feature, although the DSM IV notes that motor clumsiness may be present (Appendix 4.2 contains full DSM IV diagnostic criteria for Asperger's syndrome). At least now there is formal recognition that such a disorder exists, cases can be classified accordingly and research into the Syndrome can be standardised.

Particular features of AS make late diagnosis common in many cases. The lack of significant language impairment may result in late diagnosis because parents, or in consequence professionals, may be reluctant to recognise a developmental problem unless it is associated with marked language impairment (Tantum, 1991). Furthermore, psychological referral may not be considered if difficulties are not regarded as serious enough, or are not recognised as part of a distinct pattern. Many cases are therefore not diagnosed until their teens. This may mean that there are many children who go through 
mainstream schooling without recognition of a specific range of difficulties, and hence specialist support services are not made available to them.

The case described here explains the differential diagnosis of a 13 year old boy thought at referral to have Asperger's syndrome. The case highlights the need for a comprehensive assessment incorporating multiple sources of information; the need to consider alternative explanations for the symptom presentation and the usefulness of the diagnosis once it has been achieved.

\section{Case presentation}

Reason for Referral: Referral requested assessment for diagnosis of Asperger's syndrome of GM, a 12 year old boy, to aid in placement for secondary school education.

Presenting Problem : By the time the referral was seen, GM had already started a new school placement. This was in a special needs high school. However, the parents were keen to receive a diagnosis for GM's difficulties in the past, as well as ongoing help for his problems at home and at school.

Assessment Measures : Assessment involved interviews with $\mathrm{Mr}$ and Mrs M., interview and observations during home visits, a play session with GM, information from teachers and formal psychometric tests.

\section{Background information from interview with Mr and Mrs $M$.}

GM was induced four weeks early, but the delivery was normal. GM was bottle fed without difficulty, but cried a lot during his first year. Mr and Mrs M. report that GM was slow to sit and walk with both occurring after 12 months. Language was also delayed with single words occurring around 2 years of age and sentences developing at some point later, but exactly when was unclear.

GM attended very little pre-school activities. A nursery placement was attempted but GM did not take to this, and was withdrawn quickly. At the time Mrs M. was caring for her mother who was dying of cancer, so both Mrs M and GM spent most of their time at home. Mrs M questioned the adverse 
consequences of GM experiencing the suffering of her dying mother at a young age. Following the death of her mother Mrs M. went back to work and her father looked after GM.

Mrs M reported that her father was very strict with GM, and lost his temper quickly, which in turn made GM very upset. In subsequent years GM became very distressed around his grandfather, did not want to be with him, and insisted on sleeping on the floor when at his house. His general behaviour pattern also deteriorated. GM was later the focus of an abuse investigated by the social services. Abuse of GM by his grandfather was never proved however. Mrs M has had no contact with her father since this time. Following this enquiry, GM had substantial contact with local social service departments, becoming involved with several group activities in an attempt to raise self esteem.

GM has always experienced difficulties in school. From his first years of school onwards GM did not mix well with his peers, and never developed friendships in or out of school. In the last 3 years of primary school GM suffered bouts of bullying. Within the mainstream primary schools, GM received individual support to help with his academic difficulties. GM is reportedly doing much better at his new high school. He has developed some friendships and is coping with the curriculum.

Mrs M reported GM to be difficult to manage at home. She stated that he was very moody, swinging from being very aggressive to very cuddly in a short period of time. She stated that GM will not explain his feelings to her even when he has had a good day at school, but is quick to shout that no one listens to him when he is in a mood. Mr and Mrs M reported that GM had a narrow range of interests, focusing on collecting things (coins, toy cars and toy soldiers) and drawing. According to $\mathrm{Mr}$ and Mrs M, GM had difficulty with changes in routine, experiencing new things, seeing new faces and changes to his environment. They also reported some stereotyped movements, twirling objects in his hand repeatedly. The biggest difficulty for GM was social interactions, according to $\mathrm{Mr}$ and $\mathrm{Mrs} \mathrm{M}$. He displayed anxiety when they have friends over to the house, remaining silent for long periods of time and only becoming involved with people by drawing them a picture. He does not mix with children of his same age, but does play games with younger children (around 7 years).

GM is the youngest of two children, his sister is 17 and they both live at home with their parents. 
There is no history of mental illness in the family, although Mrs M has suffered depression in the past, and was diagnosed with dyslexia as a child.

\section{Presentation at assessment}

GM is a pleasant boy, tall for his age and quite stocky. He was slow in his movements but did not appear to have either fine or gross motor difficulties, and there was no indication of clumsiness.

Although quiet at first he is easy to engage in conversation. GM has a good sense of humour, being able to tell jokes as well as understand jokes told to him. He displayed considerable understanding about his difficulties, and was able to describe his feelings toward his old school, his bullying and lack of friends. GM appeared immature for his age, in both his emotional expression and social skills. He displayed no signs of significant receptive or expressive language difficulties, and no signs of stereotyped behaviours.

Test results : See Appendices 4.3-4.5 for full results.

WISC III R (UK) - Weschler Intelligence Scale for Children: GM's overall score placed him in the mild learning disability range of intellectual functioning ( full IQ 69). His verbal IQ was 70 and performance IQ was73. His lowest score on performance scale was on the coding subtest. This is a test of accuracy and speed within set time limits and is open to distraction. His highest score on performance items was block design, a test of visuospatial ability. On the verbal scales GM performed poorly on the vocabulary test and the similarities subtest ( a test of abstract thinking) suggesting that he may be rather concrete in his thinking and reasoning. His highest verbal test score was on the arithmetic test requiring number ability and short term memory. GM performed better than expected on picture arrangement and comprehension subscales (two tests requiring social understanding).

WORD - Weschler Objective Reading Dimensions : GM did not perform well on this test of reading, spelling and reading comprehension. The WISC III R scaled score equivalents were 2,3,3 respectively. This suggests that he may have specific difficulties in these areas over and above his level of intellectual functioning. 
Vineland Adaptive Behaviour Scales (VABS) : The VABS was utilised as a functional assessment of skills required for everyday living. Four domains are measured : communication, daily living skills, socialisation, and motor skills. The interview schedule of this assessment was completed with Mrs $\mathrm{M}$. GM's overall adaptive behaviour composite score was in the 'severe deficit' range compared to other children of his age. His percentile scores were less than 0.1 for each of the domains (communication, daily living skills, motor skills).

Sally-Anne Test : This is a 'theory of mind test', often used as an adjunct in the diagnosis of Autistic spectrum disorders. It is used to test the capacity to attribute mental states to other people (e.g. 'I think she thinks'). The child sees a doll (Sally) hide a ball in her basket and leave the room, after which another doll (Ann) moves the marble to her own box. The child is asked ' where will Sally look for the ball?'. The first use of this test during the play session with GM was equivocal in its result. GM appeared to have failed the test (i.e. he stated the ball was in Ann's basket), but on closer questioning his reasoning was that Sally looked in her own basket, and assumed Ann had stolen the ball! It was therefore not clear if he had passed this test or not. However a second variation of the test was conducted in a later session, which GM understood and passed without difficulty.

Differential Diagnosis : It was concluded that GM did not meet the criteria for Asperger's syndrome. In particular, GM had clinically significantly delay in language development, cognitive development and adaptive behaviour skills. In addition he did not meet criteria for a qualitative impairment in social interaction or a restricted pattern of interest abnormal in intensity.

GM only displayed one of the criteria for impairment in social interaction namely failure to develop peer relationships to an appropriate developmental level. He did display non verbal communication abilities, emotional reciprocity and spontaneous sharing of interests. These social abilities were evident from throughout the play session at Yorkhill, and home visits. In addition GM understood and passed the Sally-Ann theory of mind test. This test is usually passed by most normally developing 4 year olds, but $80 \%$ of autistic children fail (Happe, 1994). 
GM did not display a restricted pattern of interests or behaviours. Although he had specific interests which were not necessarily appropriate to his peer group, he was able to discuss a range of interests. He was not inflexible in his thinking and did not display adherence to routine. He did not display stereotyped behaviour.

Furthermore the pattern of WISC III R results is not commensurate with previous findings for Asperger Syndrome. Recent studies have found children with Asperger's syndrome to have greater verbal than performance scores, and troughs on object assembly and coding subtests (Ehlers, Nyden, Gillberg, Sandberg, Dahlgren, Hjelmquist, Oden, 1997). GM did have a significant weakness in the coding subtest but his performance scores were slightly higher than his verbal scores. Although the pattern of WISC III R results does not constitute a diagnosis, they do add further information to the assessment.

A diagnosis of mild learning disability was felt to be appropriate. GM's intellectual abilities were within this range, and he displays concurrent impairments in adaptive functioning (with onset before age 18). The DSM IV criteria for mild mental retardation (learning disability) was thus met (code 317 ).

\section{Discussion}

The case described highlights the need for multiple information sources in an assessment. If a diagnosis had to be made after the interview with $\mathrm{Mr}$ and Mrs M, Asperger's syndrome would have been the most likely candidate. They emphasised information pertinent to Aspergers e.g. social impairment, restricted range of interests etc, and downplayed the strengths in GM's presentation. This was undoubtedly due to Mr and Mrs M reading Autism / Aspergers literature, and pre-empting a diagnosis for their son. However on meeting GM and observing his interactions, a different emphasis on his clinical presentation became evident. Optimally, information from various sources must be reviewed and integrated by a clinician to obtain a full explanation of the child's presentation. Information from a single information source is obviously below standard for clinical practice. 
Although some of the symptoms of Asperger's syndrome were evident in this case, they did not reach full diagnosis. Alternative explanations regarding why these features were present are therefore required to complete the clinical picture. Specifically GM experienced difficulties in social interactions. He had not made friends at school, he only played with children much younger than himself at home, and experienced difficulties expressing his feelings. There are several factors that may have contributed to these difficulties. Firstly, GM has social skills deficits. This may be a result of his underlying learning disability or his lack of opportunity to develop these skills (or a combination of both).

Secondly GM experiences low self esteem and lack of self confidence. GM has experienced many years of being teased, buliied and failing academically at school. Furthermore, at home he was emotionally abused by his grandfather over several years, and was perhaps sexually abused also. These factors are undoubtedly contributing to GM having a negative opinion of himself and being socially anxious (he did not however reach criteria for a diagnosis of a depressive disorder or an anxiety disorder). This formulation of GM's social difficulties is given credence by his current successes at his new school.

GM is forming friendships as well as enjoying his academic work. This may be because the pressure to succeed has been withdrawn, and GM's abilities are in par with other children around him.

The final point this case study raises is the usefulness of a diagnosis. In the case described here the diagnosis itself was of less significance than the individual profile established by the assessment. Whether GM had met criteria for Asperger's syndrome or not, recommendations would have been made to support his emotional, social and academic development. This could be achieved through activities to increase his self esteem, and by providing a structured academic environment with lessons to improve his deficit in adaptive behaviour (e.g. community skills, self help skills etc), as well as formal academic subjects. In other words confirmation of a syndrome was far less significant than identifying the individual pattern of problems that GM presented with, and recommending appropriate social and academic services for both GM and his family. To this end, an Asperger Syndrome diagnosis or a diagnosis of mild learning disability, could be used on a Record of Needs to argue for additional services for a child. 
Furthermore Mr and Mrs M were looking for an explanation of the difficulties that GM experienced. However it was not a label they were looking for, but advice on management strategies, support services and prognosis. This advice was provided for them, along with referral to further child psychology services. Once again the specific diagnosis was secondary to the additional support and advice for the family's management of the child.

There is some evidence that parents may accept a diagnosis of Asperger's syndrome more readily than a diagnosis of autism due to the stereotyped negative views of autism (Wing, 1986). However there is no such research evidence for the acceptability of a diagnosis of learning disability vs a diagnosis of Asperger syndrome diagnosis. This may be an interesting area for future research.

It is important that service providers remember that diagnosis applies to disorders and not to people. A diagnosis is only the first step in accessing appropriate services for continuing educational, social and emotional growth of a child with special needs. A diagnosis needs to be supplemented by details of the strengths and weaknesses of an individual child and services tailored to meet these individual needs. It is often psychologists who can provide the first stepping stones to service provision by providing appropriate recommendations based on accurate assessment of both patterns of symptoms (i.e. syndromes) and individual profiles of the children we see. However, it is another matter entirely as to whether children with learning disabilities will be provided with the services that are most beneficial for their needs. 


\section{References}

American Psychiatric Association. (1994). Diagnostic and statistical manual of mental disorders ( $4^{\text {th }}$ ed.). Washington, D.C. Authors.

Ehlers, S., Nyden, A., Gillberg, C., Sandberg, A.D., Dahlgren, S., Hjelmquist, E., \& Oden, A. (1997). Asperger's syndrome, autism, and attention disorders: a comparative study of the cognitive profiles of 120 children. Journal of Child Psychology and Psychiatry, 38, 2, 207-217.

Ghaziuddin, M., Tsai, L.Y., \& Ghaziuddin, N. (1992). Brief report: a comparison of the diagnostic criteria for Asperger Syndrome. Journal of Autism and Developmental Disorders, 22, 643-649.

Gilmore, L., \& Hayes, A. (1996). Asperger's syndrome: a case diagnosed in late adolescence. Clinical Child Psychology and Psychiatry, 1(3), 431-439.

Happe, F.G.E. (1994). Annotation : current psychological theories of autism : the 'theory of mind' account and rival theories. Journal of Child Psychology and Psychiatry, 35 (2),215-229.

Sparrow, S.S., Balla, D.A., \& Cicchetti, D.V. (1984). Vineland Adaptive Behavior Scales. American Guidance Service, Minnesota.

Tantam, D. (1991). Asperger syndrome. In Adolescents and Adults with Asperger syndrome. National Autistic Society.

Wechsler Intelligence Scale for Children-Third Edition UK (1993). The Psychological Corporation. Wechsler Objective Reading Dimensions (1993). The Psychological Corporation.

Wing, L. (1981). Asperger's syndrome: a clinical account. Psychological Medicine, 11, 115-129. Wing, L. (1986). Classification on Asperger's syndrome (letter to the editor). Journal of Autism and Developmental Disorders, 16, 513-515.

World Health Organisation. (1992). The ICD-10 classification of mental and behavioural disorders: clinical descriptions and diagnostic guidelines. Geneva: Author. 


\section{CHAPTER 7}

\section{Single case research study}

Using the transtheoretical model of change as a framework to explain treatment success in a woman presenting with obsessive compulsive disorder.

(written for submission to 'Behaviour Research and Therapy'. See Appendix 5.1 for notes for contributors) 


\begin{abstract}
The treatment of obsessional-compulsive disorder (ocd) has progressed dramatically over the past 30 years. Exposure and response prevention provides up to $75 \%$ of patients with relief from their symptoms. However large numbers of patients drop out of treatment. The transtheoretical model of change (Prochaska and DiClemente, 1984) is proposed as a useful model to increase the numbers of patients remaining in treatment. By matching treatment to the stage of change that patients are in, success with treatment may be more likely. The treatment of a 36 year old woman with obsessive compulsive disorder is presented. Resistance to exposure and response prevention was eventually overcome, resulting in significant decreases in the frequency of compulsive clock changing behaviour. The case is discussed in terms of using the stages of change framework to explain this womans passage through treatment.
\end{abstract}

Key words : Obsessive-compulsive; transtheoretical model of change. 


\section{Introduction}

Psychological models of obsessive compulsive disorder (ocd) were first reported by Meyer (1966).

Since that time research has developed the investigation and treatment of this disorder (see review by Marks, 1987).

Obsessions are described as persistent ideas, thoughts, impulses or images, which are usually regarded as intrusive and senseless. Patients commonly attempt to ignore or suppress the obsession or neutralise it with another thought or action. These are known as compulsions. Compulsions are repetitive purposeful behaviours performed in response to the obsession. They often are performed according to certain rules or in a stereotyped fashion. Obsessions are often dominated by thoughts of aggression, contamination, orderliness, sex, religion or pervasive doubting. Compulsions frequently manifest themselves in rituals of cleaning or checking known as overt compulsions; but can also be covert rituals in the form of prayers or neutralising statements. Ocd patients frequently develop avoidance behaviours, particularly avoiding situations where obsessional thoughts may be triggered.

Exposure and response prevention has been the main emphasis of treatment for obsessive compulsive behaviour for over 20 years. The procedure encourages desensitisation to obsessive stimuli and creates alternative ways of responding to them. Approximately $65-75 \%$ of patients improve with this technique (Riggs and Foa, 1993). Cognitive therapy has also been combined with exposure and response prevention to some effect (Kearny and Silverman, 1990 ; Emmelkamp and Beens, 1991).

However, the treatment of OCD has always been problematic. Salkovskis (1989) found that less than $50 \%$ of patients who are suitable for, and seeking treatment, improve. This figure reflects high rates of drop out, treatment refusal and treatment failure. A more recent study has reported that $25 \%$ of patients drop out of treatment (Araujo, Marks \& Deale, 1995). Methods of keep patients in ocd treatment is obviously needed.

One option would be to consider the transtheoretical model of change proposed by (Prochaska and DiClemente, 1984; Prochaska, DiClemente \& Norcross, 1992). They have found five stages of change 
involved with the modification of behaviour across a range of addictive behaviours, e.g. smoking, alcohol abusc, substance abuse. The five stages are precontemplation, contemplation, preparation, action and maintenance. These stages are not linear but spiral in nature. This concept reflects the findings that people attempting to change their behaviour move through some of these stages, only to relapse and return to an earlier stage in the change cycle. The stages of change are (briefly) described as follows.

At the precontemplation stage there is no intention to change behaviour in the foreseeable future. Individuals are often unaware of their problems, although family and friends may be acutely aware that precontemplators have problems. Contemplation is the stage in which individuals show an awareness of their problem, but have not made serious commitments to take action. Preparation is seen as the early precursor to action; preparation is the stage where people are intending to take action in the near future. They may have made some minor behavioural changes but have not reached an effective action stage. The action stage is where individuals modify their behaviour, experiences or environment in order to overcome their problems. This involves commitment of time and energy. The final stage is maintenance where people work to prevent relapse and consolidate gains made during the action phase.

Interacting with the stages of change are processes of change. These are activities and events that create successful modification of behaviour. They include consciousness raising, self re-evaluation, contingency management and stimulus control. These change processes have been identified across a variety of problem behaviours including smoking, anxiety, obesity and substance abuse (Prochaska, 1995).

The treatment implications for this model are that different processes of change may be appropriate at different stages of change (Prochaska and DiClemente, 1983). Action oriented therapies may be effective with patients who are in the preparation or action stages. However, these treatments may be ineffective with patients in precontemplation or contemplation stages (Prochaska, DiClemente \& Norcross, 1992). These principles may need to be applied to ocd treatment in an attempt to decrease drop out rate 
This paper describes the successful treatment of a 36 year old female teacher presenting with an unusual overt compulsion, namely clock changing. The transtheoretical model of change is then proposed as a conceptual framework for explaining the way in which treatment progressed.

\section{Case Presentation}

Reason for Referral : AB, a 36 year old woman, was referred to the Psychology Department by her G.P. for long standing anxiety / depression problems.

Presenting Problem : AB described chronic self-esteem problems. She had a very negative view of herself, and considered herself a failure at everything. A range of obsessive compulsive behaviours had developed which had intruded into her personal life at different points in her history. AB came for treatment following a bout of depression for which she attended her G.P.

Personal History : AB grew up in Lanarkshire with her mother and father and one elder sister, whom all live locally. She completed school, and at age 17 began her teacher training. She has been a primary school teacher for 15 years, and currently holds a Senior Teacher post.

$\mathrm{AB}$ met her first husband during college and was married at age 21. Six months into the marriage, AB discovered her husband had been seeing another woman throughout their relationship. At this time her husband became violent towards her, and they subsequently divorced. Four years before coming to therapy, AB met her second husband and they married in 1993. He is a self-employed computer engineer. $A B$ describes her husband as very supportive, patient and understanding. They do not have any children.

History of Presenting Problem: AB describes being a worrier as a child and throughout school. At seven she was taken to her G.P. for 'fizzy blue medicine' to help with her anxiety. Her low self confidence continued throughout school and into her adult life.

After the break down of her first marriage, $\mathrm{AB}$ recalls blaming herself and feeling guilty at the separation. Even though she remembers knowing her husband was at fault, she felt that deep down she was to blame. 
In relation to her professional life, $\mathrm{AB}$ describes perfectionist tendencies and thoughts. She spends considerable personal time preparing work for school, but rarely feels it is of a high quality. She describes worrying that others will think she is a bad teacher, and often takes on too much extracurricular activities in an attempt to compensate. She gets particularly anxious when meeting with parents, anticipating that they will think she is a fraud.

Shortly after AB remarried, her husband worked away from home, returning on weekends. This was a stressful time for both parties and $\mathrm{AB}$ reports having many depressive symptoms at this time. Her eating and sleeping pattern was disrupted, her sex drive diminished, she only left the house to go to work, and she experienced low mood and lethargy. These feelings affected the time AB spent with her husband on weekends, and spiralled into increased feelings of worthlessness and inability to cope. At this point she contacted her G.P. whom, after limited success with medication (Gamanil), referred her to Psychology.

$\mathrm{AB}$ recalls participating in obsessive-compulsive behaviours for many years. Although there appears to be no specific onset, they have been part of her life since teacher training. The content and intrusiveness of the obsessions and associated compulsive behaviour is varied including : contamination (washing clothes, cleaning) ; orderliness (completing actions in correct manner) and accidental harm (retracing routes in her car). At their most intrusive (before AB's second marriage) these behaviours controlled AB's personal life, filling many hours of the day. These problems never impinged upon her professional life however. At the time of assessment, the only current compulsive behaviour was clock changing. The obsessional compulsive behaviour displayed by this woman involved a number of stages. The behaviour was triggered by obsessional thoughts of being unable to complete the tasks that she had set for herself, and the consequences that this may bring (she would consider herself to be a failure). $\mathrm{AB}$ would then select a time in the near future (e.g. 4.30) when she would commence her tasks for the evening. The next stage involved moving the hands of a clock forward in time to a point a few minutes prior to her target time (e.g. 4.27). Invariably when the clock reached the target time, it would not 'feel right', and a separate clock would be used to begin this behaviour again. This cycle would be repeated 
until she did actually commence her tasks, having reached an acceptable time to begin. This cycle of clock changing could take up to several hours before she started her desired activity. The pattern of clock changing behaviour was thus self perpetuating as she would have less time to successfully complete her goal list, and a greater chance of seeing herself as a failure. This compulsive behaviour was triggered by thoughts of time hurriedness i.e. not having sufficient time to complete all of her desired activities and hence feeling a failure. At assessment no other compulsive behaviours were reported to be part of her current functioning.

Assessment Measures : Full results are to be found in Appendices 5.2-5.3.

AB completed the General Health Questionnaire (GHQ), Beck Depression Inventory (BDI) and Bcck Anxiety Inventory (BAI) as screening measures. At pre-treatment she scored in the 'moderate - severe' range of anxiety and in the 'mild - moderate' range of depression. AB scored zero on the GHQ. AB also completed the Dysfunctional Attitudes Scale (DAS; Burns, 1980) which measures the beliefs and assumptions thought to underlie maladaptive cognitions. In addition $\mathrm{AB}$ was asked to keep automatic thought diaries. Frequency of obsessive compulsive behaviour was recorded by $\mathrm{AB}$ as therapy progressed.

Formulation: $\mathrm{AB}$ suffers from long term self confidence problems resulting in a negative view of herself and low self-esteem. AB judges her merit entirely by her perception of other people's evaluation of her, and hence has a pervasive sense of inadequacy. These feelings of worthlessness have been present since childhood, and were reinforced by her traumatic first marriage. A negative interpretation of her selfworth predisposes her to depressive episodes when her regular support mechanisms are removed. Obsessive compulsive behaviours have developed over the years to provide $\mathrm{AB}$ with a false sense of control over her life. These behaviours have disabled her personal life extensively on occasions, but have not invaded her professional environment.

At assessment AB did not reach DSM IV diagnosis of major depressive disorder. She did reach criteria for obsessive compulsive disorder (code 300.3). 
Treatment Rationale : A cognitive behavioural approach to treatment was adopted. Treatment was in two stages : cognitive therapy for negative cognitions, and exposure and response prevention for obsessive compulsive behaviours.

From the initial interview and results of the DAS, it was clear that $\mathrm{AB}$ had a set of cognitive distortions that influenced her day to day life. The assumptions and beliefs that $\mathrm{AB}$ held undoubtedly maintained her low opinion of herself and had fed into her previous period of depression. It was decided to target and restructure these cognitions to provide $\mathrm{AB}$ with some control over her negative thinking pattern and hence bolster her own self efficacy. Success at this stage of therapy would then lead to increased ability to cope with the second stage of treatment (exposure and response prevention). Given the strong links between obsessive compulsive disorder and depression (Salkovskis, 1984 ; Barlow, 1988) this approach seemed justified. The cognitive model of depression (Beck et. al., 1979), was followed to elicit and challenge automatic thoughts.

Treatment Sessions : The initial sessions were devoted to interview and assessment procedures. Cognitive therapy rationale was then introduced and the next sessions focused on challenging automatic negative thoughts from $\mathrm{AB}$ 's thought diaries. $\mathrm{AB}$ accepted the cognitive model without hesitation and found it easy to generate numerous negative automatic thoughts and challenge them. In session 7 the exposure and response prevention rationale was introduced, as well as the recording of clock changing frequency. Due to the nature of the target problem (clock changing behaviour), therapist guided exposure could not be conducted in-session, so the therapist had to rely on patient compliance out with the therapy sessions. To this end, response prevention contracts were collaboratively established between therapist and patient. These were reviewed and amended as necessary. The final sessions focused on coping statements, generalisation of techniques and time management.

\section{Outcome of Treatment :}

By the end of the therapy sessions $\mathrm{AB}$ scored in the normal range for both BAI and BDI scores, indicating substantial decreases from pre treatment measures (Appendix 5.2). 
$\mathrm{AB}$ became adept at challenging her negative thoughts outside of the treatment sessions. She grasped the cognitive methods early on within the sessions, and reported substantial success using them at work and at home. By the end of treatment she reported being more 'in control' of her thoughts and felt able to work through negative thoughts, moving on to her next activity without perseverating on the outcome of the last one. She reported an increased ability to cope with the stresses in her life by using the thought challenging techniques. $\mathrm{AB}$ also reported feeling more positive about herself which led to increased confidence at work and in her social life.

Appendix 5.3 contains the frequency scores for clock changing behaviour. They show a significant drop from baseline frequency, and on the last session were down to three per week. Non-compliance with treatment goals was an issue at the start of the response prevention phase of treatment. Compliance with homework dropped, with $\mathrm{AB}$ not recording the frequency of the behaviour and then not attempting the exposure and response prevention exercise. On AB's suggestion, we then changed the content of the response prevention contracts and discussed at length the rationale and reasoning to the exercise, as well as the predicted long term benefits. From session 11 onwards a dramatic decrease in clock changing behaviour occurred. This change in compulsive behaviour appears to have remained over time.

An 18 month follow up suggested that these treatment gains had been maintained. A telephone conversation indicated that $\mathrm{AB}$ had experienced no depressive periods since our last session, and that clock changing behaviours were no longer present in her everyday life. She did state however that she still worried about the way people thought about her and sometimes spent excessive periods of time worrying about this. She did not report any substituted compulsive behaviours however. 


\section{Discussion}

Although AB was co-operative in therapy and showed interest and motivation throughout the cognitive therapy section of treatment, an impasse was reached when we began to target the clock changing behaviour. There are several possible explanations as to why this impasse in treatment was suddenly turned into a significant and long lasting treatment gain.

Firstly, the treatment was reliant on exposure and response prevention at home, as opposed to insession exposure with a therapist. This may have initially decreased adherence to exposure work. Allowing $\mathrm{AB}$ the opportunity to modify the response prevention contracts may have increased her commitment to the treatment process. It was following these changes that $\mathrm{AB}$ began to decrease her compulsive behaviour.

An alternative explanation would be that the underlying meaning of performing the compulsive behaviour had been modified. This would be consistent with Teasdale's work with propositional and implicational meanings of events. Only by working with implicational (generic) representations can effective change be implemented (Teasdale, 1993; Teasdale \& Barnard, 1993). By challenging thoughts that contributed to, or triggered, the clock changing behaviour, we may have altered the underlying basis of performing the compulsive behaviour. This change in meaning of the behaviour may have allowed change to occur more readily.

A further way of looking at this case would be to consider the transtheoretical model of change proposed by (Prochaska and DiClemente, 1984). This framework would suggest that AB became stuck in a stage of change, and treatment successes did not begin until she moved through that stage onto action.

$\mathrm{AB}$ entered treatment aware that she had a problem. She was outwardly seeking help to rectify it, but had not necessarily made a full commitment to change. This suggests that she was at least in the contemplation stage. The contemplation stage involves weighing the pros and cons of the problem and the solution to the problem. Patients at the contemplation stage are open to consciousness raising 
procedures (e.g. self monitoring), but are unlikely to respond to direct behaviour change. In this case, decreased compliance with homework and attempts at exposure and response prevention, could be seen as resistance to moving through the contemplation stage. AB may not have been ready for the move to the preparation stage. She may have become stuck at the contemplation stage, evaluating the course of her future behaviour.

Individuals in the preparation stage are reported to re-evaluate their values, their problems, and themselves. They are also reported to make some small steps toward action. A step toward action was taken by $\mathrm{AB}$ when she changed the content of the response prevention contracts. This may symbolise her move from the contemplation stage to the preparation stage. After this point AB successfully engaged in exposure and response prevention treatment. This was undoubtedly the action stage of treatment. The maintenance phase involves investing in relapse prevention exercises. These were introduced by both the therapist (e.g. coping statements) and $\mathrm{AB}$ (requesting time management advice). However for this case, the most pertinent aspect of maintenance was reflected in changes to self evaluation by AB. This was eloquently described in Prochaska, DiClemente \& Norcross, 1992, as 'the sense that one was becoming the kind of person one wanted to be'(p1 109). This was particularly significant to $A B$, and summarises her evaluation of the changes she made throughout treatment.

Although this is a 'post hoc' explanation of how the stages of change model could have influenced this case, it provides a useful interpretation of events. It highlights the need for therapists to be aware of the potential stage of change that their clients may be entering, and selecting treatments to match.

Exposure techniques that require patients to actively face their fear, are only likely to be successful with those patients who are prepared for such action oriented therapy. Patients who are in pre-contemplation or contemplation stages are likely to resist such treatment (as in this case) or drop out of treatment altogether.

Stage based variables have been found to be the best predictor of drop out in studies of both mental health and addictive behaviours (Prochaska, 1995). However, by matching the content of treatment to the stage patients are in, stage of change has been shown to be eliminated as a significant predictor of 
dropout. In at least three studies, precontemplators participating in stage matched treatments have been found to complete treatments as often as those who were at the preparation stage (Prochaska, 1995).This finding has only been demonstrated in studies of smoking cessation however. As previously stated drop out rates are high for the treatment of ocd. One of these factors may be that treatments are mismatched for stage of change in patients.

The main limitation in adopting the stage theory of behaviour change for ocd is its over reliance on research evidence based on the addictive behaviours. Most research has been based on smoking cessation. Stage theories may not translate to other psychological problems as easily. However, moving from an 'action paradigm' to a 'stage paradigm' may be an effective way of improving success rates and drop outs from ocd treatments. Further research would certainly be welcome. 


\section{References}

American Psychiatric Association. (1994). Diagnostic and statistical manual of mental disorders ( $4^{\text {th }}$ ed.). Washington, D.C. Authors.

Araujo L.A., Ito, L.M., Marks, I.M. \& Deale A. (1995). Does imagined exposure to the consequences of not ritualising enhance live exposure for OCD? British Journal of Psychiatry, 167, 65-70.

Barlow D.H. (1988). Anxiety and its Disorders. Guildford Press. New York.

Beck, A.T., Rush, A.J., Shaw, B.F., and Emery, G. (1979). Cognitive Therapy of Depression. Guildford, New York.

Burns, D.D. (1980). Dysfunctional Attitude Scale. In Feeling Good : The New Mood Therapy. Morrow and Co.

Emmelkamp, P.M.G., and Beens, H. (1991). Cognitive therapy with obsessional compulsive disorder : a comparative evaluation. Behaviour Research and Therapy, 29, 293 - 300.

Kearny, C.A., and Silverman, W.K. (1990). Treatment of an adolescent with obsessional compulsive disorder by alternating response prevention and cognitive therapy : an empirical analysis. Journal of Behaviour Therapy and Experimental Psychiatry, 21, 39-47.

Marks, I.M.(1987). Fears, phobias, and rituals. New York : Oxford University Press.

Meyers, V. (1966). Modification of expectation in cases with obsessional rituals. Behaviour Research and Therapy, 4, 273-280.

Prochaska, J.O. (1995). Common problems : common solutions. Clinical Psychology Science and Practice, 2, 101-105.

Prochaska, J.O. \& DiClemente, C.C.(1983). Stages and processes of self change in smoking : toward an integrative model of change. Journal of Consulting and Clinical Psychology, 51, 390-395.

Prochaska, J.O. \& DiClemente, C.C.(1984). The transtheoretical approach : crossing traditional boundaries of change. Homewood, IL: Dorsey Press.

Prochaska, J.O., DiClemente, C.C. \& Norcross, J.C.(1992). In search of how people change: Applications to the addictions. American Psychologist, 47, 1102-1114. 
Riggs, D.S., and Foa, E.B. (1993). Obsessional Compulsive Disorder. In Barlow D.H. Clinical Handbook of Psychological Disorders. 2nd Ed. Guildford Press. New York.

Salkovskis, P.M. (1984). Obsessive Compulsive problems : A cognitive behavioural analysis. Behaviour Research and Therapy, 23, 571-583.

Salkovskis, P.M.(1989). Obsessions and Compulsions. In Cognitive Therapy : a clinical case book. (Ed's J. Scott, J.M.G. Williams, \& A.T. Beck). Routledge, London.

Teasdale, J.D. (1993). Emotion and two kinds of meaning: cognitive therapy and applied cognitive science. Behaviour Research and Therapy, 31, 339-354.

Teasdale, J.D., \& Barnard, P.J. (1993). Affect, cognition, and change. Hove: Lawrence Erlbaum Associates 
APPENDIX 1

MAJOR RESEARCH PROJECT LITERATURE REVIEW 


\section{Notes for Contributors AIDS Care}

Papers accepted become the copyright of the Journal, unless otherwise specifically agreed.

Manuscripts, should be sent to Dr Lorraine Sherr, Department of Primary Care and Population Sciences, Royal Free Hospital School of Medicine, Rowland Hill Street, London NW3 2PF, United Kingdom or to Professor Michael Ross, Center for Health Promotion Research \& Development, School of Public Health, University of Texas at Houston, PO Box 20186, Houston, TX 77225, USA. Papers can be considered only if four complete coplea in the style of the American Paychological Association, and not exceeding 10,000 words are submitted, and all submissions will be sent anonymously for the observations of referees. Manuscripts can be in three formata; (i) Long articles (up to 5,000 words); (ii) Short reports for rapid publication (not exceeding 2,000 words); (iii) In practice. Manuscripts should be typed on one side of the paper, double spaced, with ample margins of at least one inch. The first sheets should include the title of the paper, name(s) of author(s), and for each author academic and/or professional qualifications as commonly used by the author, main appointment and address for correspondence and proofs, including, if possible, telephone and fax numbers and Email addreas. The second page should repeat the title, and contain an abstract of not more than 200 words. The third page should repeat the title as the heading to the start of the main text of the paper. All pages should be numbered. Proofs for checking will normally be sent to the first author named to whom any correspondence and offprints will also be addressed. Footnotes to the text should be avoided wherever this is reasonably possible.

Papers will be considered providing that they have not previously been published or submitted simultaneously elsewhere for publication.

References should follow the style of the American Psychological Association (Publication Manual. 4th Edition, 1994), i.e. they should be indicated in the typescript by giving the author's names, with the year of publication, in parentheses, e.g. (Smith, 1984); or if there are more than two authors-(Smith et al., 1984). If several papers from the same author(s) and from the same year are cited, (a), (b), (c), etc. should be put after the year of publication. The references should be listed in full alphaberically at the end of the paper on a separate sheet (double-spaced) in the following standard form with regard to the existing style of punctuation and capitalisation:

Di Clemente, RJ. \& Peterson, S. (1994). Preventing AIDS: theories and methods of behavioral intervention. New York: Plenum Press.

PhIPOT, C.R., Harcourt, C.L. \& EDwarDs, J.M. (1991). A survey of female prostitutes at risk of HIV infection and other sexually transmissible diseases. Genitourinary Medicine, 67, 384-388.

SELWVIN, P.A. \& ANTONIELLO, P. (1993). Reproductive decision-making among women with HIV infection. In M.A. JohiNson \& F.D. JohNstoNe (Eds), HIV infection in women (pp. 173-185). Edinburgh: Churchill Livingstone.

Titles of journals should not be abbrevated.

Illustrations should not be inserted in the text but each provided separately and numbered on the back with Figure numbers, title of paper and name. All photographs, graphs and diagrams should be referred to as Figures and should be numbered consecutively in the text in Arabic numerals (e.g. Fig. 3). A lis of captions for the figures should be submitted on a separate sheet and should make interpretation possible without reference to the text. Captions should include keys to symbols.

Tables should be typed on separate sheets and should be given Arabic numbers (e.g. Table 3). Their approximate position in the text should be indicated. Units should appear in parentheses in the column heading but not in the body of the table. Words or numerals should be repeated on successive lines: 'ditto' or 'do' should not be used.

Proofs will be sent to the author if there is sufficient time to do so. Proofs including proofs of illustrations are supplied for checking and making essential corrections, not for general revision or alteration. Proofs should be corrected and returned within 3 days of receipt.

Ofiprints. Fifty offprints of each paper are supplied free. Additional copies may be purchased and should be ordered when the proofs are returned. Offprints, together with a complete copy of the relevant journal issue, are sent about two weeks after publication.

Printed and Bound in Great Britain by Wace Journals, Abingdon, Oxfordshire, England 


\section{APPENDIX 2}

MAJOR RESEARCH PROJECT PAPER 
Appendix 2.1.

\section{NOTES FOR CONTRIBUTORS}

1. The aim of the British Journal of Health Psychology is to provide a forum for high quality research relating to health and illness. The scope of the Journal includes all areas of health psychology across the life span, ranging from experimental and clinical research on aetiology and the management of acute and chronic illness, responses to ill-health, screening and medical procedures, to research on health behaviour and psychological aspects of prevention. Research carried out at the individual aspects of prevention. Resels is caried our an the individual, group and community levels is weicome, and submissions particularly encouraged.

particularly encouraged.

(a) Papers reporting original empirical investigations

(b) Theoretical papers which may be analyses or commentaries on established theories in health psychology, or presentations of theoretical innovations

(c) Review papers, which should aim to provide systematic overviews, evaluations and interpretations of research in a given field of health psychology

(d) Methodological papers dealing with methodological issues of particular relevance to health psychology.

2. The Journal is international in its authors and readers. Contributors should bear the international readership in mind, particularly when referring to specific health services.

3. Pressure on Joumal space is considerable and brevity is requested. Papers should normally be no more than 5000 words.

4. Supplementary data too extensive for publication may also be deposited with the British Library Document Supply Centre. Such material should be submitted to the Editors together with the article for simultaneous refereeing. Further details of the scheme are given in the Bulletin of the British details of the scheme are given in the Bulletin of the British
Psychological Society, 1977, 30, February, p. 58. A copy of Psychological Society, 1977, 30, February, p. S8. A

5. This Journal operates a policy of blind peer review. Papers will normally be scrutinized and commented on by at least two independent expent referees as well as by an editor or associate editor. The referees will nor be made aware of the identity of the author. All information about authorship identity of the author. All information about authorship affiliations should be confined to a removable front page (and the text should be free of such clues as identifiable selfthe text should be free of such clues as identifiable self-
citations ('In our earlier work...').) The paper's title should be citations ('In our earlier work...').
repeated on the first page of text.

6. The editors will reject papers which evidence discriminatory, unethical or unprofessional practices.

7. Subrnission of a paper implies that it has neither been publishod elsewhere nor is under consideration by another joumal.

8. In preparing material for submission authors should follow these guidelines:

(a) Contributions must be typed in double spacing with wide margins and on only one side of each sheet. Sheets must be numbered. Four good copies of the manuscript should be

submitted and a copy should be retained by the author

(b) Tables should be typed in double spacing, each on a separate sheet of paper. Each should have a self-explanatory title and be comprehensible without reference to the text.

(c) Figures are usually produced direct from authors' originals and should be presented as good black and white images preferably on high contrast glossy paper, carefully labelled in initial capitallower case lettering with symbols in a form consistent with text use. Unnecessary background patterns or lines and shading should be avoided. Paperclips leave damaging indentations and should be avoided. Any necessary instructions should be written on an accompanying photocopy. Captions should be listed on a separate sheet. (d) The Editors propose to adopt structured abstracts and all articles should be preceded by a structured abstract of between 100 and 250 words (less in the case of a short paper), giving a concise statement (lise intention and a short pape giving a concise statement of the intention and results or conclusions of the aricle. Authors requining further details on structured abstracts should contact the Journals Office (details on inside front cover).

(e) Bibliographic references in the text should quote the author's name and the date of publication thus: Hunt (1995). Multiple citations should be given alphabetically rather than chronologically: (Blackburn, 1996; Fortheringhame, 1994

Norman, 1995). If a work has two authors, cite both names in the text throughout: Choi \& Salmon (1995). In the case of reference to three or more authors, use all the names on the first mention and et al. thereafter except in the reference list. $(f)$ References cited in the text must appear in the list at the end of the article. The list should be typed double spaced in the following format:

Hunter, M. (1994). Cownselling in Obstetrics and Gynaecology. Leicester: The British Psychological Society.

Pruitt, S.D. \& Elliott, C.H. (1989). Paediatric procedures. In M. Johnstone \& L. Wallace (Eds), Stress and Medical Procedures, pp. 157-174. Oxford: Oxford University Procedure

Ray, C., Phillips, L. \& Weir, W.R.C. (1993). Quality of attention in chronic fatigue syndrome: Subjective reports of everyday attention and cognitive difficulty, and performance on tasks of focused attention. British Journal of Clinical Psychology, 32, 357-364.

Note that journal titles are cited without abbrevation.

(h) Measurements should be in units of the International System. A guide to these is included in The British Psychological Society's Style Guide, available at $\$ 3.50$ per copy from the Society at St Andrews House, 48 Princess Road East. Leicester LE1 7DR, UK.

(i) If the title of the article is longer than 80 characters, a (i) If the title of the article is longer than 80 characters,
short title should be provided for use as a running head.

(j) Footnotes are expensive to set and should be avoided.

(9) Proofs are sent to authors for correction of print but not for rewriting or the introduction of new material. Fifty complimentary copies of each paper are supplied to the senior author, but further copies may be ordered on a form supplied with the proofs.

(10) Authors should consult the Joumal editor concerning prior publication in any form or in any language of all or part of their article.

(11) To protect authors and journals against unauthorized reproduction of articles, The British Psychological Society requires copyright to be assigned to itself as publisher, on the express condition that authors may use their own material at any time without permission. On acceptance of a paper submitted to The Journal, authors will be requested to sign an appropriate assignment of copyright form. 


\section{Appendix 2.2.}

Pilot Study Information

In order to identify some of the factors that encourage or inhibit seeking an HIV test in this population, semi-structured interviews were administered to 17 volunteer patients at the Falkirk G.U.M clinic. The themes that emerged were that people only identified the negative aspects of HIV testing (they found it difficult to name any benefits). Negative aspects to testing included : worrying about test results knowing you are going to die, not being able to cope if positive, not having a future, stigma of having AIDS, and people would be able to find out the test results. Only a few people could name any benefits to testing. These were usually based on knowing your HIV status one way or the other and being able to protect your partner if HIV positive. Almost all of those interviewed did not know there were drugs to help fight the AIDS virus; or that there were specific support services available to those who are HIV positive. Apart from the two people who had already been tested for HIV (both HIV negative ex injecting drug users), only two people could name sites where HIV tests were available. Factors that may encourage people to obtain HIV tests were highlighted as : getting the results back on the same day as the test; being able to obtain a test without having to make an appointment; not having to give your name; and being able to take the test at home.

From this pilot study it was decided to partially replicate a recent study by Kalichman et al., 1996. This study assessed perceived costs and benefits of HIV testing, as well as denial of risk, unawareness of the need to be tested and negative thinking. These items were developed from the HIV testing decision making, testing policy and psychological responses to testing literature's. As the items used in the Kalichman study were very similar to the costs and benefits identified in the pilot sample, it was decided to replicate these. One additional question was added concerning early access to medical treatments. Replicating this study will allow comparisons to be made across GUM clinic samples. Costs and 
benefits have been shown to have influenced decisions in many other health related behaviours (e.g. screening for raised blood pressure, cervical cancer and genetic abnormalities ; Marteau, 1995).

Perceived benefits of HIV testing may therefore motivate some people to seek HIV testing, whereas perceived costs may inhibit those at risk (Kalichman et al., 1996). 


\section{Interview Questions}

\section{Costs / benefits}

What do you consider as the potential benefits (advantages) of having an HIV test?

What do you consider as the potential pitfalls (disadvantages) of having an HIV test?

2. If you were thinking of having the test for HIV..

a) What things / factors / influences would make it easier for you to go for testing ?

b) What things / factors / influences would make it harder for you to go for testing ?

c) What things might put you off going for an HIV test ?

d) What things might encourage you to go for an HIV test?

\section{Access.}

a) Where can you go to have an HIV test?

b) What would make it easier for you to go to one of these places?

c) What would make it harder for you to go to one of these places?

?evening clinics ; walk -in clinics , appointments

\section{Confidentiality}

a) Would you have concerns over the confidentiality of test results?

What are they?

b) Do you know the difference between confidential / anonymous testing ?

(...give details).

c) Which type (conf / anon) of testing would you feel more comfortable with?

d) Do you know which type of testing (conf / anon) this clinic uses? 
5. Test results.

a) What do you think about having to wait 2 weeks for test results ?

b)Would you be more willing to be tested if you could receive your results within the same day?

c) Would you be willing to use home testing kit if one became available?

\section{Diagnosis / Treatment.}

a) Can anything be done to help someone diagnosed as HIV +ve ?

b) Are there any treatments available?

c) How do you think receiving a positive test result would effect someone's life the most??

d) How do you think receiving a positive test result would effect someone's life the most? 


\section{Study Information Sheet}

You have been asked to take part in a study conducted by a psychologist in postgraduate clinical training at the University of Glasgow. The study is aiming to identify some of the reasons why people do / do not have HIV tests.

Your participation in the study will consist of an informal interview and should take no more than 20-30 minutes. You will be asked what kind of things put you off going for an HIV test, and what kind of things would make it easier for you to go for an HIV test. We are interested in all kinds of responses and there are no right or wrong answers.

All information we receive in the course of the study will remain strictly confidential. You will not be identified from the data analysis or any publications resulting from this research. Your interview will be taped anonymously, with no identification what so ever. The recording of the interview will be erased after it has been coded.

If you do decide to participate in the study, you can withdraw at any time and for any reason. If you decide to withdraw your tape will be immediately erased.

Participation or non participation in this study will have no effect on your current treatment.

Wee hope that you will be interested in taking part in this study.

Yours sincerely,

JEFF SALT

Trainee Clinical Psychologist

University of Glasgow/

Greater Glasgow Community +

Mental Health NHS Trust
DR J HARVEY

Consultant in G.U. Medicine

Falkirk Royal Infirmary

Falkirk 


\section{Consent Form}

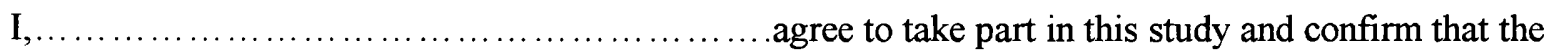
nature and purpose of this study has been explained to me.

I have read the accompanying information sheet and understand that my interview will be taped.

I understand that participation or non participation in this study will have no effect upon my current treatment.

Signature of participant.

Date 


\section{Appendix 2.3}

Please complete the following information about yourself.

SEX (please circle) :

MALE

FEMALE

AGE:

MARITAL STATUS (please circle) : $\quad$ MARRIED

UNMARRIED COUPLE

NEVER MARRIED

DIVORCED, SEPARATED, WIDOWED

JOB (please circle):

EMPLOYED
UNEMPLOYED
STUDENT
RETIRED

ANNUAL INCOME (please circle) : $\quad 0-£ 5000$

$£ 5000-10,000$

$£ 10,000-15,000$

over $£ 15,000$

At what age did you finish full time education?

Please answer the next question by marking the line at the point where you believe you fit between the two end points?

What is your personal risk for getting the AIDS virus?

no risk at all extremely high risk

Please circle the answer to the next questions.

Have you ever been tested for the AIDS virus?

Do you intend to be tested for the AIDS virus in the next month?

YES / NO

Have you been to this clinic before today?

YES / NO

PTO 


\section{Please complete the following by circling the number on the scale that most accurately answers the question.}

E.G. The AIDS virus can be transmitted through saliva

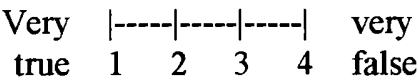

There is nothing that can be done to help someone who has AIDS / HIV

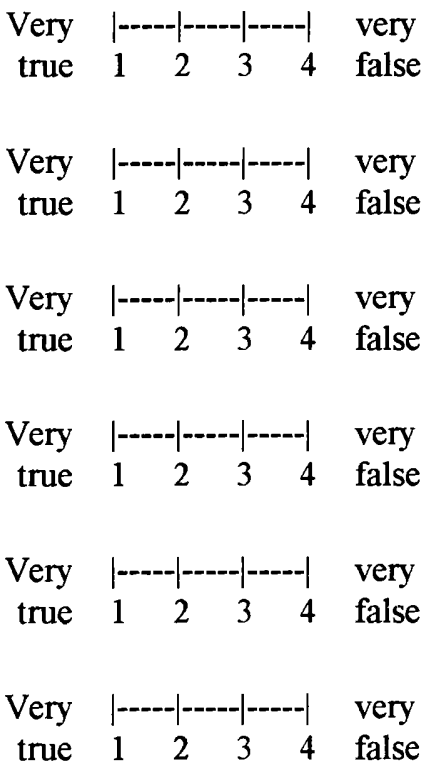

The results of an AIDS test carried out in a G.U.M. clinic remain within the clinic setting

In central region, where can you get an AIDS test? (name as many places as possible) 


\section{following questions are about your general health and the way in which you think about your health.}

Please complete the following by circling the number on the scale that most accurately answers the question as it applies to you.

G. Taking vitamins keeps me healthy.

Strongly

Disagree

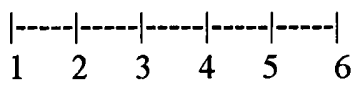

Strongly

Disagree

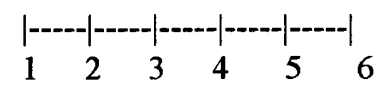

Strongly

Agree

Strongly

Disagree

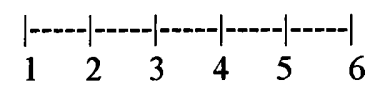

Strongly

Agree

Strongly

Agree

Disagree

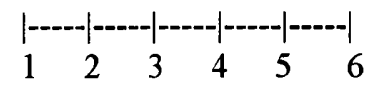

Strongly

Disagree

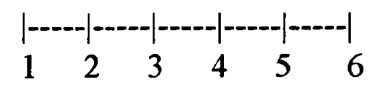

Strongly

Agree

Strongly

Agree

Strongly

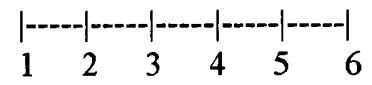

Strongly

Agree

Disagree

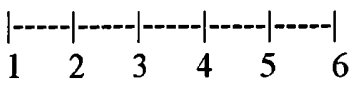

Strongly

Disagree

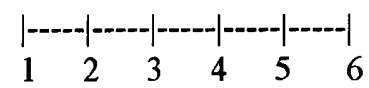

Strongly

Agree

Strongly

Agree

Strongly

Disagree

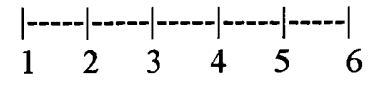

Strongly

Agree

PTO 
alth professionals control my health.

y good health is largely a matter of good fortune.

he main thing that affects my health is what I do myself.

I take care of myself I can avoid illness.

then I recover from an illness, its usually because other people g. doctors, nurses, family, friends) have been taking good care of me.

o matter what I do I am likely to get sick.

its meant to be I will stay healthy.

I take the right actions. I can stay healthy.

egarding my health I can only do what my doctor tells me to.
Strongly

Disagree

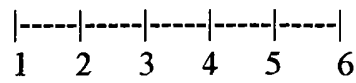

Strongly

Agree

Strongly

Disagree

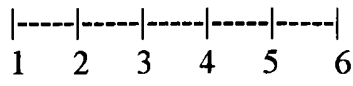

Strongly

Agree

Strongly

Disagree

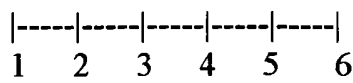

Strongly

Agree

Strongly

Disagree

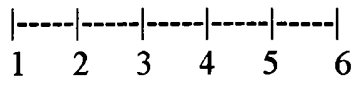

Strongly

Agree

Strongly

Disagree

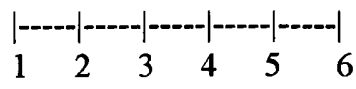

Strongly

Agree

Strongly

Disagree

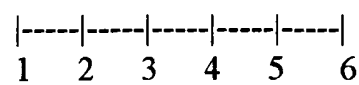

Strongly

Agree

Strongly

Disagree

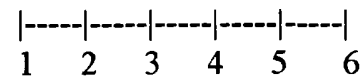

Strongly

Agree

Strongly

Disagree

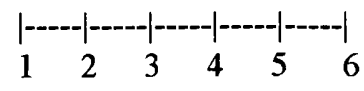

Strongly

Agree

Strongly Disagree

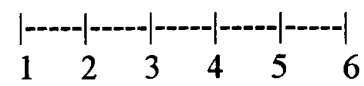

Strongly

Agree 


\section{The following questions are about your feelings towards HIV/AIDS tests. Please complete the following by circling the number on the scale that most accurately describes the way you feel.}

E.G. Taking the test for the AIDS virus is a difficult decision to make.

I do not know enough about AIDS to know if I need to be tested.

Knowing the results of my AIDS test would allow me access to medical treatments.

I would rather forget about getting tested for the AIDS virus.

People in my life would leave me if I had the AIDS virus.

I probably have the AIDS virus so why bother getting tested.

People should get tested for the AIDS virus to protect their partners.

People outside the clinic can find out the results of an AIDS test.

I am so sure I do not have the AIDS virus that I do not have to get tested.

If I got tested for the AIDS virus today I would be scared about the results.

I would rather not know if I have the AIDS virus.

It is better for me not to know if I have the AIDS virus.

Getting tested for the AIDS virus would help me feel better about my health.

I am so sure that I have the AIDS virus I do not need to get tested.
Not at all true for me

\section{Not at all |----|-----|----| very true $\begin{array}{lllllll}\text { true for me } & 1 & 2 & 3 & 4 & \text { for me }\end{array}$ \\ Not at all true for me $\begin{array}{lllll}1 & 2 & 3 & 4 & \text { for me }\end{array}$ \\ Not at all true for me

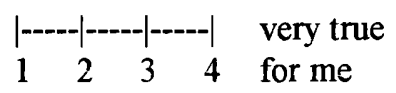 \\ Not at all true for me $\begin{array}{cccc}1 & 2 & 3 & 4\end{array}$ for me \\ Not at all

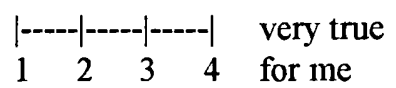 true for me

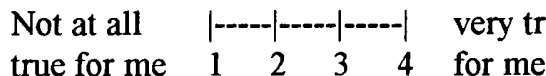 \\ Not at all true for me $\begin{array}{llllll}1 & 2 & 3 & 4 & \text { for me }\end{array}$ \\ Not at all

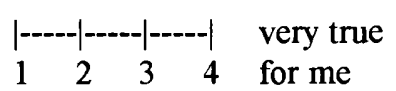
true for me

Not at all $\mid \begin{array}{llll}|---|---|----| & \text { very true } \\ 1 & 2 & 3 & 4\end{array}$ $\begin{array}{llllll}\text { true for me } & 1 & 2 & 3 & 4 & \text { for me }\end{array}$

Not at all |-----|-----|----| very true $\begin{array}{llllll}\text { true for me } & 1 & 2 & 3 & 4 & \text { for me }\end{array}$

Not at all $\quad|----|----|----| \quad$ very true $\begin{array}{llllll}\text { true for me } & 1 & 2 & 3 & 4 & \text { for me }\end{array}$

Not at all true for me $\begin{array}{lllll} & 1 & 2 & 3 & 4\end{array}$ for me

Not at all true for me

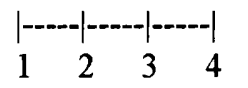

very true

for me 
The following questions are about your sexual behaviour. Please be as honest as possible in answering these questions. Remember that your answers are anonymous and cannot be traced back to you.

How would you describe your predominant sexual orientation (please circle)

heterosexual bisexual homosexual

\section{WITHIN THE LAST MONTH :}

How many sexual partners have you had?

How many times did you have vaginal sex?

How many times did you have vaginal sex without a condom?

How many times did you have anal sex?

How many times did you have anal sex without a condom?

\section{WITHIN THE LAST YEAR:}

How many sexual partners have you had?

Did you have vaginal sex YES / NO

How often did you use a condom during vaginal sex NEVER / SOMETIMES /ALWAYS.

Did you have anal sex YES / NO

How often did you use a condom during anal Sex NEVER / SOMETIMES / ALWAYS

\section{IN YOUR LIFETIME :}

Have you ever : shot up drugs with a needle YES / NO Have you ever : had a sexual partner who shot up drugs with a needle YES / NO Have you ever : had a sexual partner who had HIV / AIDS YES / NO Have you ever : had a sexually transmitted disease YES / NO 
The following statements are about which things would make it easier for you to take an AIDS test.

Please respond to the following statements by circling the number on the scale that best fits.

It would be easier for me to take an AIDS test if......

I could get the results on the same day.

I did not have to give my name.

I could have the test while attending another clinic.

I could have the test at home

I could walk in without having to make an appointment.
Not at all
true for me

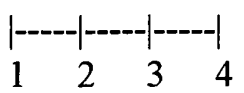

very true

for me

Not at all true for me

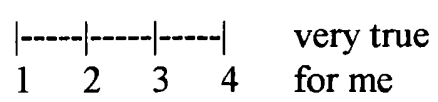

Not at all true for me

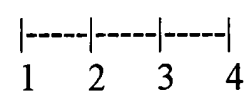

very true for me

Not at all true for me

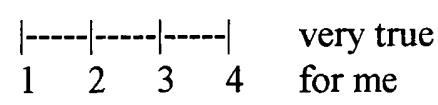

Not at all true for me

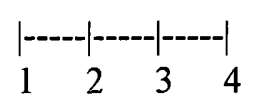

very true for me

Please circle the correct answer to the following questions in relation to the clinic you are now attending.

Does this clinic offer anonymous testing?

Can you walk in without an appointment?

Does this clinic take the names of individuals being tested for the AIDS virus?
YES / NO / DON'T KNOW

YES / NO / DON'T KNOW

YES / NO /DON'T KNOW

\section{THANK YOU.}


Appendix 2.41.

Risk behaviours divided into past month, last year and lifetime risks for HIV, by testing group.

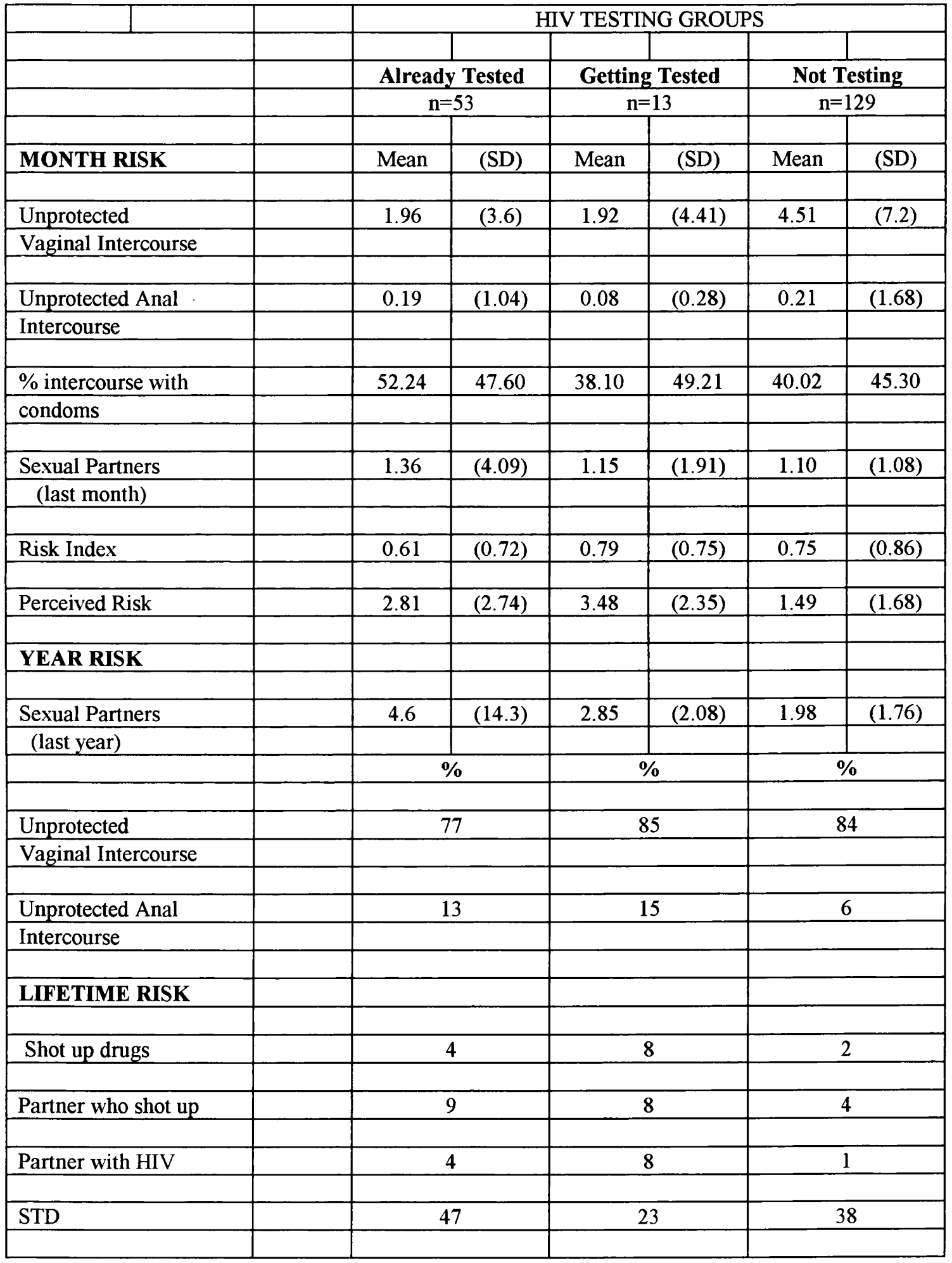




\section{Appendix 2.42}

Additional data / comments

Confidentiality / support services

It was hypothesised that the not testing group would have less accurate information

regarding support services and confidentiality issues than the testing group.

Table 7 below contains the results of questions concerning treatment / support for those who are diagnosed HIV positive, and questions concerning the confidentiality of test results. MannWhitney tests between the responses of the two groups indicated that those not seeking testing believed that GP's cannot tell anyone else the results of an HIV test, significantly more than the testing group $(\mathrm{u}=3271.5, \mathrm{p}<.001)$.

Table 7 : Means and standard deviations of confidentiality and HIV+ support questions. Items scored on 4 point scale $1=$ very true, $4=$ =very false.; $F=$ false $T=$ true

\begin{tabular}{|l|c|c|c|c|c|c|c|c|}
\hline & \multicolumn{2}{|c|}{ Testing } & \multicolumn{2}{c|}{ Not testing } & & \multicolumn{3}{c|}{ Total } \\
\hline & \multicolumn{2}{|c|}{$\mathrm{n}=66$} & \multicolumn{2}{c|}{$\mathrm{n}=129$} & & & \multicolumn{2}{c|}{$\mathrm{n}=195$} \\
\hline & Mean & SD & Mean & SD & u & p & Mean & SD \\
\hline $\begin{array}{l}\text { No drug treatments exist for HIV } \\
\text { (F) }\end{array}$ & 3.50 & .81 & 3.39 & .89 & 3950 & ns & 3.43 & .86 \\
\hline $\begin{array}{l}\text { Support networks exist for HIV+ } \\
\text { people (T) }\end{array}$ & 1.18 & .55 & 1.28 & .62 & 3752.5 & $\mathrm{~ns}$ & 1.25 & .60 \\
\hline $\begin{array}{l}\text { Nothing can be done to help people } \\
\text { with HIV(F) }\end{array}$ & 2.98 & 1.01 & 2.75 & 1.00 & 3516.5 & $\mathrm{~ns}$ & 2.83 & 1.01 \\
\hline $\begin{array}{l}\text { GP cannot disclose results to } \\
\text { anyone (F) }\end{array}$ & 1.82 & 1.09 & 1.41 & .88 & 3271.5 & $\mathrm{p}<.001$ & 1.55 & .97 \\
\hline $\begin{array}{l}\text { Results remain within the GUM } \\
\text { clinic (T) }\end{array}$ & 1.62 & .88 & 1.75 & .92 & 3559 & $\mathrm{~ns}$ & 1.70 & .91 \\
\hline $\begin{array}{l}\text { Partners are automatically told } \\
\text { result of test (F) }\end{array}$ & 3.63 & .74 & 3.53 & .87 & 3986 & $\mathrm{~ns}$ & 3.56 & .83 \\
\hline
\end{tabular}

$\mathrm{sd}=$ =standard deviation; $\mathrm{u}=$ Mann-Whitney score; $\mathrm{p}=$ significance level; $\mathrm{ns}=$ not significant 
Knowledge of clinic policy

Extract from HIV testing questionnaire :

Please circle the correct answer to the following questions in relation to the clinic you are now attending.

Does this clinic offer anonymous testing?

Can you walk in without an appointment?

Does this clinic take the names of individuals being tested for the AIDS virus?
YES / NO / DON'T KNOW

YES / NO / DON'T KNOW

YES / NO /DON'T KNOW

Chi square tests on the above questions revealed some interesting associations.

There was a significant association between knowledge of anonymous testing between the two testing groups $(\chi=32.5, \mathrm{df}=2, \mathrm{p}<.0001)$. There was also a significant association between the two testing groups on knowledge of name taking i.e. confidential testing $(\chi=34.5$, $\mathrm{df}=2, \mathrm{p}<.0001$ ). However the exact interpretation of these results is complex due to the majority of people answering 'don't know' on both questions. Perhaps of more interest is the fact that in the testing group 17 people (5 in the not testing group) responded yes to both questions.

The only clear conclusion from these results is that people using the GUM services do not know what testing policy the clinic uses.

A chi square for the 'walk in' clinic question was not significant $(\chi=1.06, \mathrm{df}=2, \mathrm{~ns})$. 
Home Access Testing

Table 6 in the main paper contains data relevant to these comments.

This study found that out of 5 service options relating to the delivery of HIV tests, having the test at home was least endorsed in both testing groups. This would appear to be a curious finding. Considering that many people have concerns over anonymity / confidentiality of HIV testing, and do not want to wait for test results, home testing should be a desirable alternative to a GP or GUM clinic.

With the Food and Drug Administration (FDA) in the U.S. now licensing home access HIV testing, it will be interesting to discover how widely it is used. Further research into the British publics opinions of home access testing would seem warranted.

Further information :

Stryker, J. and Coates, T.J. (1997). Home access HIV testing : what took so long?. Archives of Internal Medicine, 157,261-262.

Bayer, R.B., Stryker, J. \& Smith, M.D. (1995).Testing for HIV infection at home. The New England Journal Of Medicine, 332(19)1296-1299. 
APPENDIX 3

Single Case Research Study 
Appendix 3.1.

\section{CLINICAL CHILD PSYCHOLOGY AND PSYCHIATRY}

\section{AIMS AND SCOPE}

Clinical Child Psychology and Psychiutry brings together clinically oriented work of the highest distinction from an international and multidisciplinary perspective, offering comprehensive coverage of clinical and treatment issues across the range of treatment modalities.

Clinical Child Psychology and Psychiatry is interested in advancing theory. practice and clinical research in the realm of child and adolescent psychology and psychiatry and related disciplines.

\section{INSTRUCTION TO AUTHORS}

The Editor apologizes for the apparent pedantry of these instructions. but emphasizes that adherence to them will ensure rapid and efficient processing of your contributions. and will enhance the article itself.

Peer revien process. The Editor will screen manuscripts for their overall fit with the aims and scope of the journal. Those that fit will be further reviewed by two or more independent reviewers. Papers will the evaluated by the Editorial Board and refereed in terms of merit, readability and interest. Unsolicited manuscripts will not be returned to the author.

Submission of MSS. Four copies of each manuscript, typed in double spacing throughout, and on une side only of white A4 or US standard size paper. should be sent to the Editor at the address given below.

Format of MSS. Each manuscript should contain the following, in the correct order.

(a) Title page to include the title of the paper, fuil name of each author. current professional position and work context, and indicators of which author will be responsible for correspondence. A word count should also be included.

(b) Abstract page: the abstract itself not to exceed 200 words (150 for preference). and up to $5 \mathrm{key}$ words to be listed on the same page. This page should carry the title of the paper but not the author name(s).

(c) Main text: not usually to exceed 7500 words and to be clearly organized, with a clear hierarchy of headings and subheadings ( 3 weights of heading maximum).

(d) References: Citation of references follows APA (American Psychological Association) style. References cited in the text should read thus: Brown (1955: 63-64): (Brown. 1995, pp. 63-64: Green \& Brown, 1992, p. 102. table 3). The letters a. b. c. etc. should distinguish citations of different works by the same author in the same year (Black, 1989a, 19S9b). All references cited in the text should appear in an alphabetical list. after the Notes section.

(c) Figures. tables. etc.: should be numbered consecutively. carry descriptive captions and be clearly cited in the text. Keep them separate from the text unhappy, they...
The journal directs its attention to matters of clinical practice, including related topics such as the ethics of treatment and the integration of research into practice.

Multidisciplinary in approach, the journal includes work by, and is of interest to, child psychologists. psychiatrists and psychotherapists, nurses, social workers and all other professionals in the fields of child and adolescent psychology and psychiatry.

itselc, but indicate an approximate location on the relevant text page.

(f) Author biographics: On a separate sheet provide a one-paragraph bio-bibliographical note for each author - up to 100 words for a single author, but none to exceed 65 words in a multi-authored paper.

Sivle. Use a clear and readable style, avoiding jargon. If technical terms must be included, define them when first used. Use plurals rather than he/she. (s)he, his or hers: 'If a child is unhappy. he or she... is much better expressed as 'When children are

Spelling. British or American spellings may be used (the ' $z$ ' versions of British spellings are preferred to the ' $s$ ' versions. as given in the Oxford English Dictionary).

Punctuation. Use single quotation marks, with double inside single. Present dates in the form 9 May 1996. Do not use points in abbreviations, contrac. tions or acronyms (e.g. DC, USA, DR, UNESCO).

Covering letter. Attach to every submission a letter confirming that all authors have agreed to the submission and that the article is not currently being considered for publication by any other journal. The name. address, telephone and fax number of the corresponding author should always be clearly indicated. and an email address would be very welcome.

Disks. On acceptance of your MS for publication you will be asked to supply a diskette (IBM-compatible or Mac) of the final version.

Copvright. Before publication authors are requested to assign copyright to Sage Publications. subject to retaining their right to reuse the material in other publications written or edited by themselves and due to be published preferably at least one year after initial publication in the Journal.

Muiling. Address MSS to the Editor: Dr Bryan Lask, Consultunt Psychiatrist, Department of Psychological Medicine, Great Ormond Street Hospital. Great Ormond Street, London WC1N 3JH, UK.

Books for review should be sent to: Bernadette Wren. 177 Brooke Road, London ES 8.AB, UK. 
Appendix 3.2.

\section{Successful bedtime routine}

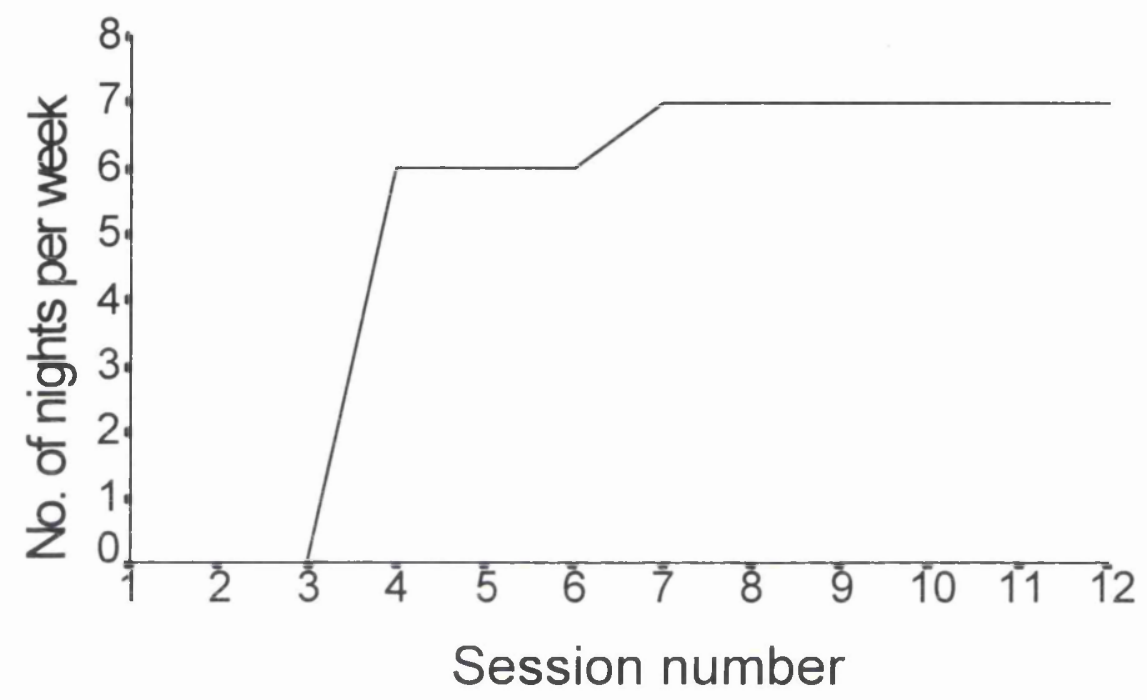

Session 1: initial interview;

Sessions $2+3$ : baseline;

Sessions $4-7$ : treatment.

Sessions 8-12: follow up

Treatment sessions are defined as sessions in which the bedtime routine was specifically targeted. Follow up sessions are defined as sessions occurring after removal of star chart as reinforcer. 
Appendix 3.3.

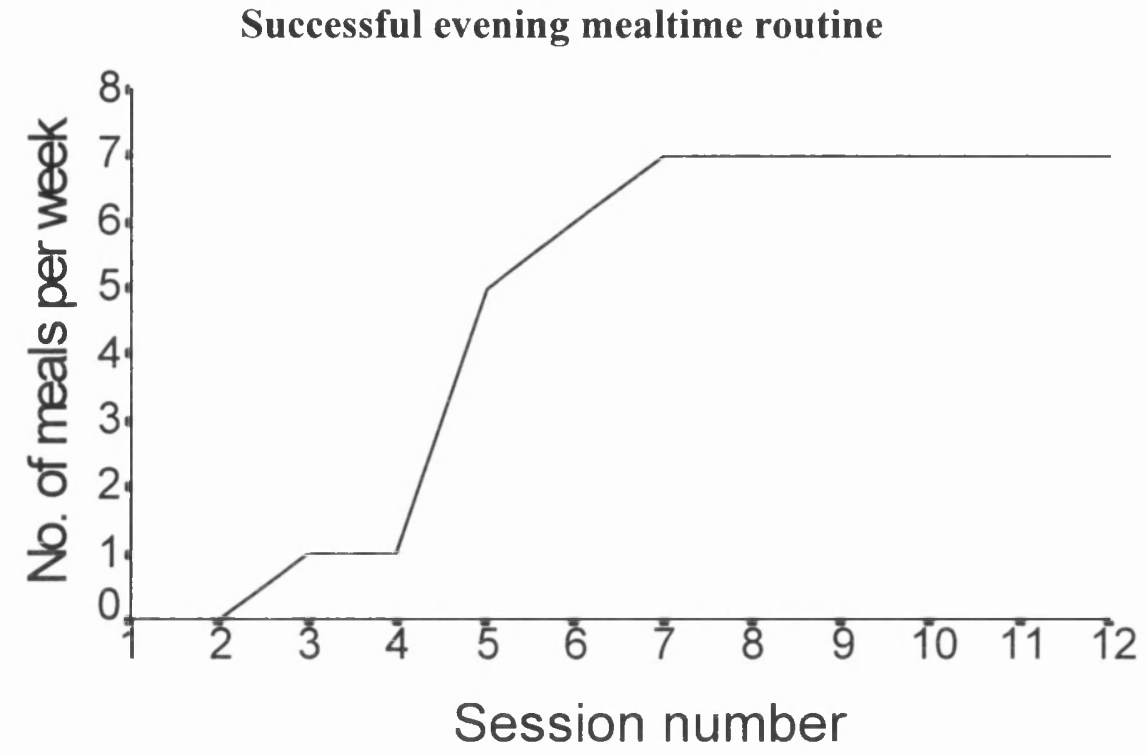

Session 1 : initial interview;

Sessions 2 - 4 : baseline;

Sessions 5 - 7 : treatment;

Session $8-12$ : follow up.

Treatment sessions consisted of specific work focusing on mealtime management.

Follow up sessions are defined by no direct work regarding mealtime management. 
Appendix 3.4.

Temper tantrums per week

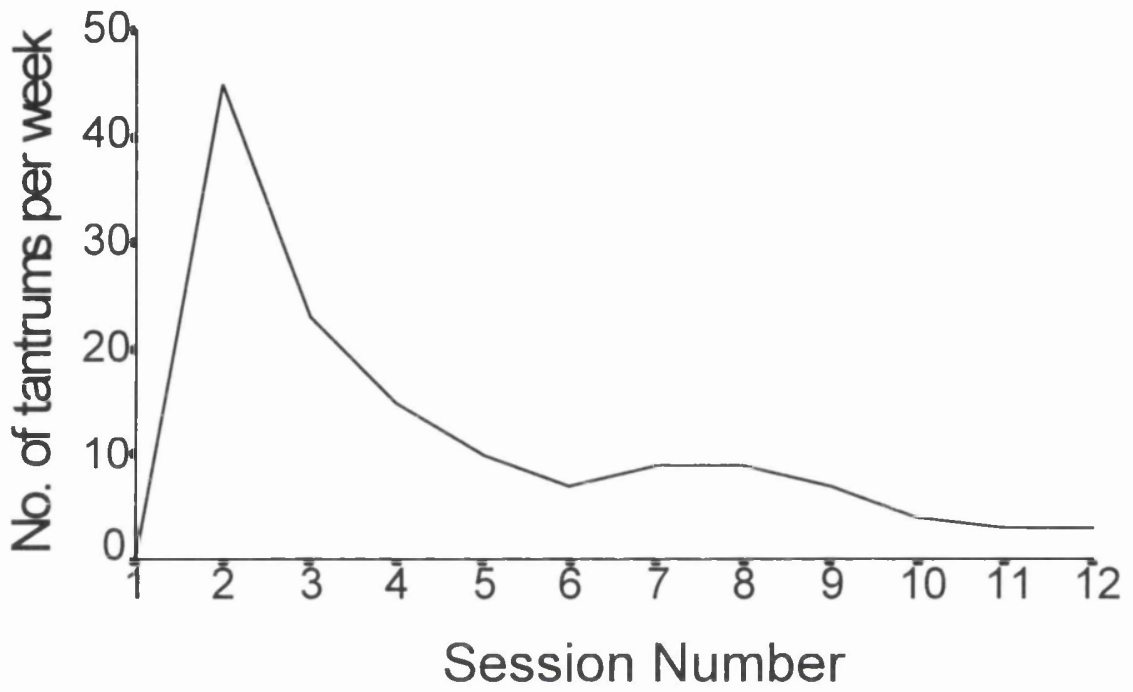

Session 1: initial interview;

Sessions $2+3$ : baseline;

Sessions 4-10 : treatment;

Sessions 11-12 : follow up.

Treatment sessions are defined by all parent management work.

Follow up sessions did not include specific advice / strategy for prevention or management of temper tantrums. 
Appendix 3.5.

WISC III UK - Wechsler Intelligence Scale for Children

$\begin{array}{lcr}\text { subtest } & \text { verbal scaled score } & \begin{array}{r}\text { performance } \\ \text { score }\end{array} \\ \begin{array}{l}\text { picture completion } \\ \text { information } \\ \text { coding }\end{array} & 10 & 7 \\ \begin{array}{l}\text { similarities } \\ \text { picture arrangement } \\ \text { arithmetic } \\ \text { block design } \\ \text { vocabulary } \\ \text { object assembly }\end{array} & 9 & 4 \\ & 4 & 6 \\ & 7 & 8\end{array}$

IQ

verbal

84

performance

77

full scale

79 
Appendix 3.6.

WORD - Wechsler Objective Reading Dimensions

standard score

basic reading

spelling

reading comprehension

WORD composite
86

82

79

79
WISC III UK scaled score

7

6

6

6 
APPENDIX 4

Single Case Research Study 


\section{Autism: An International Journal of Research and Practice}

\section{Notes to Authors}

\section{Aims}

The aim of the Journal is to publish original research or original contributions to the existing literature on autism. Papers should not previously have been published elsewhere.

Papers may have a research, clinical or theoretical basis and good review articles will also be welcome. However, all submissions should be of potential practical relevance to work in the field of autism or related disorders.

\section{Length of papers}

Both brief reports (up to 3,000 words) and more substantial reports (between 5 - 8,000 words) will be considered for the Journal. There is scope for longer papers to be published on an occasional basis but please consult with the Editors before submission.

\section{Number of copies}

When submitting papers for consideration please supply four hard copies. If a paper is accepted for publication then a copy on disc will be required (see notes of disc preparation).

\section{Language and terminology}

Jargon or unnecessary technical language should be avoided as should the use of abbreviations (such as coded names for conditions). Please avoid the use of nouns as verbs (e.g. to access) or the use of adjectives as nouns (e.g. autists, normals or retardates). Wherever possible use phrases such as 'children with autism' instead of 'autistic children'. Language that might be deemed sexist or racist should also be avoided.

\section{Notes and references}

The Harvard system for bibliographical references is to be used, with notes, references, tables, figures and acknowledgements placed at the end of the manuscript. This entails providing a full bibliography in alphabetical order at the end of the article, e.g.

Boswell, J. (1988) The Abandonment of Children. Harmondsworth: Penguin.

Burman, E. and P. Smith (1995) 'The Abnormal Distribution of Development: Policies for Southern Women and Children', Gender, Place and Culture 2 (1): 21-37.

Nelken, D. (1994a) 'Can Legal Culture Be Measured? A Theoretical Agenda', paper Presented at the Workshop on 'Comparing Legal Cultures', University of Macerata, Italy 18-20 May 1994. Forthcoming in D. Nelken (ed.) Comparing Legal Cultures. Aldershot: Dartmouth

Nelken, D. (1994b) 'Whom Can You Trust? The Futures of Criminology', pp. 220-43 in D. Nelken (ed.) The Futures of Criminology. London: Sage

Qvortrup, J. (1994) 'Childhood Matters: An Introduction', in J. Qvortrup, M. Bardy, G. Sgritta and H. Wintersberger (eds): Childhood Matters: Social Theory, Practice and Politics. Aldershot: Avebury. 


\section{Appendix 4.2.}

Diagnostic criteria for 299.80 Asperger's Disorder

A. Qualitative impairment in social interaction, as manifested by at least two of the following:

(1) marked impairment in the use of multiple nonverbal behaviours such as eye to eye gaze, facial expression, body postures, and gestures to regulate social interaction.

(2) failure to develop peer relationships appropriate to developmental level.

(3) a lack of spontaneous seeking to share enjoyment, interests or achievements with other people (e.g. By a lack of showing, bringing or pointing out objects of interest to other people).

(4) lack of social of emotional reciprocity.

B. Restricted repetitive and stereotyped patterns of behaviour, interests and activities as manifested by at least one of the following:

(1) encompassing preoccupation with one or more stereotyped and restricted patterns of interest that is abnormal either in intensity or focus.

(2) apparently inflexible adherence to specific, non functional routines or rituals.

(3) stereotyped and repetitive motor mannerisms ( e.g. Hand or finger flapping or twisting or complex whole body movements).

(4) persistent preoccupation with parts of objects.

C. The disturbance causes clinically significant impairment in social occupational or other important areas of functioning.

D. There is no clinically significant general delay in language (e.g. Single words used by age two years, communicative phrases used by age three years).

E. There is no clinically significant delay in cognitive development or in the development of age appropriate self help skills, adaptive behaviour (other than in social interaction), and curiosity about the environment in childhood.

F. Criteria are not met for another specific Pervasive Developmental Disorder or Schizophrenia. 
Appendix 4.3.

WISC III UK - Weschler Intelligence Scale for Children

\begin{tabular}{|c|c|c|c|}
\hline subtest & verbal scaled score & $\begin{array}{c}\text { performance scaled } \\
\text { score }\end{array}$ & \\
\hline picture completion & & & \\
\hline information & 6 & 2 & \\
\hline coding & & & \\
\hline similarities & 3 & 7 & \\
\hline picture arrangement & & 9 & \\
\hline arithmetic & 7 & & \\
\hline block design & & & \\
\hline vocabulary & 3 & & \\
\hline object assembly & & & \\
\hline comprehension & 6 & & \\
\hline & & & \\
\hline & IQ & & \\
\hline & 70 & & \\
\hline verbal & 73 & & \\
\hline performance & 69 & & \\
\hline full scale & & & \\
\hline
\end{tabular}




\section{Appendix 4.4}

WORD - Weschler Objective Reading Dimensions

\begin{tabular}{|l|c|c|}
\hline & standard score & WISC III uk scaled score \\
\hline & & 2 \\
\hline basic reading & 62 & 3 \\
\hline spelling & 64 & 3 \\
\hline reading comprehension & 66 & $(0)$ \\
\hline WORD composite & $<40$ & \\
\hline
\end{tabular}


Appendix 4.5.

Vineland Adaptive Behaviour Scale

\begin{tabular}{|c|c|c|c|c|c|c|}
\hline Domain & & Raw & Total & Standard & Percentile & Adaptive \\
\hline & & & & Score & & Level \\
\hline & Receptive & 26 & & & & \\
\hline \multirow[t]{4}{*}{ Communication } & Expressive & 48 & 81 & 40 & $<.0 .1$ & severe \\
\hline & Written & 7 & & & & deficit \\
\hline & & & & & & \\
\hline & Personal & 60 & & & & \\
\hline \multirow[t]{4}{*}{ D.L.S. } & Domestic & 10 & 82 & $<20$ & $<0.1$ & profound \\
\hline & Community & 12 & & & & deficit \\
\hline & & & & & & \\
\hline & interpersnl & 31 & & & & \\
\hline \multirow[t]{2}{*}{ Social } & leisure & 17 & 55 & 40 & $<0.1$ & severe \\
\hline & coping & 7 & & & & deficit \\
\hline & & & & & & \\
\hline \multirow[t]{2}{*}{ (Motor) } & gross & 40 & 68 & & & \\
\hline & fine & 28 & & & & \\
\hline \multirow{2}{*}{ Composite } & & & & 31 & $<01$ & severe \\
\hline & & & & & & deficit \\
\hline
\end{tabular}


APPENDIX 5

Single Case Research Study 


\section{BEHAVIOUR RESEARCH AND THERAPY incorporating ADVANCES IN BEHAVIOUR RESEARCH AND THERAPY}

\section{Information for Contributors}

Behatiour Research and Therap! incorporating Adrances in Behaviour Research and Therap! will be published monthly. authors

Neither the Editors nor the publisher accept responsibility for the views or statements expressed by

In order to expedite the selection and prompt publication of papers, we have decided to discontinue the practice of supplying copies of referee's reports. Correspondence regarding decisions reached by the editorial cominittee is not encouraged.

This journal should be cited in lists of references as Behaviour Research and Therapy:

Manuscripts

All manuscripts submitted for publication for the regular section of the journal and all scientific correspondence should be sent to the Editor: Dr S. RaChMan. Department of Psychology, University of British Columbia, Vancouver, British Columbia. Canada V6T 1Z4. Manuscripts for the Behavioral Assessment Section should be sent to Dr S. TAYLOR. Department of Psychiatry, 2255 Wesbrook Mall, Vancouver, British Columbia, Canada V6T 2AI.

Manuscripts should be typewritten on ome side of the paper, double spaced and in triplicate (one original and two carbon copies). The original manuscript and diagrams will be discarded one month after publication unless the publisher is requested to return original material to the author.

Manuscripts must be carefully checked and proof alterations-except printer's errors-should be minimal.

Disks

Authors are encouraged to submit a computer disk (5.25" or $3.5^{\prime \prime}$ HD DD disk) containing the final tersion of the paper along with the final manuscript to the editorial office. Pleatse observe the following criteria:

1. Send only hard copy when first submitting your paper.

2. When your paper has been refereed. revised if necessary and accepted. send a disk containing the final version with the final hard copy. Make sure that the disk and the hard copy match exactly.

3. Specify what software was used. including which release. e.g. WordPerfeci 5.1

4. Specify what computer was used (either IBM-compatible PC or Apple Macintosh).

5.' Include the text file and separate table and illustration files. if available.

6. The file should follow the general instructions on style/arrangement and. in particular, the reference style of this journal als given below.

7. The file should be single-spaced and should use the wrap-around end-of-line feature, i.e. no returns at the end of each line. All textual clements should begin flush left: no paragraph indents. Place two returns after every element such as title. headings. paragraphs. figure and table call-outs.

8. Keep a back-up disk for reference and safety.

The articles submitted must contain original material which has not been published and which is not being considered for publication elsewhere. Papers accepted by Bchariour Re'securch and Therap! may not be published elsewhere in any language without the consent of the Editor.

The title of the paper. the author's name and surname and the name and address of the institute. hospital etc. Where the work wals carried out. should be indicated at the top of the paper. Where possible. the Fax number of the corresponding author should be supplied with the manuscript. for use by the publisher.

Stummaries. A summary, not exceeding 200 words, should be submitted on a separate sheet in duplicate. The summary will appear at the beginning of the article.

Kenwords. Authors should include up to six keywords with their article. The controlled list of keywords is based on the APA list of index descriptors. however. authors ma! include one or two additional free keywords if they wish to do so.

References should be prepared carefully using the Publication Mamual of the American Psichological - Association for style. They should be placed on a separate sheet at the end of the paper. double-spaced, and in alphabetical order.

References should be quoted in the text by giving the author's name. followed by the year. e.g. (Hersen \& Barlow, 1976) or Hersen and Barlow (1976).

For morc than furo authors. all names are given when first cited. but when subsequently referred to. the name of the first author is given followed by the words " $" t$ al." as for example-First citation: Nau. Caputo and Borkovec (1974) but subsequently. Nau et al. (1974). 


\section{BEHAVIOUR RESEARCH AND THERAPY incorporating BEHAVIORAL ASSESSMENT}

Information for Contributors-continued]

References to journals should include the author's name followed by initials, year, paper title, journal title, volume number and page numbers, e.g.

Singh, N. N. (1980). The effects of facial screening on infant self-injury. Journal of Experimental Therapy and Experimental Psychiatry, 11, 131-134.

or

Beck, A. T., Ward, C. H., Mendelson, M., Mock, J., \& Erbaugh, J. (1961). An inventory for measuring depression. Archives of General Psychiatry. 4, 561-565.

References to books should include the author's name followed by initials, year, paper title, editors, book title, volume and page numbers, place of publication, publisher, e.g.

Brownell, K. D. (1984). Behavioural medicine. In C. M. Franks, G. T. Wilson, P. C. Kendall, \& K. D. Brownell (Eds.), Annual review of behavior therapy (Vol. 10, pp. 11-20). New York: Guilford Press.

Footnotes, as distinct from literature references, should be indicated by the following symbols: ${ }^{*}, \uparrow, \ddagger, \S, \|, \uparrow$. commencing anew on each page.

Illustrations and diagrams should be kept to a minimum: they should be numbered and marked on the back with the author's name. Captions accompanying illustrations should be typewritten on separate sheets. Diagrams and graphs must be drawn with Indian ink on stout paper or tracing linen.

Photographs and photomicrographs should be submitted unmounted and on glossy paper.

The following standard symbols should be used in line drawings since they are easily available to the printers:

\section{$\triangle \nabla \Delta \nabla \circ \bullet \square \square \odot \oplus \otimes \Theta$}

Tables and figures should be constructed so as to be intelligible without reference to the text, each table and column being provided with a heading.

Tables. Captions should be typewritten together on a separate sheet. The same information should not be reproduced in both tables and figures.

\section{BUSINESS COMMUNICATIONS}

All communications regarding advertising, subscriptions, changes of address, reprints etc., should be addressed to the publishers, Elsevier Science Ltd, The Boulevard, Langford Lane, Kidlington, Oxford OX5 IGB, England.

Copyright. All authors must sign the 'Transfer of Copyright' agreement before the article can be published. This transfer agreement enables Elsevier Science Ltd to protect the copyrighted material for the authors, but does not relinquish the author's proprietary rights. The copyright transfer covers the exclusive rights to reproduce and distribute the article, including reprints, photographic reproductions, microform or any other reproductions of similar nature and translations, and includes the right to adapt the article for use in conjunction with computer systems and programs, including reproduction or publication in machine-readable form and incorporation in retrieval systems. Authors are responsible for obtaining from the copyright holder permission to reproduce any figures for which copyright exists.

Proofs. Page proofs will be sent to the author (or the first-mentioned author in a paper of multiple authorship) for checking. Corrections to the proofs must be restricted to printer's errors. Any substantial alterations other than these may be charged to the author. Please note that authors are urged to check their proofs carefully before return, since the inclusion of late corrections cannot be guaranteed. In order to facilitate rapid publication, authors are requested to correct their proofs and return them immediately to Elsevier Science Ltd, Bampfylde Street, Exeter EXI 2AH, England.

Reprints. Reprints and copies of the issue (at a specially reduced rate) may be obtained at a reasonable cost, provided that they are ordered when the proofs are returned and using the reprint order form which will accompany the author's proofs. 
Appendix 5.2.

General Screening Measures

\begin{tabular}{|l|c|c|c|}
\hline & Pre-treatment & 12 th session & $15^{\text {th }}$ session \\
\hline BDI & 11 & 6 & 3 \\
\hline BAI & 23 & 14 & 9 \\
\hline GHQ & 0 & 0 & 0 \\
\hline
\end{tabular}


Appendix 5.3.

\section{Frequency of Clock Changing Behaviour}

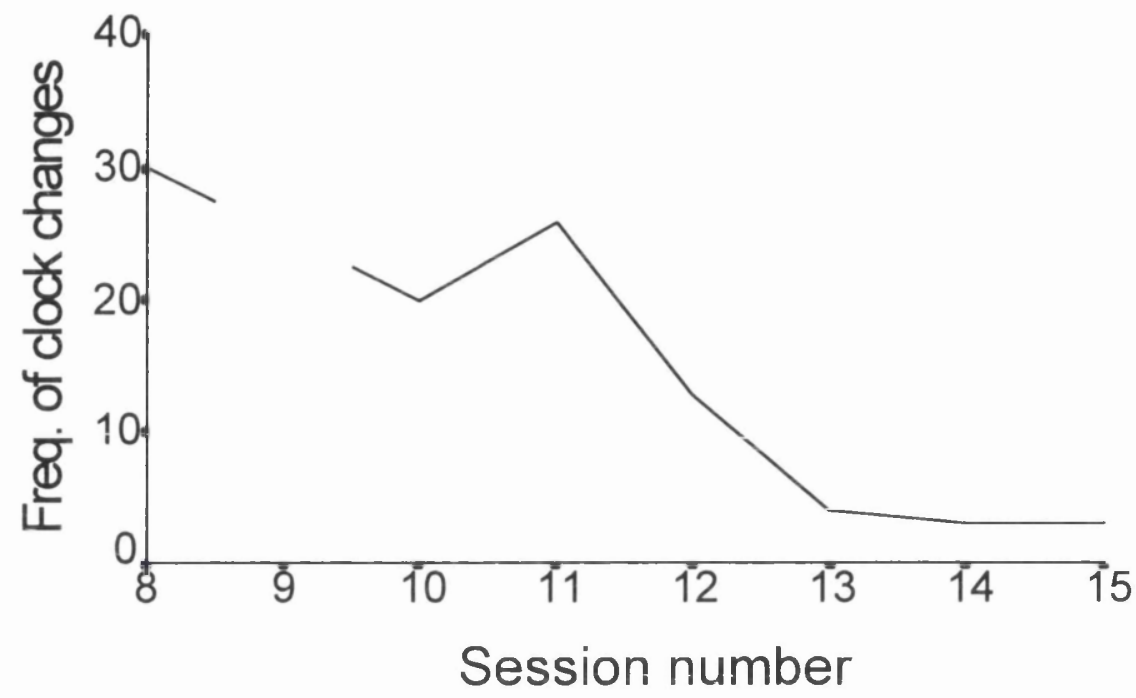

Note : missing data for session 9.

Sessions $8+9$ were baseline.

Sessions 10-15 were treatment. 